\title{
ADDRESSING CHILDHOOD OBESITY \\ THROUGH THE BUILT ENVIRONMENT: \\ THE GUADALUPE CASE STUDY
}

\author{
A Professional Project \\ presented to \\ the Faculty of California Polytechnic State University, \\ San Luis Obispo
}

\author{
In Partial Fulfillment \\ of the Requirements for the Degree \\ Master of City and Regional Planning
}

by

Sophia Y Lai

June 2014 
(C) 2014

Sophia Y Lai

ALL RIGHTS RESERVED 


\section{COMMITTEE MEMBERSHIP}

TITLE:

AUTHOR:

DATE SUBMITTED:

COMMITTEE CHAIR:

COMMITTEE MEMBER:

COMMITTEE MEMBER:
Addressing Childhood Obesity Through the Built Environment: The Guadalupe Case Study

Sophia Y Lai

June 2014

Dr. Kelly D. Main, Assistant Professor

City and Regional Planning Department

Chris Clark, JD, Lecturer

City and Regional Planning Department

Matt Dwyer, Food Services Director

Guadalupe Union School District 


\section{ABSTRACT \\ Addressing Childhood Obesity Through the Built Environment: The Guadalupe Case Study}

Sophia Y Lai

This project takes a look at the impacts of our built environment on obesity in children living in racial and ethnic communities in relation to city planning. The results of this project results in a comprehensive report to provide an in-depth look into understanding the important relationships between children's health and the built environment and understanding the best practices and recommendations for improving health in Guadalupe.

Located in the Santa Barbara County, the City of Guadalupe is mainly an agricultural town with over 85 percent of its residents who are of Hispanic Origin. With almost half of its Latino population under 17 years of age, Guadalupe is an ideal location to examine the number of complex social, economic, and environmental matters that can contribute to higher overweight and obesity rates among Latino children.

The food environments and physical environments were examined using Community Assessments and outreach efforts with school children and the residents of Guadalupe. Current professional and academic literature on childhood obesity, the built environments, food environments, and schools were reviewed for this project.

Responses from a multitude of methods were analyzed and compared to create a list of recommendations for improving children's health in Guadalupe. These methods included Community of Excellence (CX3) field surveys, walkability surveys, and a Photovoice project with school children.

Key Words: built environment, food environment, childhood obesity, children's health 


\section{ACKNOWLEDGMENTS}

I would like to express my deepest appreciation to all those who provided me the possibility to complete this project.

A special thank you to my advisor, Professor Kelly Main, for her continued support and guidance. Your useful comments and engagement, and especially your continued optimism, through this entire learning process kept me pushing on. Thank you for making time every week to provide me feedback.

I would like to thank Professor Chris Clark for his support and feedback, helping to make it possible for the children to illustrate their visions and mine.

I would like to thank Matt Dwyer for helping me connect more closely with Guadalupe and allowing me to see the first hand work he does to keep the children healthy and thriving.

A tremendous thank you to Jeff Foote for allowing me the chance to work with him and his $6^{\text {th }}, 7^{\text {th }}$, and $8^{\text {th }}$ grade students. Without you, a huge part of this project would not have been possible. Working with your students and getting a chance to bring technology into this project has been a fantastic experience.

Thank you to the Guad Squad (CRP 552 \& 554) for a memorable second year and for your help with this project.

A big thanks to the students of CRP 470 for your assistance and patience with all your fieldwork.

Additional thanks to:

THRIVE Guadalupe

Mary Buren Elementary

Kermit McKenzie Junior High School

Downtown Guadalupe Businesses

And thank you to my family and friends for your love and support each day. 


\section{TABLE OF CONTENTS}

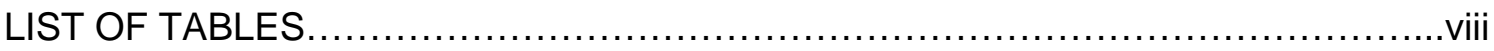

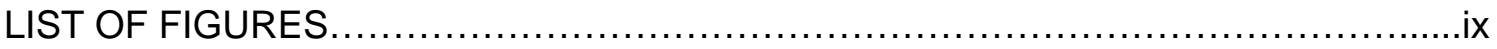

CHAPTER

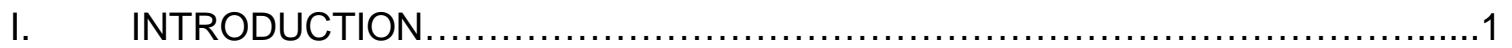

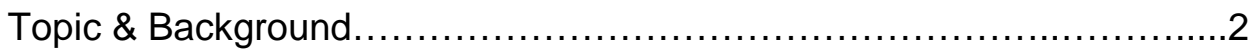

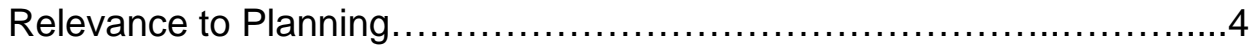

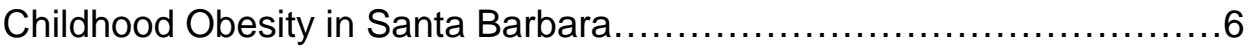

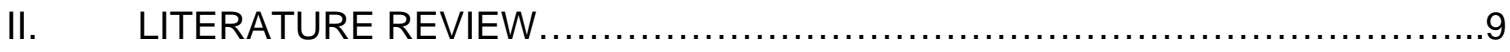

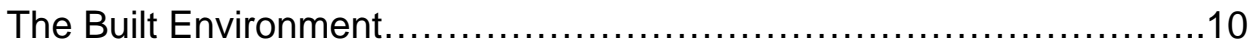

Access to Healthy Foods $\ldots \ldots \ldots \ldots \ldots \ldots \ldots \ldots \ldots \ldots \ldots \ldots \ldots, 11$

Access to Recreational Activities. ..............................

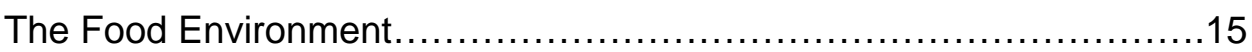

Foods In and Out of the School Environments..................16

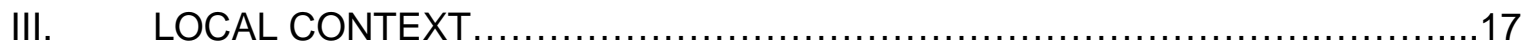

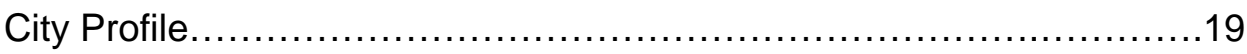

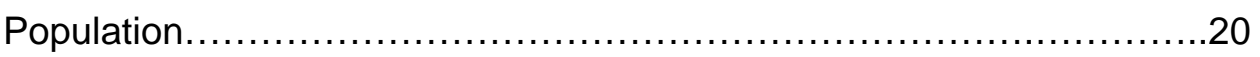

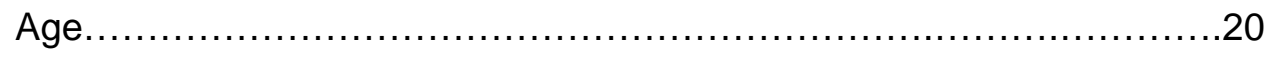

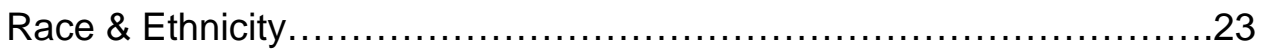

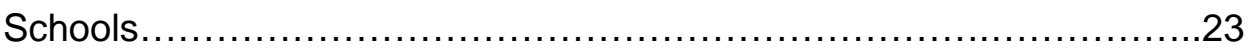

Breakfast \& Lunch Programs........................................ 24

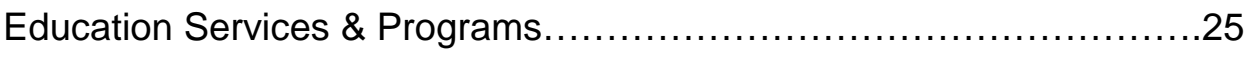

ASES After School Program ...................................25

Tutoring- Supplemental Education Services (SES) .............26

Youth Education Enhancement Programs (YEEP)..............26 


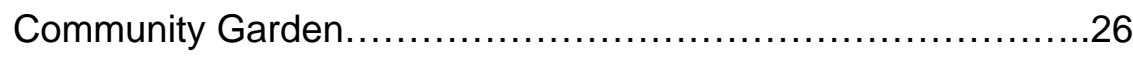

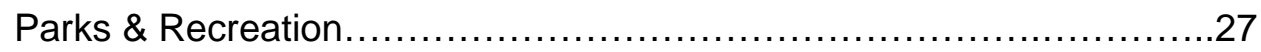

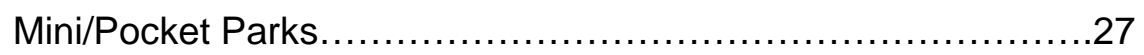

Guadalupe Dunes Center................................28

Guadalupe Cultural Arts and Education Center................29

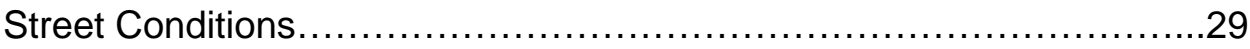

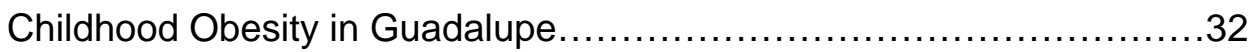

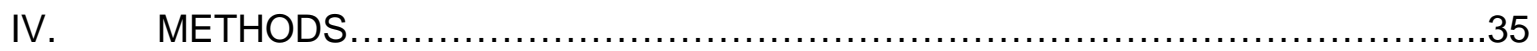

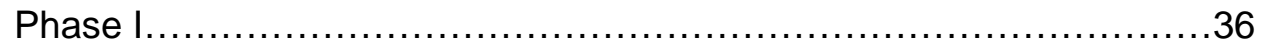

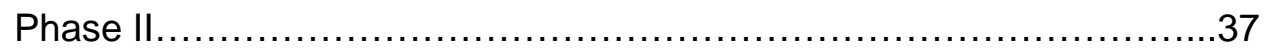

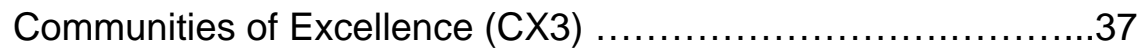

Walkability Assessment..................................42

The Guadalupe Photovoice Project..........................43

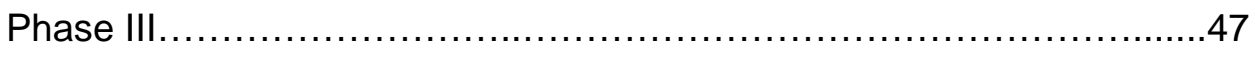

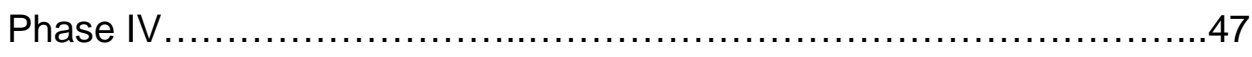

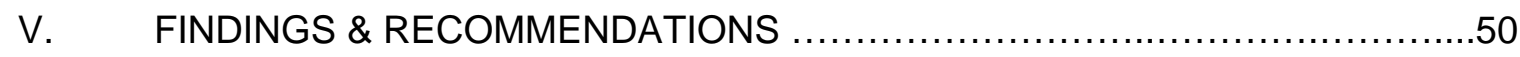

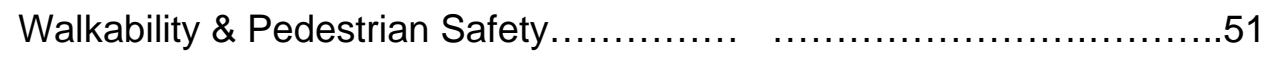

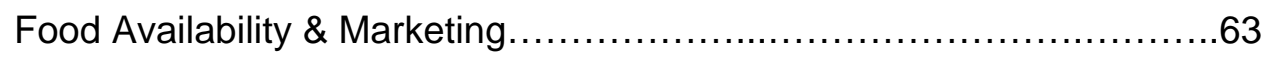

The Guadalupe Photovoice Project...............................6 67

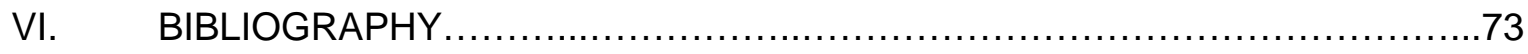

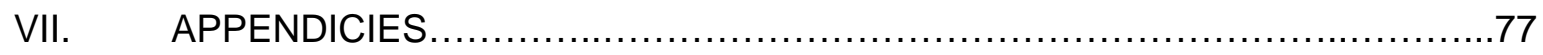

$\mathrm{CX}^{3}$ Food Availability \& Marketing Survey..............................

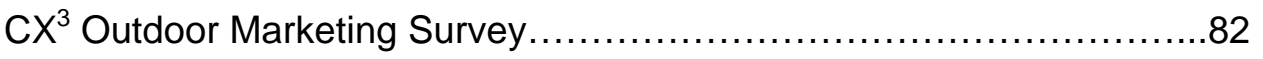

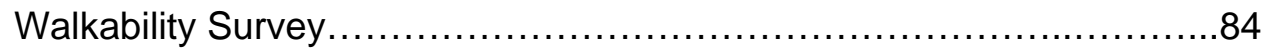




\section{LIST OF TABLES}

\section{TABLES}

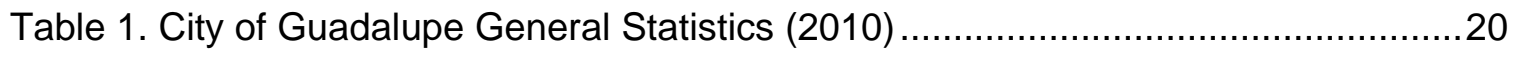

Table 2. Age Distribution- Guadalupe vs. Santa Barbara County .............................21

Table 3. Population Growth- Children in Guadalupe 2000 vs. 2010 ...........................22

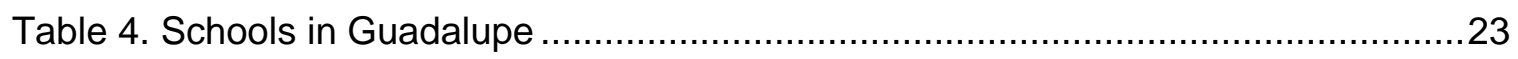

Table 5. Student Eligibility to Receive Free Reduced Price School Meals ...................25

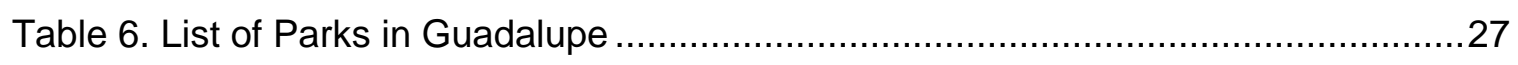

Table 7. Case Studies \& Comprehensive Report: Questions \& Sources......................48

Table 8. Walkability Survey Rating Results................................................... 53

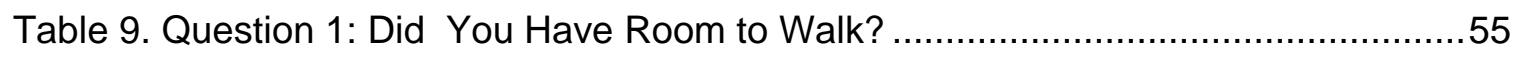

Table 10. Question 2: Was it Easy to Cross Streets? ..........................................56

Table 11. Question 3: Did Drivers Behave Well? ............................................. 58

Table 12. Was it Easy to Follow Safety Rules? Could you and your Child..................58

Table 13. Question 5: Was your Walk Pleasant? .............................................. 60

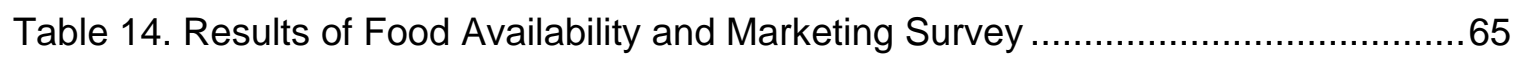

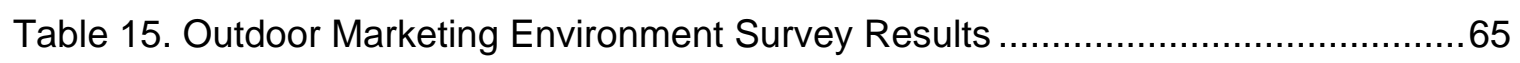




\section{LIST OF FIGURES}

\section{FIGURES}

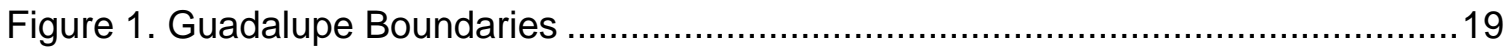

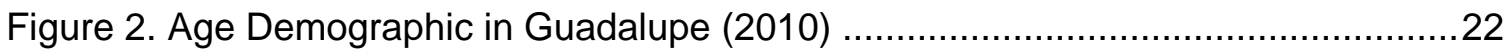

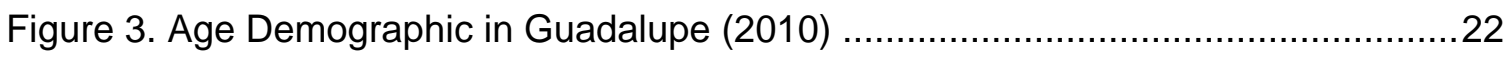

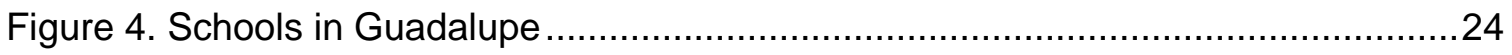

Flgure 5. Breakfast in the Classroom bags for food distribution.......................24

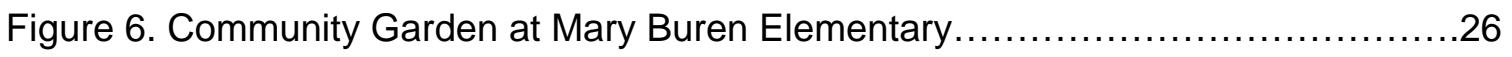

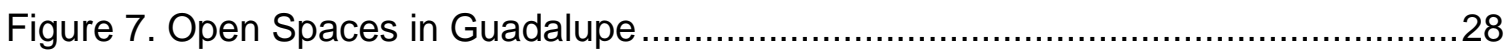

Figure 8. Bike and Pedestrian Facilities in Guadalupe ........................................ 31

Figure 9. Percent of Kindergarten Children with Healthy BMI .................................. 33

Figure 10. Percent of Kindergarten Children Screened for Developmental and Social-

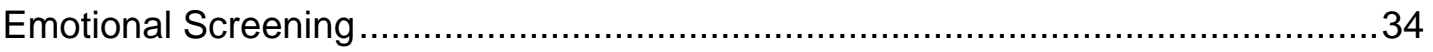

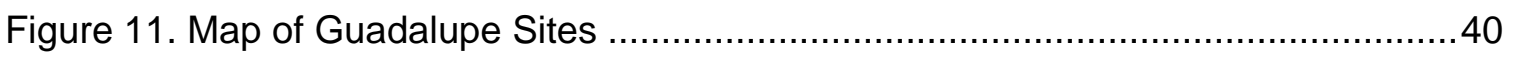

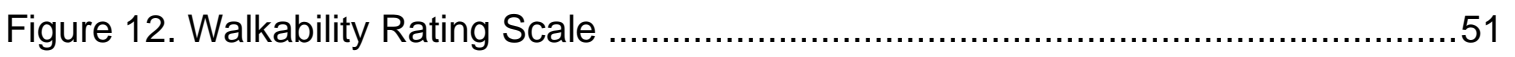

Figure 13. Rating Score: How Walkable is Guadalupe? ........................................52

Figure 14. Rating Score: How Walkable is Jack O' Connell Park ...............................52

Figure 15. Cross walk with flashing lights on Guadalupe Street ...............................54

Figure 16. Wide roads around Jack O' Connell Park ............................................55

Figure 17. Types of Problems Walking Around Guadalupe Street.............................56

Figure 18. What are Some Problems Crossing Guadalupe Street? ............................57

Figure 19. What are Some Problems Crossing Jack O' Connell Park? .........................57

Figure 20. What are Some Problems Noticed About the Drivers on Guadalupe Street? 58

Figure 21. Was it Easy to Follow Safety Rules? Could you and our Child___ on

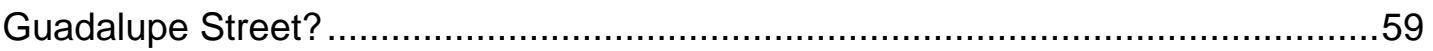


Figure 22. Was it Easy to Follow Safety Rules? Could you and Your Child at Jack O' Connell Park? 59

Figure 23. Problems that Made Walking on Guadalupe Street Unpleasant. 60

Figure 24. Problems that made walking at Jack O' Connell Park Unpleasant ..... 61

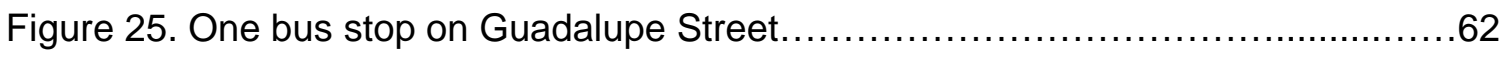

Figure 26. One market located on Guadalupe Street............................63

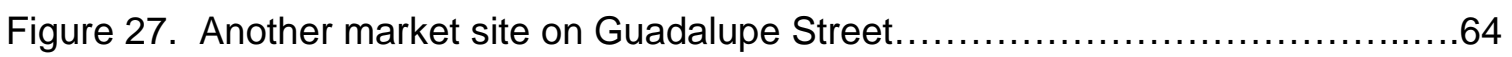

Figure 28. Students with their Photovoice board.................................67

Figure 29. Picture of a "dirty pile" in Guadalupe that could be cleaned up ...................68

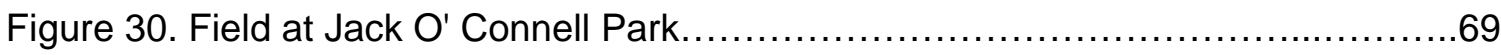

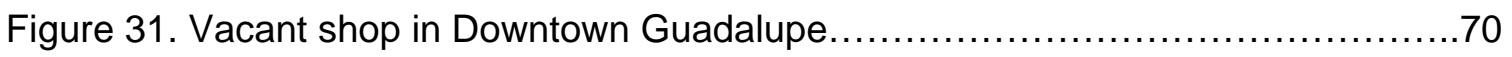

Figure 32. Donut and Deli shop across the street from Kermit McKenzie Junior High...72 
INTRODUCTION 


\section{INTRODUCTION}

\section{TOPIC \& BACKGROUND}

As one of the greatest nations in the world today, the United States is facing a health crisis that has been growing exponentially since the 1980s: obesity. The consequences

of having excess body fat are so dismaying not only because they lead to so many forms of potential death, but because many of these health complications are now being recognized in young children too. According to the Centers for Disease Control and Prevention, childhood obesity has more than doubled in children and tripled in adolescent in the past 30 years (CDC, 2014). These health complications found in obese children include increased risk of Type II Diabetes, coronary heart disease, cancers, liver and gallbladder disease, osteoarthritis, reproductive health complications, and mental health conditions. Childhood obesity rates are found to be highest in certain racial and ethic communities. Sharply higher rates of overweight and obesity have occurred among Latino, African-American and American Indian and Alaska Native children and adolescents (Leadership for Healthy Communities, 2010). While the causes for childhood obesity can range from genetics to the physical built environment, this professional project will be looking primarily at the impacts of our built environment on obesity in children living in racial and ethnic communities.

The aim of this project is to create a comprehensive report that takes a look at the impacts of our built environment on obesity in children living in Guadalupe. The report will include existing conditions of childhood obesity in Guadalupe and existing conditions of the built environment in Guadalupe, recommendations based on the results and findings collected from $\mathrm{CX}^{3}$ field surveys, walkability surveys, and a Photovoice project for improving children's health in Guadalupe. Data collected using the $\mathrm{CX}^{3}$ framework 
will help to see how the community currently "measures up" and where it needs to improve on to become a community of excellence for its residents. Walkability surveys will be used to evaluate whether the area is safe and accessible for pedestrians, especially children. A Photovoice project will also be done to help gather a better sense of existing conditions in the community and give children an opportunity to express their viewpoints about their communities. Production of an "easy to read' brochure with evaluated strategies and family based planning suggestions as a reference for families will be created if time permits.

Located in Santa Barbara County, the City of Guadalupe is chiefly an agricultural town with over $85 \%$ of its residents who are of Hispanic or Latino Origin. 9.5\% are $0-4$ years old, $24.7 \%$ are $5-17$ years old, $57.8 \%$ are $18-64$ years old, and $8 \%$ are 65 years and over. With almost half of the Latino population under 17 years of age, Guadalupe is an ideal location to examine the number of complex social, economic, and environmental matters that can contribute to higher overweight and obesity rates among Latino children. Latino children and adolescents are at greater risk of overweight and obesity than their white or African-American peers (Leadership for Healthy Communities, 2010). It will be interesting to take a further look at the factors that create opportunities and barriers for childhood obesity through the built environmental in Guadalupe.

The built environment includes all aspects of the environment that range from homes, schools, workplaces, parks, and food environments. It is evident that the environment that nourishes adolescents from childhood to adulthood plays a powerful role in influencing their physical activity and eating habits. Thus, it becomes important to address how our built environment can be improved to combat childhood obesity. Improving surroundings such as increasing access to healthier food outlets, creating 
more walkable communities, encouraging more physical activity, and designing more communities that are pedestrian and biker friendly are just a few steps that can be taken.

One approach to identifying the existing conditions of a community is doing a Community Assessment. While there are multiple methods of scoring the built environment around us, this professional project will be using the Communities of Excellence $\left(\mathrm{CX}^{3}\right)$ framework. $C X^{3}$ is a series of surveys that was developed by the California Public Health Department to score the quality of the built environment and to addresses factors: nutrition, physical activity, and obesity prevention. These factors are a part of the primary themes this professional project is focused on looking into: the effects of the built environment and the food environment on children. Data collected from the $\mathrm{CX}^{3}$ surveys will be used to take a look at the current conditions of the built environment and childhood obesity in the City of Guadalupe and provide recommendations for addressing childhood obesity. While assessment tools are necessary to help gather a better sense of existing conditions in the community, outreach efforts such as school surveys and a Photovoice project will help to better understand children's needs, viewpoints, and current health conditions. These methods of data collection will be further described later in the Methods Chapter.

\section{RELEVANCE TO PLANNING}

Decisions about zoning, transportation, land use, and community design all have the potential to influence the distances people travel to work or school, the convenience of purchasing healthy and unhealthy foods, and the safety and attractiveness of neighborhoods for walking. There is also growing evidence to link the built environment with chronic health conditions among adults. For example, physical inactivity has been found to significantly contribute to a number of health problems, including obesity, 
diabetes, cardiovascular disease, certain forms of cancer, and depression [39]. Physical inactivity is estimated to be responsible for over 200,000 deaths each year in the United States [40] (Kiipke, Iverson, Moore, Booker Ruelas, Peters, and Kaufman, 2007). While many of these chronic health conditions have been known to appear in older folks, young children are now just as susceptible to these adverse chronic diseases.

The linkages between childhood obesity and the built environment include topic matters from the location of schools, the design of safe and appealing neighborhoods, the availability and access to healthy food outlets for fresh produce, the amount of marketing advertisements promoting high caloric foods with little nutritious value on television, to the amount of physical activity they partake in daily. Adolescents spend a considerable amount of time in and around these built environments, which play an influential role in their decision-making on physical activity and eating habits. Thus, it becomes important to improve their living environments by addressing these topics with policies that promote health and well-being (Wakefield, 2004).

According to Surgeon General, Richard Carmona of the U.S. Public Health Service, obesity is the fastest growing cause of disease in America. And it's completely preventable (Carmona, 2003). While there are multiple factors that influence the increase of this epidemic, one factor we can play a role in addressing is the built environment we live in. Solving an epidemic like obesity will rely on the choices we determine to make as individuals as they affect the people around us. According to Robert Pool, author of Fat: Fighting the Obesity Epidemic,

When public health officials are faced with a plague that is making its way through the population, they generally respond with a two-pronged approach. 
First they attempt to treat the affected individuals, protecting them as best as possible from the ravages of the plague, and second they look to find the cause of the plague and stop it. In the case of obesity, the response has been almost completely of the first sort. (Pool, 2001, p.13)

This "plague" Pool identifies is clearly making its way through our population and as public health officials are combating it with the means of prevention, planners can also play a partnership role in addressing this epidemic. Planners can play an important role in removing barriers and developing plan and policies that support local food production in urban and rural areas, reduce food related pollution and waste, and improve access to healthy food (American Public Health Association, 2014). Essentially, there needs to be more partnerships among coalitions to encourage greater communication between nutrition, nursing, public health and planning professionals from the local to the national level.

\section{CHILDHOOD OBESITY IN SANTA BARBARA}

Knowing that there are numerous reasons to be concerned about the increasing prevalence of childhood obesity, individuals, families, communities, schools, worksites, health care, media, organizations, and government need to determine their role and take actions to prevent a decrease in obesity. In Santa Barbara County, more than half of its residents are overweight or obese. Over half of adults (54.3\%), and a third of teens (34.4\%) were overweight or obese in 2009 (Santa Barbara County Public Health Department, 2012). Over a third (36.8\%) of local $5^{\text {th }}, 7^{\text {th }}, 9^{\text {th }}$ graders are overweight or obese in 2010 , slightly below the state average of $38 \%$, but above rates in Ventura and San Luis Obispo Counties (Babey, Wolstein, Diamant, Bloom, and Goldstein, 2011). Obesity rates are generally higher in lower-income groups and Latinos. The 
Santa Barbara County Education Office Health Linkages program found a combined overweight/obesity rate of $43 \%$ in $2010-2011$ in the screening of lower-income preschool and kindergarten children (Health Linkages Program SB County Education Office, 2011). One third (33.5\%) of 2-5 year olds served by the County's Women and Infants and Children (WIC) nutrition program in 2010 were overweight or obese (Santa Barbara County Public Health Department, 2012). The national Pediatric Nutrition Surveillance System reported that $45.5 \%$ of local lower-income youth aged 5-20 were overweight or obese in 2009 (Santa Barbara County Pubic Health Department, 2012). Additionally, these health issues take a toll on the economy through increases in health care costs, worker compensation and loss of productivity costs.

As of the 2010 Census Demographics Data, $86.2 \%$ of Guadalupe is of Hispanic or Latino Origin. 9.5\% are 0-4 years old, $28 \%$ are 5-19 years old, 54.2\% are 20-64 years old, and $8 \%$ are 65 years and over.With almost half of the Latino population under 17 years of age, it becomes crucial to educate the youth in Guadalupe about making healthy choices and staying active. The percentage of children with a healthy BMI has increased from $47 \%$ in $2010-2011$ to $59 \%$ in $2012-2013$. The five-year goal for Guadalupe is for $64 \%$ of Grade K children to meet these criteria by 2015-2016 (THRIVE, 2013). Although the percent of children with a healthy BMI has improved, there is still a need for more informed and sensitive approaches to present Guadalupians information about preventive approaches that can be taken to address and treat health issues related to overweight and obesity.

This project will begin by discussing current professional and academic literature on childhood obesity, the built environments, food environments, and schools in Chapter 2. After a discussion of the academic research, existing conditions in the City of Guadalupe 
pertaining to childhood obesity and the built environment and existing conditions of the built environment in Guadalupe will be laid out in Chapter 3. To reach a better understanding of the built environment and its affect on childhood obesity, various methods of data collection will be executed and discussed in depth in Chapter 4. All findings and recommendations based off the findings from this project will be discussed in Chapter 5. 


\section{LITERATURE REVIEW}




\section{LITERATURE REVIEW}

This Literature Review draws from academic literature, professional reports from notable organizations such as the California Department of Public Health, the American Planning Association, Leadership for Healthy Communities, and the Santa Barbara County Public Health Department. A review of these existing sources on childhood obesity and the built environment help to provide a well-grounded understanding for the creation of the Comprehensive Report and future recommendations.

\section{THE BUILT ENVIRONMENT}

The built environment includes all aspects of the environment that range from homes, schools, workplaces, parks, and the food environments. It is evident that the environment that nourishes adolescents from childhood to adulthood plays a powerful role in influencing their physical activity and eating habits. In Making Healthy Places, the built environment is defined as consisting of settings designed, created, and maintained by human efforts-buildings, neighborhoods, public plazas, playgrounds, roadways, and more. Even seemingly natural settings, such as parks, are often part of the built environment because they have been sited, designed, and constructed by people (Dannenberg, Frumkin, \& Jackson, 2011, p. 5). These issues will be looked further into in academic journals and articles include access to the healthy foods, access to recreational activities, community design that promotes or discourages physical activity, and the street conditions and safety. The following three topics relevant to addressing childhood obesity are covered in this section: 1) Access to Foods; 2) Access to Recreational Activities 3) Foods In and Out of School Environments. 


\section{Access to Healthy Foods}

In a research article by Larson, Story, and Nelson (2009) the links between poor dietary patterns and obesity have been assessed. The differences in how neighborhoods are laid out play an important role in influencing the relationships between dietary patterns and health disparities. Findings from this article suggest that neighborhood residents who have better access to supermarkets and limited access to convenience stores tend to have healthier diets and lower levels of obesity. In their review, Larson, Story, and Nelson (2009) examined more than fifty studies that have documented unequal distribution of food resources measured by the proximity of retail food outlets for various communities. They examined in their case studies, the availability of health-enhancing nutritional options in communities. Supermarkets and convenient stores were the target of interest. Their results found supermarkets to offer greater variety of high quality products at the lowest cost, whereas convenience stores sold mostly prepared, highcalorie foods and little fresh produce at higher prices. It is known that childhood obesity is associated with an imbalance between calorie intake and calories utilized.

In one of their smaller bodies of research used to identify relevant research studies completed in the U.S. and published between 1985 and April 2008, an assessment of the products sold in retail outlets was performed. From the results, a trend was found relating the availability of more fresh vegetables varieties in local stores to greater vegetable consumption. No similar trends were found for fruits (Larson, Story, \& Nelson, 2009, p. 75). While, a snowball strategy was used to identify relevant research studies on this topic, it would be interesting to analyze the surveying materials on food environments to see the types categories of interest and the methods the surveys. The availability and convenience of having healthy selections may help to encourage healthier eating habits and improve healthier caloric intake. 
The relevant studies examined accessibility to healthy foods as opposed to the proximity of home and convenience stores. Only one study was found that identified associations between access to retail food stores and dietary intake among youth. As examined by Larson, Story, and Nelson (2009), this study suggested that young adolescents with greater access to convenience stores eat fewer fruits and vegetables, however no studies in older youth, specifically those with driving privileges. This project is primarily interested in looking at young school children who are still without driving privileges, thus it would be appropriate to analyze the walking and physical activity they engage in as it plays a part in encouraging a healthier lifestyle.

As discussed by Kipke, Iverson, Booker, Ruelas, and Peters (2007), neighborhood differences and compositions may play an important influence on the identified associations as mentioned above. Findings from this research suggest that residents in urban settings, particularly inner-city, poor neighborhoods, are less likely than residents in the suburbs to have access to full-service markets. Instead, inner-city residents are forced to depend on smaller grocery and convenience stores that tend to have a limited selection of healthful foods and at higher prices (Kipke, et al., 2007). These articles have significance that go over the relationship between neighborhood access to foods and weight status. While these two studies examined the proximity of home and convenience stores to the accessibility of more and less healthy foods, it would be beneficial to look at the proximity of schools to convenience stores and to examine the products available at these convenience stores in future research. Just as it is important to consider the environment inside of school, it is just as important to consider the outside influences of the environment children spend out of school bounds that may steer their daily eating and physical activity habits. 


\section{Access to Recreational Activities}

Numerous studies have shown the many benefits of engaging in physical activity. Physical activity can help people to prevent numerous physical and mental health conditions, yet most Americans do not meet recommended levels of physical activity (Dannenberg, Frumkin, \& Jackson, 2011, p. 33). Current guidelines are for young people to accumulate at least 60 minutes of moderate-to-vigorous physical activity (MVPA) daily and for adults to accumulate at least 150 minutes of MVPA or 75 minutes of vigorous physical activity, or a combination of these two, every week (US Department of Health and Human Services, 2008). As discussed in Physical activity reduces the risk of being overweight; of suffering from cardiovascular diseases such as high blood pressure, heart attacks, and stroke, and of developing type 2 diabetes (Dannenberg, Frumkin, \& Jackson, 2011, p. 34).

As examined by Kipke, Iverson, Moore, Booker Ruelas, and Peters (2007), the associations between community physical activity related settings (e.g., athletic fields, parks, bike paths) and race, ethnicity, and socioeconomic status in 409 communities throughout the United States were looked into in East Los Angeles. East Los Angeles is home to 68,688 residents, of which 61,983 or $95 \%$ are Hispanic (Kipke, et al., 2007). This study is appropriate for this project because of the demographic examined and the methods used. A mixed-methods design was carried out, which included looking at spatial analysis to examine density and proximity of food establishments relative to schools; ethnographic observation of the availability and quality of fruits, vegetables, meats, and dairy products available in grocery stores; and ethnographic observations of the availability and quality of local parks. My project will be using methods similar to this study to evaluate the neighborhood nutrition and neighborhood activity environment. Ethnographic observations of the availability and quality of the food environment can be 
easily done through field surveys and will help to address where the community can improve on to become a community of excellence.

Dannenberg, Frumkin, and Jackson (2011) summarize research linking built environments to physical activity and suggest there is a strong relationship between total physical activity and health outcomes. The significance of the finding in the East Los Angeles study raises interest on the types of recreational activities available at these parks and the quality and conditions of available park equipment. The researcher's observations of the amenities and programs available at the parks observed in East Los Angeles provide critical insight into the details that link the layout of the park environment to physical activity and raises concerns regarding safety and street conditions of the observed grounds. In addition to considering safety of the observed grounds where recreational activity takes place, it is also important to make note of the pedestrian infrastructure and maintenance. Kipke, Iverson, Moore, Booker Ruelas, and Peters (2007) found communities with higher proportions of ethnic minorities had fewer physical activity-related facilities and settings. Having convenient access to recreational facilities had also been found to consistent engagement of physical activity. For the purpose of this project, observations and assessments of the parks in Guadalupe would be an appropriate consideration because of the large ethnic makeup in the City. According to Bauman and Bull (2007), the accessibility and quality of recreation facilities can be measured through direct observational audits, GIS mapping, and self reports. This type of measurement will be done in this professional project using walkability assessments to gather a better understanding of the current built environment of Guadalupe to help make appropriate recommendations to improve on the safety and quality of facilities children utilize.

According to Dannenberg, Frumkin, and Johnson (2011), greater street connectivity and 
higher residential density are related to higher total physical activity. Street connectivity creates shorter routes to destinations, and higher residential density supports economic development and may provide social support and perceived safety that can encourage physical activity. However, the environmental attributes related to physical activity may be different for children. Streets with low connectivity are likely to be free of traffic and may be important play areas for children (Dannenberg, Frumkin, \& Jackson, 2011). While the points stated in the above discussed literature make valid arguments street connectivity and safety, perhaps more assessment is necessary to better understand the amount of physical activity children engage in with greater street connectivity. The social environment of where children interact and take part in recreational activities is also important to consider. Well-designed playgrounds can encourage children to be physically active and help to reduce childhood obesity by offering an attractive alternative to watching television and playing video games. Creation of community environments and having well maintained complete and connected streets can help to encourage walking and biking as discussed by Bauman and Bull (2007). Although this research was conducted largely with adults, the findings and context of the study done makes it an appropriate source to consider. Adults who lead more active lifestyles and take advantage of park amenities can encourage their children to enjoy the same benefits of engaging in physical activities outdoors.

\section{THE FOOD ENVIRONMENT}

The following research articles expand on the discussion of how the food environment either supports health or contributes to adverse health consequences and how food environments vary across communities. 


\section{Foods In and Out of School Environments}

When looking at the food environment and children, it is important to consider the proximity of schools to food establishments and the types of food availability in school boundaries. This project looks primarily at the impacts of our built environment on obesity in Latino children living in racial and ethnic communities. It would be appropriate to consider what accounts for the higher rates of obesity within multiethnic, low-income, inner-city neighborhoods, and if these neighborhoods put children at risk for becoming obese. Lee (2012) found that children in predominantly minority and poor neighborhoods have higher concentrations (per land area) of fast-food outlets and convenience stores than children who reside in majority white and non-poor neighborhoods. While Lee's research was focused on children's weight and BMI transitions over time in East Los Angeles, she raised relevant topics that are important to address, such as the topic of food advertising and marketing in food availability. A significant line for further research will be to better understand how accessibility, quality, and marketing interact to influence food purchasing and consumption behaviors. (Lee, 2012). Food advertising and marketing can influence the decisions children make on deciding what they want to consume.

As specified by Lee (2012), understanding marketing interaction to influence food purchasing and consumption behaviors is important to consider because these topics can work together to help inform the direction of public health policy in improving dietary practices in vulnerable communities. Children start learning at a young age and so it is important they start their early years learning about healthy eating habits and engaging in physical activity. By learning healthy habits and choosing to want healthier choices can help to influence what the market has to supply in their stores. 


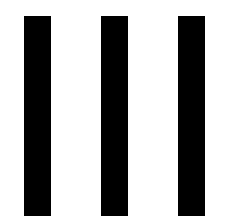

\section{LOCAL CONTEXT}




\section{LOCAL CONTEXT}

This chapter provides a detailed summary of the existing conditions in the City of Guadalupe pertaining to childhood obesity and the built environment. The background information collected helped to identify the impacts of the built environment and food environment on childhood obesity in children living in Guadalupe and to help further inform the community about addressing childhood obesity. One assessment conducted by THRIVE Guadalupe as part of THRIVE Santa Barbara County's (THRIVE SBC) initiative to look at complex issues impacting schools successes was a Thriving Children Report Card, which contributed to the creation of the comprehensive report. Another useful document was the Fitness Promotion and Obesity Prevention Plan developed by the Santa Barbara County Public Health Department. Additional information was retrieved from the Santa Barbara County Public Health Department, U.S. Census, and other state and local agencies.

The chapter begins with an overview on local demographic data and countywide demographic data, i.e. the City of Guadalupe and Santa Barbara County. This data will discuss the types of populations and vulnerable groups at risk for childhood obesity in Guadalupe. Schools, recreation facilities and afterschool programs in Guadalupe will also be examined to discuss the types of social and built environments school children are exposed to. This will help to look at factors that create opportunities and barriers for childhood obesity through the built environment. Parks and open space in Guadalupe will be discussed to look at the types of amenities available and extra curricular activities school children and the community utilize. Current statistics of childhood obesity in Guadalupe from the THRIVE report and other local reports will be discussed to lay out the current conditions of childhood obesity in Guadalupe and to help further address appropriate recommendations to combat childhood obesity. Methods of the various data 
collection used to understand the built environment and its affect on childhood obesity throughout this project will be further discussed in Chapter 4.

\section{CITY PROFILE}

Located in Santa Barbara County, the City of Guadalupe is chiefly an agricultural town on the Central Coast of California with over $85 \%$ of its residents who are of Hispanic or Latino Origin. According to the U.S. Census of 2010, the city has a population of 7,080 . California's Pacific Coast Highway, California Highway 1, runs right through the downtown of Guadalupe. Guadalupe is economically and socially tied to the City of Santa Maria, which lays about ten miles to the east. The city was established in 1840 and incorporated on August 3, 1946. Figure 1 showcases the boundaries of Guadalupe and provides a geographic context for this professional project.

Figure 1. Guadalupe Boundaries

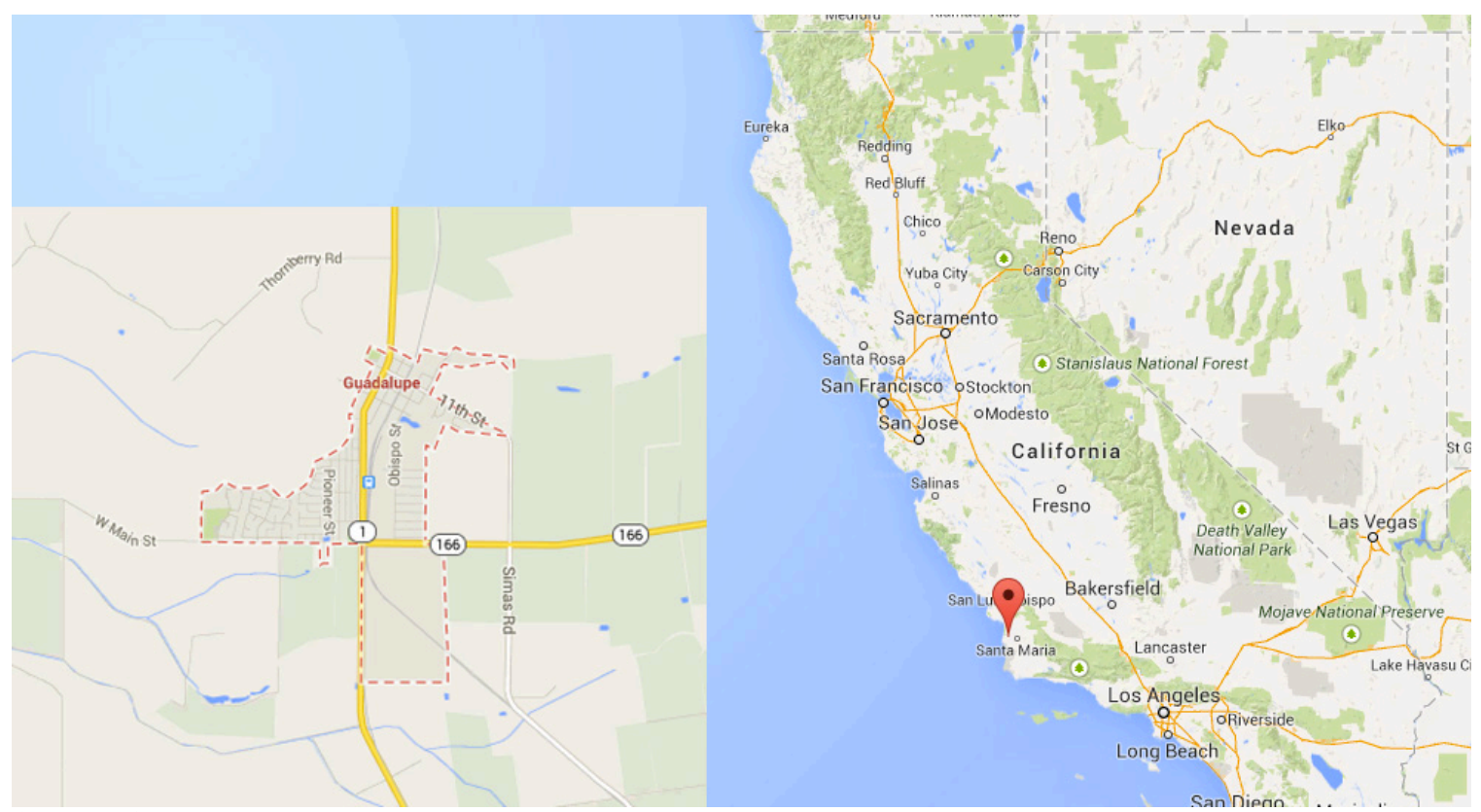

Source: Google Maps. (2014). 


\section{POPULATION}

Table 1 depicts key demographic statistics about the City of Guadalupe from the U.S.

Census (2010). Approximately 48 percent of the City's population is White and 86

percent is Hispanic or Latino (U.S. Census, 2010). There are about 1,073 households

with individuals under 18 years of age and about 431 households with individuals 65 and over. Individuals under 18 years of age and individuals 65 and over are vulnerable groups of interest for this project.

Table 1. City of Guadalupe General Statistics (2010)

\begin{tabular}{|c|c|}
\hline DEMOGRAPHICS & 2010 \\
\hline Total Population & 7,080 \\
\hline Median Age & 28.2 \\
\hline$\%$ One Race & $93.8 \%$ \\
\hline$\%$ White & $48 \%$ \\
\hline$\%$ Black or African American & $1 \%$ \\
\hline \% American Indian and Alaska Native & $1.5 \%$ \\
\hline \% Asian & $3.9 \%$ \\
\hline$\%$ Hispanic or Latino (of any race) & $86.2 \%$ \\
\hline$\%$ Some other race & $39.3 \%$ \\
\hline$\%$ Two or More Races & $6.2 \%$ \\
\hline \multicolumn{2}{|l|}{ SEX \& AGE } \\
\hline Male & 3,562 \\
\hline Female & 3,518 \\
\hline \multicolumn{2}{|l|}{ HOUSING } \\
\hline Total Households & 1,810 \\
\hline Households with individuals under 18 years & 1,073 \\
\hline Households with individuals 65 and over & 431 \\
\hline Average household size & 3.91 \\
\hline
\end{tabular}

Source: U.S. Census. (2010).

\section{AGE}

In 2010, 38 percent of City residents were under the age of 20. Senior Citizens represent 21 percent of Guadalupe. Table 2 shows that the age distribution of the City's population is younger overall than Santa Barbara County as a whole (City of Guadalupe, 2011). 
Table 3 highlights an increase of population growth on the numbers of children under the age of 20 from the years 2000 and 2010 . This suggests an opportunity to accommodate for more projects that will cater to this age range.

Table 2. Age Distribution- Guadalupe vs. Santa Barbara County

\section{AGE DISTRIBUTION - Guadalupe vs. Santa Barbara County (2010)}

\begin{tabular}{|l|c|c|c|c|}
\hline \multirow{2}{*}{ Age Group } & \multicolumn{2}{|c|}{ Guadalupe } & \multicolumn{2}{c|}{ Santa Barbara } \\
\cline { 2 - 5 } & Persons & Percent & Persons & Percent \\
\hline Total Population & 7,080 & $100.0 \%$ & 423,895 & $100.0 \%$ \\
\hline Under 5 years & 676 & $9.5 \%$ & 27,350 & $6.5 \%$ \\
\hline 5 to 9 years & 679 & $9.6 \%$ & 26,303 & $6.2 \%$ \\
\hline 10 to 14 years & 662 & $9.4 \%$ & 26,626 & $6.3 \%$ \\
\hline 15 to 19 years & 658 & $9.3 \%$ & 38,009 & $9.0 \%$ \\
\hline 20 to 24 years & 546 & $7.7 \%$ & 43,026 & $10.2 \%$ \\
\hline 25 to 29 years & 524 & $7.4 \%$ & 31,100 & $7.3 \%$ \\
\hline 30 to 34 years & 511 & $7.2 \%$ & 26,592 & $6.3 \%$ \\
\hline 35 to 39 years & 461 & $6.5 \%$ & 25,092 & $5.9 \%$ \\
\hline 40 to 44 years & 434 & $6.1 \%$ & 25,386 & $6.0 \%$ \\
\hline 45 to 49 years & 422 & $6.0 \%$ & 27,577 & $6.5 \%$ \\
\hline 50 to 54 years & 383 & $5.4 \%$ & 27,421 & $6.5 \%$ \\
\hline 55 to 59 years & 319 & $4.5 \%$ & 24,418 & $5.8 \%$ \\
\hline 60 to 64 years & 238 & $3.4 \%$ & 20,597 & $4.9 \%$ \\
\hline 65 to 69 years & 160 & $2.3 \%$ & 15,014 & $3.5 \%$ \\
\hline 70 to 74 years & 121 & $1.7 \%$ & 11,762 & $2.8 \%$ \\
\hline 75 to 79 years & 126 & $1.8 \%$ & 10,052 & $2.4 \%$ \\
\hline 80 to 84 years & 90 & $1.3 \%$ & 8,480 & $2.0 \%$ \\
\hline 85 years and over & 70 & $1.0 \%$ & 9,090 & $2.1 \%$ \\
\hline Median age & & & & 33.6 \\
\hline (years) & 28.2 & & \\
\hline Source: Us census. (2010a). & & & \\
\hline
\end{tabular}


Table 3. Population Growth- Children in Guadalupe 2000 vs. 2010

\begin{tabular}{|c|c|c|}
\hline \multicolumn{3}{|c|}{ POPULATION GROWTH - Children in Guadalupe (2000 vs 2010) } \\
\hline \multirow{2}{*}{ Age Group } & \multicolumn{2}{|c|}{ Year } \\
\hline & 2000 & 2010 \\
\hline Total Population & 5,659 & 7,080 \\
\hline Under 5 years & 522 & 676 \\
\hline 5 to 9 years & 607 & 679 \\
\hline 10 to 14 years & 551 & 662 \\
\hline 15 to 19 years & 556 & 658 \\
\hline 20 to 24 years & 444 & 546 \\
\hline
\end{tabular}

Source: US Census. (2010b).

Figure 2. Age Demographic in Guadalupe (2010)

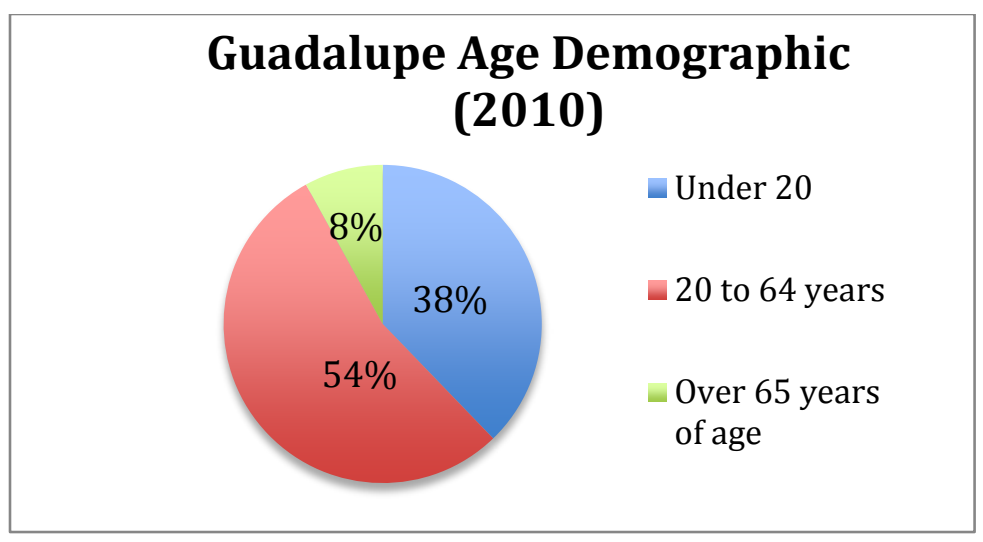

Source: U.S. Census. (2010).

Figure 3. Age Demographic in Guadalupe (2010)

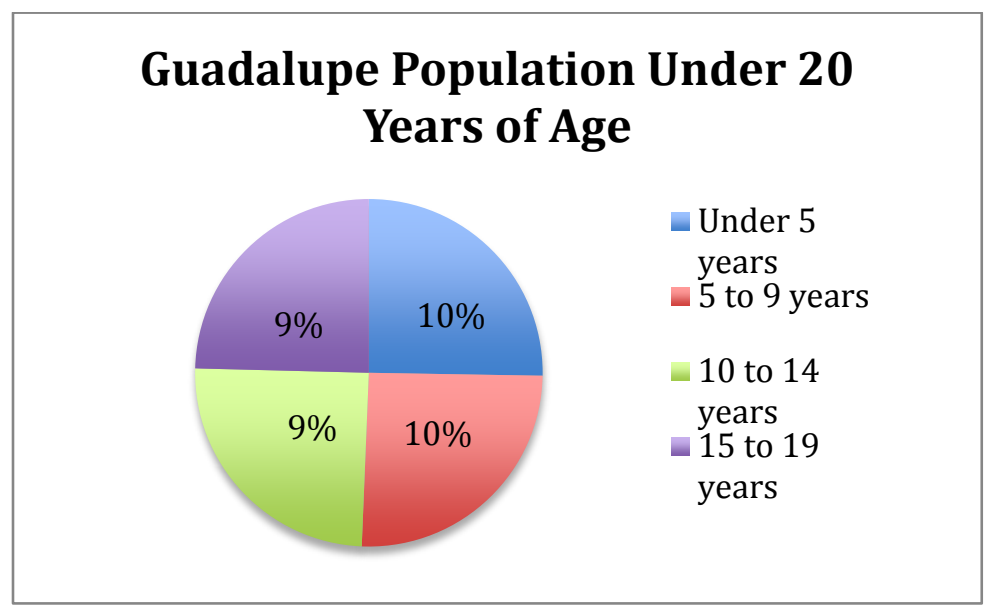

Source: U.S. Census. (2010). 


\section{RACE \& ETHNICITY}

Located in Santa Barbara County, the City of Guadalupe is chiefly an agricultural town with over $85 \%$ of its residents who are of Hispanic or Latino Origin. With $38 \%$ of the Latino population under 20 years of age, Guadalupe is an ideal location to examine the number of complex social, economic, and environmental matters that can contribute to higher overweight and obesity rates among Latino children. The percentage of children with a healthy BMI has increased from $47 \%$ in $2010-2011$ to $59 \%$ in $2012-2013$. The five-year goal for Guadalupe is for $64 \%$ of Grade K children to meet these criteria by 2015-2016 (THRIVE, 2013). The Thriving Children Report Card presents only statistics on children under the age of 5 . This is important because these are the first few years where optimal child development are needed to help children thrive and ready themselves.

\section{SCHOOLS}

There are currently two schools located in Guadalupe, which are listed below in Table 3. Mary Buren Elementary and Kermit McKenzie Junior High School are both a part of the Guadalupe Union School District (GUSD). The GUSD serves more than 1,100 students in grade $\mathrm{K}-8$.

Table 4. Schools in Guadalupe

\begin{tabular}{|l|c|c|}
\hline \multicolumn{3}{|c|}{ Grades } \\
\hline Mary Buren Elementary & K - 5 & 1050 Peralta Street. Guadalupe, CA 93434 \\
\hline Kermit McKenzie Junior High & $6^{\text {th }}$ to $8^{\text {th }}$ & 4710 W Main Street, Guadalupe, CA 93434 \\
School & & \\
\hline
\end{tabular}


Figure 4. Schools in Guadalupe

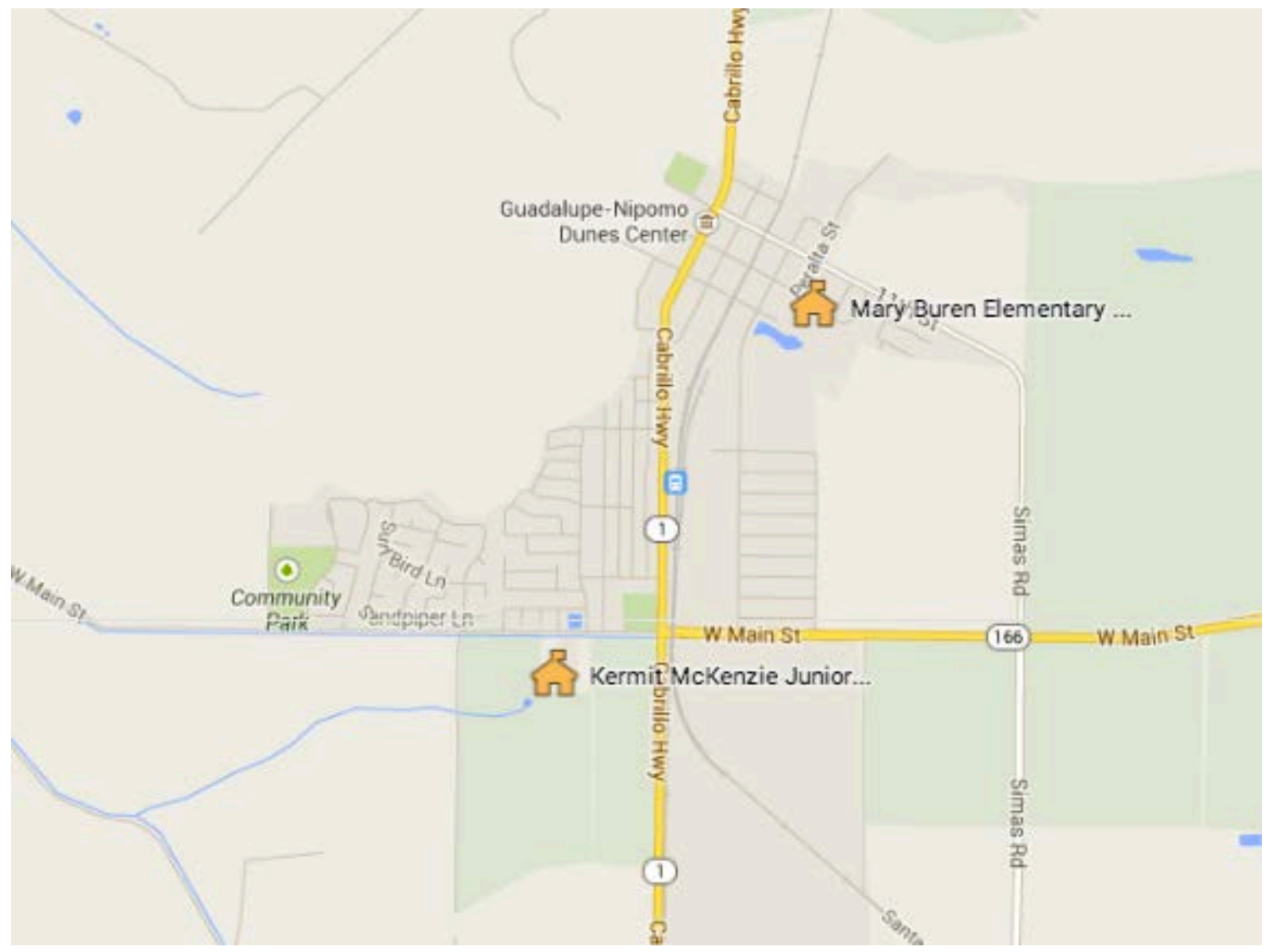

Source: Google Maps. (2014).

\section{BREAKFAST \& LUNCH PROGRAMS}

The school cafeterias in the

GUSD participate in the School

Breakfast and National School

Lunch Program which offer the

following services listed. The

lunch menus for both schools are

up to date and available online on

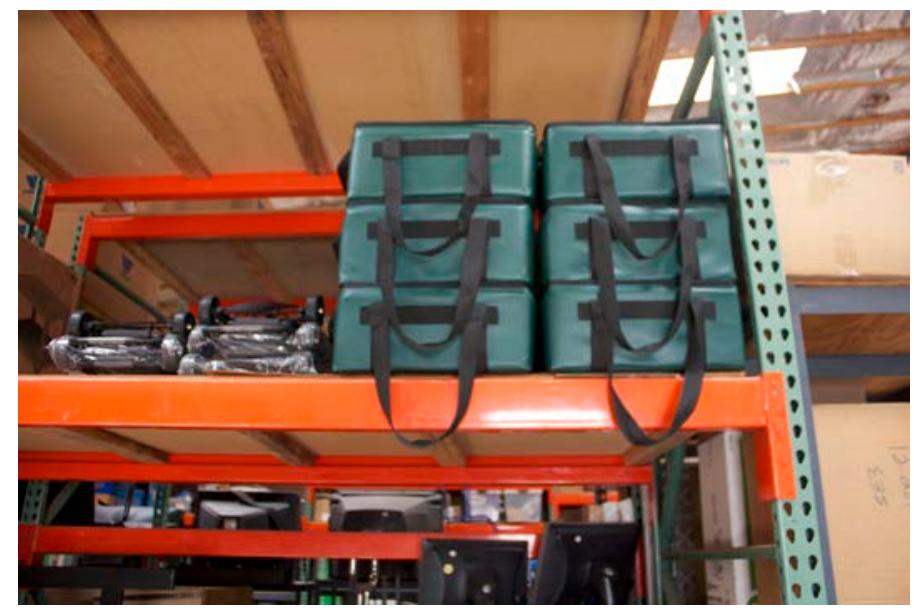

each school's website.

Figure 5. Breakfast in the Classroom bags for food distribution 
- Free and nutritional meals to all students

- Required Federal and State serving items and amounts

Kermit McKenzie Junior takes part in the Breakfast in Classroom program that takes the traditional school breakfast approach and improves it by serving it in the classroom. The Orfalea Foundation's School Food Initiative made this program available in the GUSD. Children eat together in the classroom, usually during homeroom, at the beginning of the day. They enjoy nutritionally balanced foods like break wraps, yogurt, or fruit (Breakfast in the Classroom, 2010).

Table 5. Student Eligibility to Receive Free Reduced Price School Meals

\begin{tabular}{|l|cc|}
\hline & $\begin{array}{c}\text { Guadalupe Union } \\
\text { Elementary }\end{array}$ & $\begin{array}{c}\text { Santa Barbara County } \\
\text { (Office of Education) } \\
\text { School District }\end{array}$ \\
\hline Eligible for Free Meals & $78.8 \%$ & $67.1 \%$ \\
\hline Eligible for Reduced Price Meals & $11.4 \%$ & $4.5 \%$ \\
\hline Not Eligible & $9.8 \%$ & $28.4 \%$ \\
\hline
\end{tabular}

Source: Kidsdata. (2013).

\section{EDUCATION SERVICES \& PROGRAMS}

The Guadalupe Union School District provides Education Services \& Programs for all students to help them excel in their education. These services and programs were taken from the Guadalupe Union School District website.

\section{ASES After School Program}

The ASES After School Program provides students with a safe place, after school, while parents are at home. They offer academic, enrichment, and physical education activities. More information is available at their office and on their website. 
Tutoring- Supplemental Education Services (SES)

All students from the GUSD are eligible to apply for this service; the school principals will then select students based on test results and teacher recommendation.

Youth Educational Enhancement Programs (YEEP)

The Youth Educational Enhancement Program (YEEP) in Guadalupe is offered by Peoples' Self Help- Housing. Peoples' Self Help- Housing provides affordable housing and programs leading to self-sufficiency for low-income families, seniors, and other special needs groups on California's Central Coast. YEEP is very similar to the ASES in that they offer after-school education programs. This program focuses on improving student literacy, English, and math skills. The program improves grade point averages, sharpens reading and study skills, promotes high school graduation, builds self-esteem, and fosters parent participation in their child's academic life (Peoples' Self Help-Housing, 2014).

\section{Community Garden}

As part of the students' curriculum at Mary Buren Elementary School, all students take part in spending time outdoors with the Master Gardener and their teacher learning about agriculture and a mix of other subjects. Students get a chance to

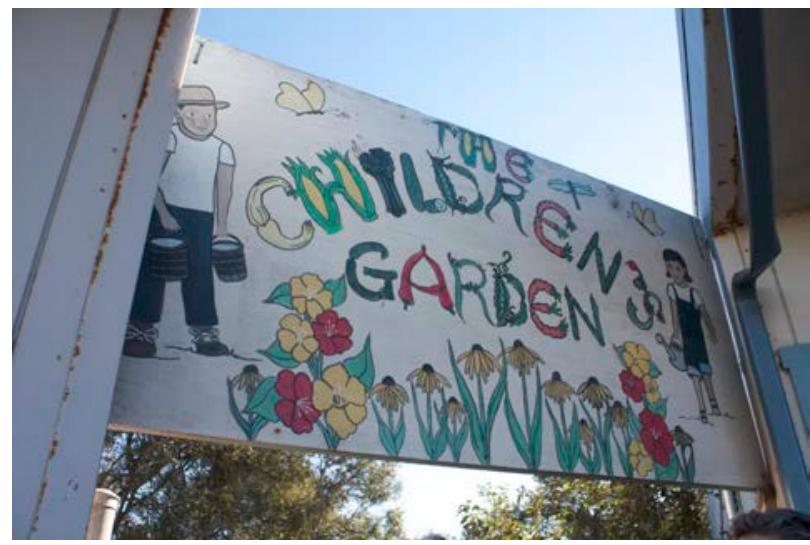

Figure 6. Community Garden at Mary Buren Elementary learn about different types of crops grown and are introduced to healthy foods. Parents are informed about these activities through flyers sent out by the school. 


\section{PARKS \& RECREATION}

There are approximately 20 acres of open park space within the City limits, including community and pocket parks as illustrated in Figure 7 . These parks also serve as recreational facilities for local schools and sports program. Recreation in Guadalupe is organized by volunteer and nonprofit organizations. No City-funded recreation programs exist, but volunteer recreation programs are available, such as the Guadalupe Bulldogs Youth Football and Cheer program and the Boys and Girls Club of Santa Maria Valley. The Boys and Girls Club of Santa Maria Valley operates a unit in Guadalupe at Leroy Park. They offer after-school recreation as well as academic programs for students in Guadalupe. Guadalupe also has two joint-use facilities in cooperation with the GUSD, and a gymnasium located at City Hall. Existing park facilities are listed below:

Table 6. List of Parks in Guadalupe

\begin{tabular}{|l|c|c|}
\hline PARKS & TYPE & ACRES \\
\hline Leroy Park & Community & $4^{*}$ \\
\hline Jack O' Connell Community Park & Community & 14.53 \\
\hline Central Park & Community & 1.38 \\
\hline Mini/Pocket Parks & Mini/Pocket & 1.58 \\
\hline
\end{tabular}

*Leroy Park consists of a 25-acre parcel, but only 4-acres are developed park. The remainder lies outside the city boundary in the Santa Maria River floodplain.

Source: Cal Poly Background Report 2013

\section{Mini/Pocket Parks}

Small area parks within the city serve as a niche for passive and recreation. Four area parks are within this designation (Cal Poly CRP 554 Graduate Studio, 2014):

- $7^{\text {th }}$ St Park: a small lot containing a native plant garden and educational signage. 
- Paco Pereyra Park: located at $3^{\text {rd }}$ Street and Lindy Drive; the park contains a small green space, built in picnic areas, children's play structure, and a basketball court.

- Tognazzini Avenue Park: contains a small children's play structure and horseshoe pit.

- Bonita Pacifica Park: contains a small open grass area and bus stop.

Figure 7. Open Spaces in Guadalupe

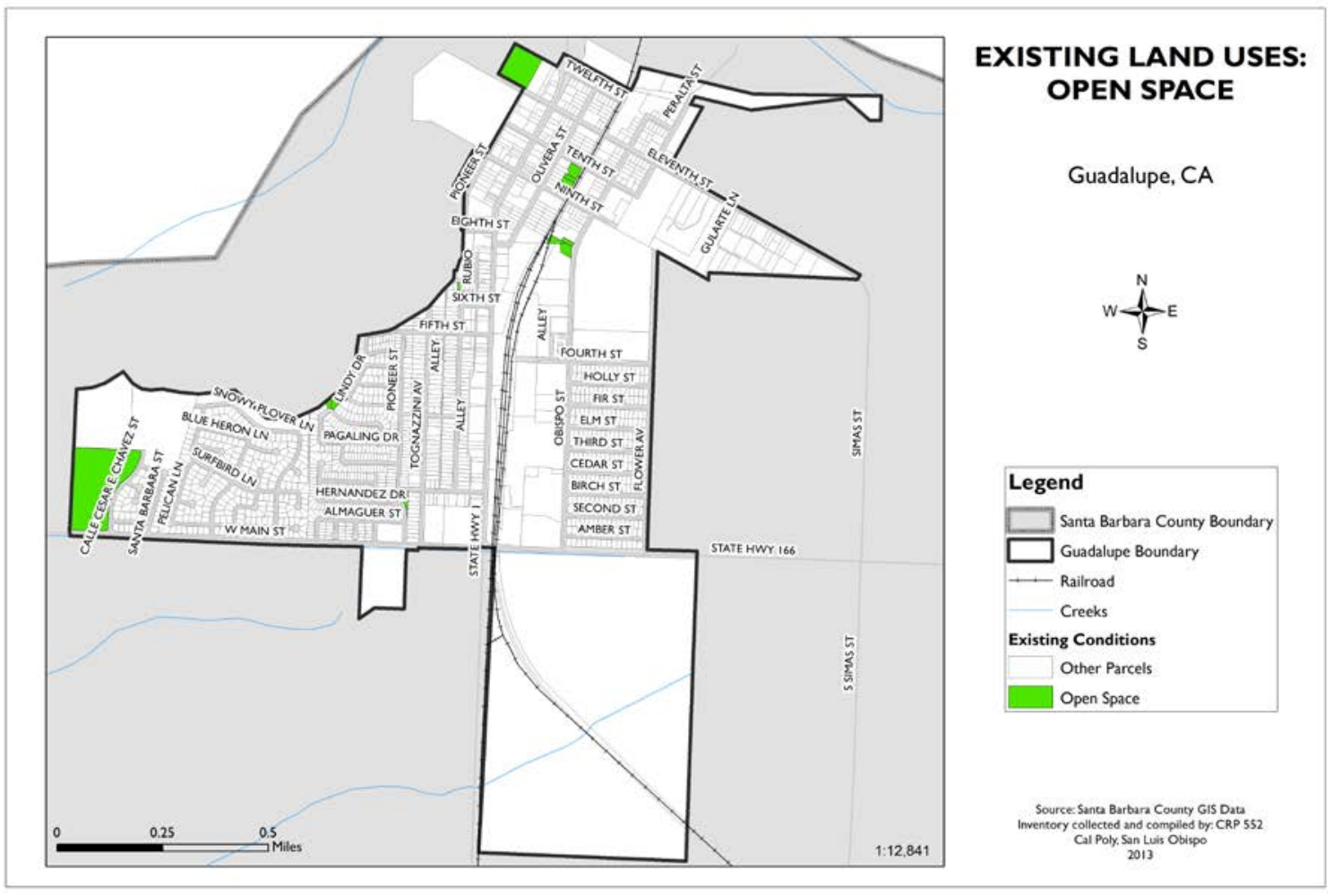

Source: Cal Poly Background Report. (2013).

There are multiple locations for recreation in Guadalupe that also provide educational opportunities for the community to take part in. Listed below are the facilities that provide educational programs for children:

\section{Guadalupe Dunes Center}

The Guadalupe Dunes Center is located at 1065 Guadalupe Street Guadalupe, CA 93434. A variety of educational opportunities is available at the Center. Interactive 
activities, a collection of short films in the local area, and educational classes are available. Education programs include classroom programs, field trips, summer and afterschool programs; group walks and hikes for a variety of age ranges and grade levels.

\section{Guadalupe Cultural Arts and Education Center}

The Guadalupe Cultural Arts And Education Center is located on 1055 Guadalupe

Street. Their mission is educational cultural awareness of diverse community groups and ethnic ties through art presentations, ethnic arts gallery and educational classes. They also provide assistance and counseling to veterans of military wars and other familyoriented services (Guadalupe Cultural Center, 2014).

\section{STREET CONDITIONS}

The current General Plan update includes visions of potential future transportation infrastructure plans to encourage healthier, active transportation throughout the City. Complete streets can allow infrastructure to be adapted to encourage people to walk downtown or ride their bikes to school. Complete street infrastructure offers the opportunity to promote physical activity in the lives of residents. This can help to reduce the risk of many diseases such as diabetes, heart disease, and stroke that are increased risks in obese children.

Complete streets can help children in getting physical activity and gain independence if the streets provide room for bicycling and walking. More children walk to school where there are sidewalks, and children who have and use safe walking and bicycling routes have a more positive view of their neighborhood. Safe Routes to School programs, 
gaining in popularity across the country, will benefit from complete streets policies that help turn all routes into safe routes. This program could be of benefit to the Guadalupe Union School District for future policy endeavors. 
Figure 8. Bike and Pedestrian Facilities in Guadalupe

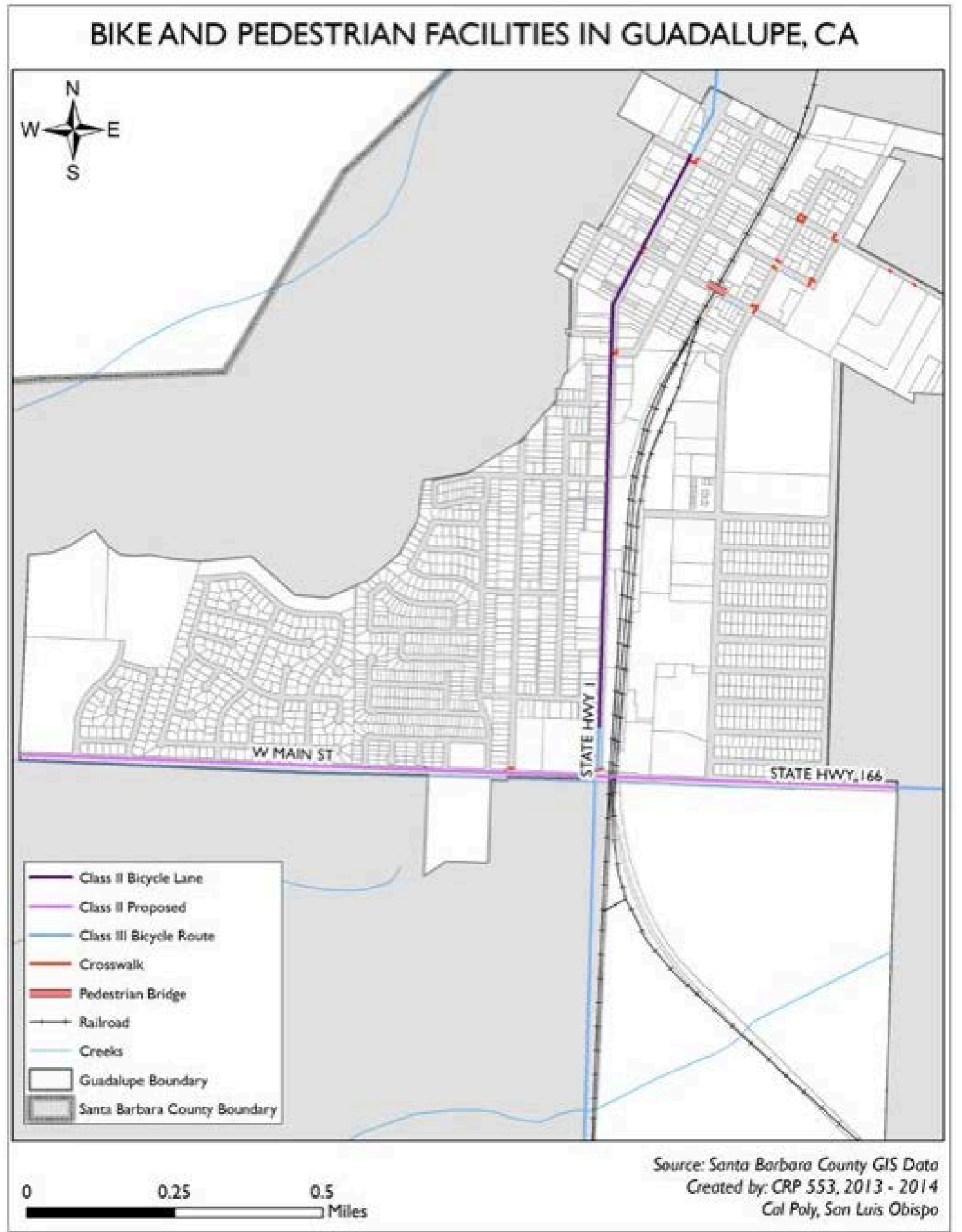

Source: Cal Poly Background Report. (2014) 


\section{CHILDHOOD OBESITY IN GUADALUPE}

In 2009, through a collaboration of private and public funders, First 5 Santa Barbara County, school districts, community and public agencies, and community members to look at the complex issues impacting school success, THRIVE Santa Barbara County (THRIVE SBC) was formed. THRIVE has supported the development of five THRIVE Community Collaborative sites throughout the County. These communities are Carpinteria, the Westside Neighborhood in Santa Barbara, Isla Vista, a neighborhood compromised by the boundaries of Fairtown and Robert Bruce Elementary School in

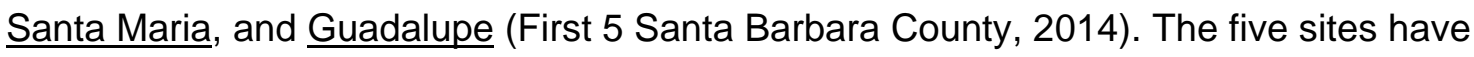
created a "Thriving Children Report Card", which is an evaluation report that identifies key results and indicators that are consistently monitored. THRIVE Guadalupe works to achieve results in four following areas:

1) Children enter school ready to learn

2) Children master grade-level content standards through Grade 3

3) Children are healthy and thriving

4) Families are actively engaged and serve as a strong support for their child's learning and development

While the listed four areas are pertinent to the development of children in Guadalupe, this project will look more thoroughly at how the children in Guadalupe are healthy and thriving. Indicators of interest include:

- Percent of children with healthy BMI

- Percent of children with a developmental screening by kindergarten

- Percent of children with a social-emotional screening by kindergarten 
Figure 9. Percent of Kindergarten Children with Healthy BMI

\section{Result 3: Children Are Healthy and Thriving}

Body Mass Index (BMI): Kindergarten Percent Healthy BMI

\begin{tabular}{|l|c|c|c|c|c|}
\hline \multicolumn{7}{|l|}{ Result 3: Children are healthy and thriving - Kindergarten Entry } & \multicolumn{2}{c|}{ Actual Performance } \\
\hline $\begin{array}{l}\text { Indicator: Percent of children } \\
\text { with healthy BMI }\end{array}$ & \multicolumn{3}{|c|}{ Growth Target } \\
\hline & Effect & Target \% & Target N & Actual \% & Actual N \\
\hline $2010-2011$ (pre-implementation) & & $47 \%$ & $60 / 129$ & $47 \%$ & $60 / 129$ \\
\hline $2011-2012$ & - & $47 \%$ & $60 / 129$ & $59 \%$ & $87 / 147$ \\
\hline $2012-2013$ & - & - & - & $59 \%$ & $68 / 116$ \\
\hline $2013-2014$ & - & - & - & & \\
\hline $2014-2015$ & - & - & - & & \\
\hline $2015-2016$ & 2.88 & $64 \%$ & $83 / 129$ & & \\
\hline $2016-2017$ & - & - & - & & \\
\hline $2017-2018$ & - & - & - & & \\
\hline $2018-2019$ & - & - & - & & \\
\hline $2019-2020$ & - & - & - & & \\
\hline $2020-2021$ & 2.78 & $80 \%$ & $103 / 129$ & & \\
\hline
\end{tabular}

\section{Percent of Children with Healthy Body Mass Index - Grade K}

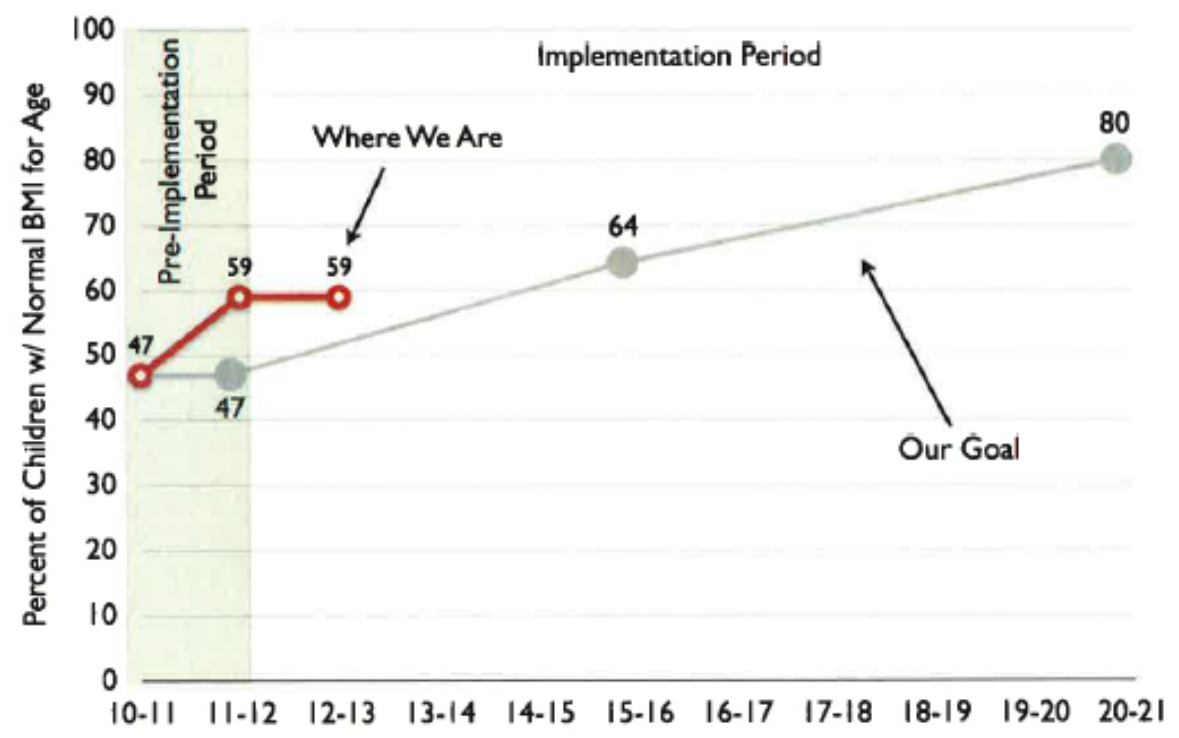

Source: THRIVE Guadalupe. (2013). 
Figure 10. Percent of Kindergarten Children Screened for Developmental and SocialEmotional Screening

\section{Developmental Screening: Kindergarten Percent Screened}

\begin{tabular}{|l|l|l|l|l|}
\hline \multicolumn{4}{|l|}{ Result 3: Children are healthy and thriving. } \\
\hline $\begin{array}{l}\text { Indicator: Percent of children } \\
\text { with a developmental screening } \\
\text { by October 1 of the K year }\end{array}$ & \multicolumn{4}{|l|}{ Targets and Actual Performance } \\
\hline & Target Percent & Norm N & Actual Percent & Actual N \\
\hline $2010-2011$ (pre-implementation) & $22 \%$ & $30 / 137$ & $22 \%$ & $30 / 137$ \\
\hline $2011-2012$ & $100 \%$ & $159 / 159$ & $40 \%$ & $64 / 159$ \\
\hline $2012-2013$ & $100 \%$ & $143 / 143$ & $46 \%$ & $66 / 143$ \\
\hline $2013-2014$ & $100 \%$ & & & \\
\hline $2014-2015$ & $100 \%$ & & & \\
\hline $2015-2016$ & $100 \%$ & & & \\
\hline $2016-2017$ & $100 \%$ & & & \\
\hline $2017-2018$ & $100 \%$ & & & \\
\hline $2018-2019$ & $100 \%$ & & & \\
\hline $2019-2020$ & $100 \%$ & & & \\
\hline $2020-2021$ & $100 \%$ & & & \\
\hline
\end{tabular}

\section{Social-Emotional Screening: Kindergarten Percent Screened}

\begin{tabular}{|c|c|c|c|c|}
\hline \multirow{2}{*}{$\begin{array}{l}\text { Indicator: Percent of children } \\
\text { with a social-emotional } \\
\text { screening by October } 1 \text { of the } \mathrm{K} \\
\text { year }\end{array}$} & \multicolumn{4}{|c|}{ Targets and Actual Performance } \\
\hline & Target Percent & Norm N & Actual Percent & Actual $\mathrm{N}$ \\
\hline 2010-2011 (pre-implementation) & $0 \%$ & $0 / 137$ & $0 \%$ & $0 / 137$ \\
\hline $2011-2012$ & $100 \%$ & $159 / 159$ & $36 \%$ & $57 / 159$ \\
\hline $2012-2013$ & $100 \%$ & $143 / 143$ & $38 \%$ & $55 / 143$ \\
\hline $2013-2014$ & $100 \%$ & & & \\
\hline $2014-2015$ & $100 \%$ & & & \\
\hline $2015-2016$ & $100 \%$ & & & \\
\hline $2016-2017$ & $100 \%$ & & & \\
\hline $2017-2018$ & $100 \%$ & & & \\
\hline $2018-2019$ & $100 \%$ & & & \\
\hline $2019-2020$ & $100 \%$ & & & \\
\hline $2020-2021$ & $100 \%$ & & & \\
\hline
\end{tabular}

Source: THRIVE Guadalupe. (2013). 
METHODS 


\section{METHODS}

For this professional project, a variety of data sources were collected to reach a better understanding of the built environment and its affect on childhood obesity. This project was broken down into four phases. Phase I consisted of a literature review covering the relationship between children's health and the built environment. This helped to provide a more solid foundation for Phase II and III. Phase II contained using community assessment tools; such as the CX3 field surveys, which included a walkability assessment, and a Photovoice project. In Phase III, information gathered from Phase II was analyzed and conclusions were drawn about the current conditions of the built environment and childhood obesity in Guadalupe. In Phase IV, a comprehensive report was developed with recommendations based on results gathered from Phase II. Methods of data collection will be further described below. Findings from these various data collection methods will be addressed in Chapter 5 and recommendations will also be made accordingly.

\section{PHASE I}

In this phase, secondary data was collected through a review of literature covering the relationship between children's health and the built environment and through Santa Barbara County's data collection on children's health in the County, more specifically, Guadalupe. Data on children's health and childhood obesity statistics in Santa Barbara County were gathered from the Santa Barbara County Public Health Department, THRIVE's Children Report on Guadalupe, and past Case Studies to support with analyzing information collected. 


\section{PHASE II}

Community Assessment tools and outreach methods were utilized in this phase. The execution of $\mathrm{CX}^{3}$ field surveys, walkability assessments and the Photovoice project were used to better understand the communities' assessment of the healthiness of children and the built environment in Guadalupe. Community Assessment tools can address county demographics, community assets, health disparities, environmental conditions, and existing policies. One Community Assessment tool currently being used by local health agencies throughout California and was used for this project is The Communities of Excellence $\left(\mathrm{CX}^{3}\right)$ framework. $C X^{3}$ field surveys were carried out primarily by Cal Poly students in the CRP 457 Public Health in Planning class at Cal Poly San Luis Obispo on the healthfulness of local Guadalupe food establishments, convenience stores, supermarkets, and physical environment. As part of the CX3 field survey, a walkability assessment was also done.

\section{Communities Of Excellence $\left(C x^{3}\right)$}

The $\mathrm{CX}^{3}$ framework was developed in 2000 by the California Department of Public Health's (CDPH) Tobacco Control Section to take an in-depth look at low-income communities to identify areas in need of improvement. Built through extensive literature reviews, expert recommendations from medical, scientific, and health associations and institutions, local practitioner input, and other sources were gathered to come up with a list of possible community indicators in the seven environments (grocery stores, small markets, fast food, mobile vending, outdoor marketing, food banks, and alternative food sources), $\mathrm{CX}^{3}$ focuses on addressing factors: nutrition, physical activity, and obesity prevention. 
Seeing that communities play a critical role in preventing obesity, $\mathrm{CX}^{3}$ examines communities in relation to a variety of obesity prevention guidelines referred to as community indicators and assets. These $\mathrm{CX}^{3}$ indicators and assets set standards of "excellence" and define was a community itself should look like in order to help prevent adverse chronic diseases related to overweight and obesity for its residents.

Using the $\mathrm{CX}^{3}$ framework as a benchmark for local data collection and research, this professional project evaluated the "excellency" of neighborhood nutrition and neighborhood activity environment in the Guadalupe Union School District community. Data collected using the $\mathrm{CX}^{3}$ framework will help to see how the community currently "measures up" and where it needs to improve on to become a community of excellence for its residents. A walkability checklist was also used to assess the street conditions and walkability of Guadalupe and will be discussed in the next section.

\section{Location:}

The $\mathrm{CX}^{3}$ field surveys and walkability assessments were conducted in several locations throughout the City of Guadalupe. The store environments, food environments, and streets of Guadalupe were assessed. These environments were looked at in proximity to the schools in Guadalupe. A map of the markets and parks that were evaluated is shown in the map below.

\section{Store Environments Sites:}

- Romo's Market

- YK Market

- Roy's Liquor and Market

- Masatani's Market 
- Super Carniceria La Chiquita

\section{Parks:}

- Jack O' Connell Community Park

\section{Schools:}

- Kermit McKenzie Junior High

- Mary Buren Elementary School

\section{Streets:}

- Guadalupe Street (Downtown Core) 
Figure 11. Map of Guadalupe Sites

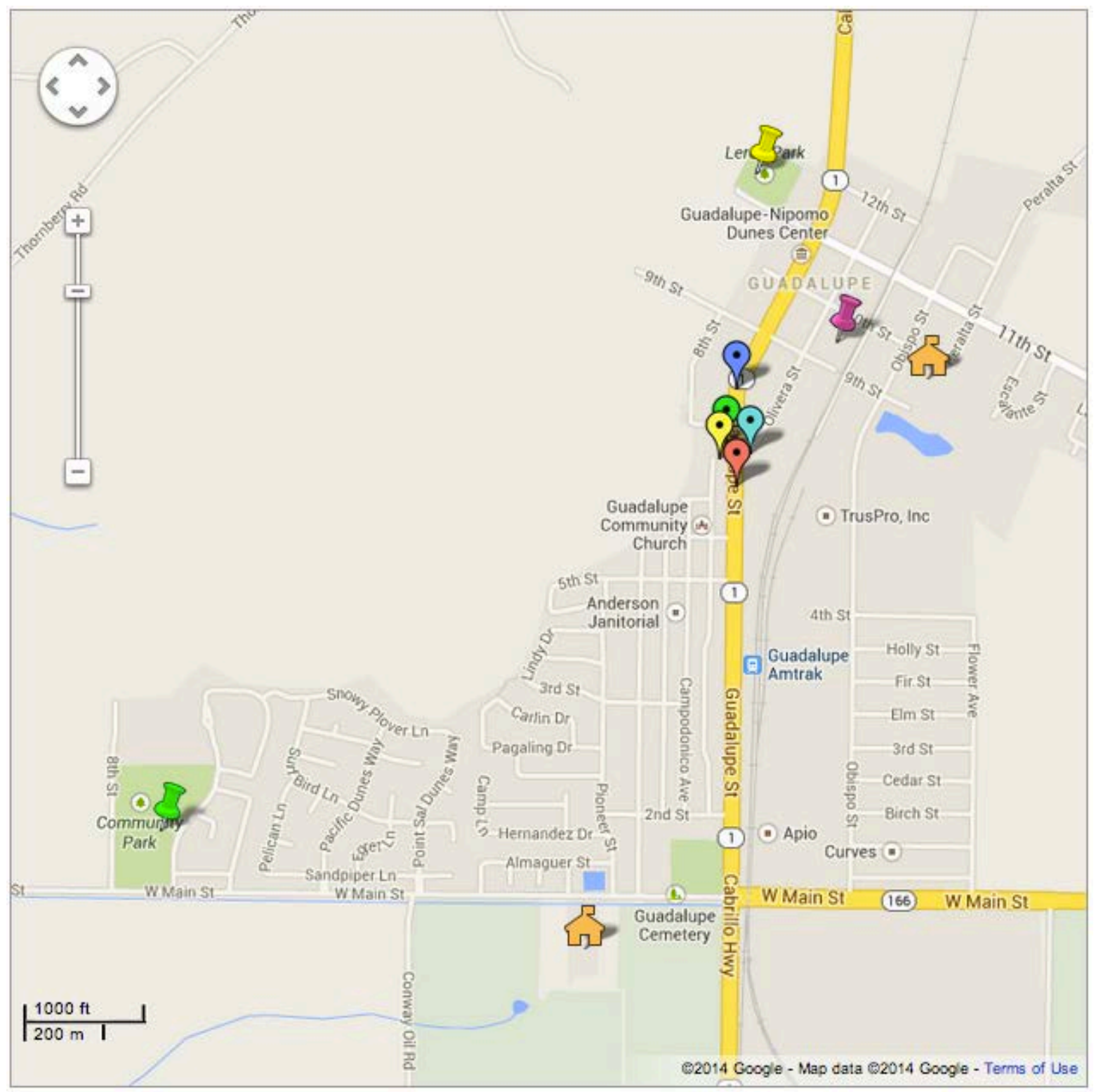

Source: Google Maps. (2014).

\section{LEGEND}

- Site 1 - Romo's Market 728 Guadalupe St

$\odot$ Site 2 - YK Market 751 Guadalupe St

- Site 3 - Roy's Liquor and Market 770 Guadalupe St

- Site 4 - Masatani's Market 771 Guadalupe St

- Site 5 - Super Carniceria La Chiquita 843 Guadalupe St
Site 6 - Leroy Park Guadalupe, CA 93434

Site 7 - Jack O'Connell Community Park Calle Cesar E Chavez

Site 8 - Central Park between 9 th \& 10 th St. off Pacheco St.

Kermit McKenzie Junior High 4710 W Main St

Mary Buren Elementary School 1050 Peralta St.Guadalupe, CA 93434 


\section{Surveyors:}

The CX3 field surveys and walkability assessments were carried out primarily by Cal Poly students in the CRP 457 Public Health in Planning Class at Cal Poly San Luis Obispo with direction from Professor Kelly Main and student researcher, Sophia Lai. All collected field survey results and walkability assessment results were handled by the student researcher. A copy of these field surveys are available in the Appendix.

\section{Materials And Procedures:}

Field surveys were used to collect in-depth information about what was really going on in the neighborhood related to food access. A variety of CX3 surveys are readily available on the California Department of Public Health Communities of Excellence website for the public's use. For the purpose of this project, the following field surveys were utilized:

- Food Availability \& Marketing Survey

- Food and Physical Activity Outdoor Marketing Survey

In addition to performing these field surveys, the students were also asked to answer the following questions on the store and food environments:

- How might consumers in this store be influenced by their food choices?

- How would you classify this store type, e.g. Supermarket, small market, convenience store, etc.

- How is the store structured and laid out? (Where in the store are different types of food found?)

- What is the overall quality of the fruits and vegetables?

- Are there healthy/unhealthy options available? 
- Can people safely walk to the store? Is it accessible?

- What are some improvements that can be done to make the store healthier?

\section{WALKABILITY ASSESSMENT}

There are numerous benefits to walking. These benefits include: improved fitness, cleaner air, reduced risks of certain health problems and a greater sense of community. Walkability is the concept that an area is designed for pedestrians in mind first (The Childhood Obesity Prevention Task Force, 2008). One method to determine the safety and friendliness of a neighborhood is a walkability checklist. The checklist used to assess the walkability of Guadalupe Street was taken from Partnership For A Walkable America (http://www.walkableamerica.org/). This checklist was use for assessing two locations in Guadalupe on their safety, crosswalks, sidewalks, speed limits of cars, visibility, and cleanliness: Guadalupe Street and Jack O' Connell Park.

\section{Surveyors}

Students in the CRP 457 Public Health in Planning Class at Cal Poly San Luis Obispo were given direction from Professor Kelly Main and student researcher, Sophia Lai to carry out these surveys on Guadalupe Street and Jack O' Connell Park. In addition to the walkability checklist, the students of CRP 457 were also asked to answer the follow questions:

- Did you have room to walk? Why? If you didn't, why not? What made you walk easy or difficult?

- What made it easy or difficult to cross the streets?

- How/did drivers affect your walk on Guadalupe Street?

- What made it safe/unsafe to walk on Guadalupe Street? 
- What made your walk pleasant/unpleasant?

- How would you describe Guadalupe Street and the area surrounding Guadalupe Street?

- Can people walk safely on this street? Is it accessible?

- Is the street being used? Who is using it?

\section{THE GUADALUPE PHOTOVOICE PROJECT}

While assessment tools were necessary to help gather a better sense of existing conditions in the community, outreach efforts such as the Photovoice project helped to better understand children's needs, viewpoints, and current health conditions.

Photovoice is a participatory technique that mixes photography and written narratives to give kids an opportunity to express their viewpoints about their communities. This engagement approach gave participants who don't usually have a say in decisions affecting their lives to make a difference. Students who took part in this Photovoice project shared their photographs and narratives with other students and community members.

Data collected using these community assessment tools and outreach methods helped to assess the opportunities for physical activity available to children and the availability of healthy food access for children in Guadalupe for this project. A proposed list of recommended strategies and policy actions were developed at the end of this project to help serve as a guide for Guadalupians to learn more about the childhood obesity epidemic and the multiple factors that attribute to it. A methodology of the Photovoice process is discussed right below. 


\section{Location:}

Kermit McKenzie Junior High School is located in Guadalupe, California, a small town of 7,176. Guadalupe is chiefly an agricultural town located in Santa Barbara County. This school is part of the Guadalupe Union School District, which serves more than 1,100 students in grades K-8. Kermit McKenzie serves students in grades six through eight.

\section{Subjects:}

There is one category of study subjects: $6^{\text {th }}, 7$ th, 8 th grade students. This Photovoice project will be working primarily with Hispanic schoolchildren. A total of 44 students from one $6^{\text {th }}$ grade class and one $7^{\text {th }} / 8^{\text {th }}$ grade class participated in this project.

\section{Administrators:}

This project was carried out primarily by the students' teacher, Mr. Jeff Foote. Mr. Jeff Foote is currently a teacher at Kermit McKenzie Jr. High. He has a B.A. in Spanish and has served well in the Guadalupe Union School District with a very high percentage of Spanish speakers. Mr. Foote also has a M.A. in Educational Administration and is currently co-director of Central Coast Science Project at Cal Poly SLO. He is excited about working with others on how 'CER' Claim Evidence Reasoning practices can be developed in sciences classes to influence how students think, speak, and write in all areas.

The student researcher, Sophia Y. Lai, Masters Candidate for City and Regional Planning, Cal Poly San Luis Obispo assisted Mr. Foote with this project. Sophia received her Bachelor's of Science in Public Health Sciences from the University of California, Irvine with a minor in Urban and Regional Planning. She is experienced in community 
health education and interested in factors that affect the built environment. All taken photographs and all written narratives by the students were managed and handled by the students' teacher and student researcher.

\section{Children Participants:}

While every Photovoice project is different, Photovoice does progress in a step-by-step fashion. The following steps were taken with influence from the projected timeline, budget, objectives, community resources, community needs and goals of the participants.

1. Connecting and Consulting with the Community

a. Good relationships take time and effort. Good connections and fair consultations with the community will help to build a strong foundation for the Photovoice research and project. A part of building a strong foundation with the community is identifying the issues of concern they are worried about. This outreach was done in the CRP 552 and CRP 554 graduate studios.

2. Planning a Photovoice Project

a. This required a collaboration with Mr. Foote to plan activities, including setting a project timeline, managing the budget, organizing equipment, and planning Photovoice events.

3. Beginning the Photovoice Project

a. Every child participant was provided a point and shoot camera they shared in groups of three to four students. The students answered 
questions that gave them a chance to show their views of Guadalupe by taking photographs. They answered the following questions:

I. What do you like/dislike about Guadalupe?

II. Where do you like to hangout in Guadalupe?

III. What does healthy look like/mean to you in Guadalupe?

IV. What would you like to change about Guadalupe?

Parental permission and children assent forms were obtained before the project and discussions took place. Both forms were available in English and Spanish. Mr. Foote undertook translation of these forms to Spanish.

\section{Data Collection}

a. This involved taking photographs, recorded discussions and guided dialogues during class time with the teacher and researcher, written narratives, and feedback from the teacher and researcher.

\section{Data Analysis}

a. Students selected their own photos with the help of their teacher. They wrote narratives about what the photographs meant to them through dialogue with other participants. After voicing their experiences through discussions, the students identified different themes and categories of issues they addressed in their Photovoice Exhibit.

b. The student researcher further analyzed data collected from this Photovoice project and findings will be discussed in the Findings and Recommendations Chapter. 
6. Preparing and Sharing the Photovoice Exhibit

a. Students were guided by a Photovoice technique called "SHOWeD". The letters of this acronym each correspond to a question and the series of questions prompted the participants to critically analyze the content of their photographs.

\title{
SHOWeD
}

\author{
What do we See here? \\ What is really Happening here? \\ How does this relate to Our lives? \\ Why does this situation, concern or strength Exist? \\ What can we Do about it?
}

\section{PHASE III}

Data analysis of the information collected was carried out in this phase to reach conclusions about current conditions of the built environment and childhood obesity in the City of Guadalupe. Scoring instructions on $\mathrm{CX}^{3}$ field surveys were followed as given by the California Public Health Department.

\section{PHASE IV}

In this final phase of the project, a comprehensive report with developed recommendations based on $\mathrm{CX}^{3}$ field surveys and the Photovoice project was created. Creation of a brochure with evaluated strategies and family based planning suggestions 
will produced if time permits. Below is a matrix that was used to help breakdown and address topics that were answered in the comprehensive report.

Table 7. Case Studies \& Comprehensive Report: Questions \& Sources

\begin{tabular}{|c|c|}
\hline \multicolumn{2}{|c|}{ Case Studies } \\
\hline \multicolumn{2}{|c|}{ How has the built environment affected obesity rates in children? } \\
\hline Sub-questions & Sources \\
\hline $\begin{array}{l}\text { - What recommendations have other plans } \\
\text { proposed? } \\
\text { - Are the recommendations appropriate for } \\
\text { children in the City of Guadalupe? } \\
\text { - What nutrition standards are proposed in } \\
\text { the US? }\end{array}$ & $\begin{array}{l}\text { - } \\
\text { Onvironment and Obesity in San Luis } \\
\text { - Santa Barbara Obesity Prevention Plan } \\
\text { - } \quad \text { USDA Implications for the Success of } \\
\text { New Nutrition Standards } \\
\text { - National Health and Nutrition } \\
\text { Examination Survey National (NHANES) } \\
\text { - } \quad \text { Nouth Fitness Survey } \\
\text { National Center for Health Statistics }\end{array}$ \\
\hline \multicolumn{2}{|c|}{ Comprehensive Report } \\
\hline \multicolumn{2}{|c|}{ What is the existing condition of childhood obesity in Guadalupe? } \\
\hline $\begin{array}{l}\text { - What are the socioeconomic factors? } \\
\text { - What are the BMI statistics? } \\
\text { - What is the proximity of schools to food } \\
\text { stores? } \\
\text { - How is the children's overall health? }\end{array}$ & $\begin{array}{l}\text { - } \text { US Census } \\
\text { - } \quad C X^{3} \text { School Surveys } \\
\text { - } \quad C X^{3} \text { GIS Mapping } \\
\text { - } \quad C X^{3} \text { Food and Physical Activity Outdoor } \\
\text { Marketing Surveys } \\
\text { - } \quad \text { United States Department of } \\
\text { - } \text { Agriculture, Food and Nutrition Service } \\
\text { Children Report: THRIVE Guadalupe }\end{array}$ \\
\hline \multicolumn{2}{|c|}{ What is the existing condition of the built environment in Guadalupe? } \\
\hline $\begin{array}{l}\text { - What is the proximity of schools to other } \\
\text { businesses? } \\
\text { - Where are the recreational facilities? } \\
\text { - What foods are being produced and offered } \\
\text { locally? } \\
\text { - How is the food environment? } \\
\text { - How is the physical environment laid out? } \\
\text { - } \text { space? } \\
\text { - How is the quality of landscaping in open } \\
\end{array}$ & $\begin{array}{l}\text { - } \text { City of Guadalupe Department of Parks } \\
\text { and Recreation } \\
\text { - Santa Barbara County Department of } \\
\text { Agriculture } \\
\text { - } \quad \mathrm{CX}^{3} \text { Field Surveys } \\
\text { - } \quad X^{3} \text { GIS Mapping } \\
\text { - Santa Barbara County Department of } \\
\text { Public Health } \\
\text { - Community Outreach }\end{array}$ \\
\hline What resources and services currently ex & fect childhood ol \\
\hline
\end{tabular}


- What programs are being offered at schools?

- Are there afterschool programs that promote health education and physical activity?

- How do children get to school?

- What kinds of recreation are available?

- What do the lunch programs at school serve?

What are the best practices for improving children's health?

- What has been implemented and is currently working?

- What has been implemented and is not as effective?

- What's being done locally?
- Guadalupe Union School District

- THRIVE

- First 5 Program

- Community Outreach
- Healthy and Active School Communities: A Resource Kit for Schools

- Safe Routes to Schools

- Let's Move!

- Chefs Move to Schools

- Breakfast in the Classroom

- Pink and Dude Chefs 


\section{FINDINGS \& RECOMMENDATIONS}




\section{FINDINGS \& RECOMMENDATIONS}

In this chapter, findings from the $\mathrm{CX}^{3}$ field surveys, walkability surveys, and the Photovoice project will be discussed and analyzed. Recommendations most appropriate for Guadalupe based on current professional and academic literature and suggestions and findings from the community and results from the findings will help to inform the proposals listed below. These findings address three main themes that are an important topic of discussion for this project: Walkability \& Pedestrian Safety, Physical Activity, Food Availability \& Marketing.

\section{WALKABILITY \& PEDESTRIAN SAFETY}

In Santa Barbara County, Guadalupe Street and Jack O' Connell Park located in the City of Guadalupe were surveyed by university students from the CRP 457 Public Health in Planning Class at Cal Poly San Luis Obispo. These areas were surveyed because both these locations are secondary environments children from local schools, Mary Buren Elementary School and Kermit McKenzie Junior High School, spend time in outside of school. Guadalupe Street was examined to assess the access to and safety of walking in and around neighborhood food stores and to also assess how well the area measured compared to other areas around Guadalupe. This walkability assessment was most interested in evaluating whether the area was safe and accessible for pedestrians, especially children. The following rating scale was used for the walkability checklist created by Partnership for a Walkable America:

Figure 12. Walkability Rating Scale

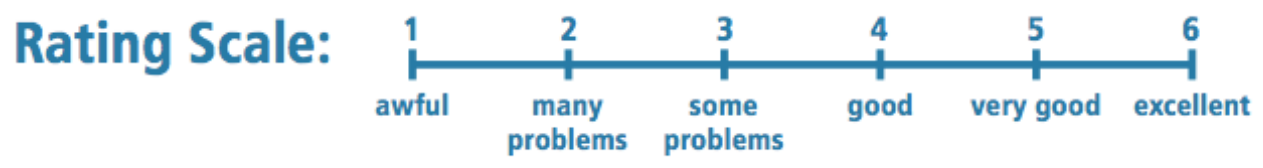


Figure 13. Rating Score: How Walkable is Guadalupe?

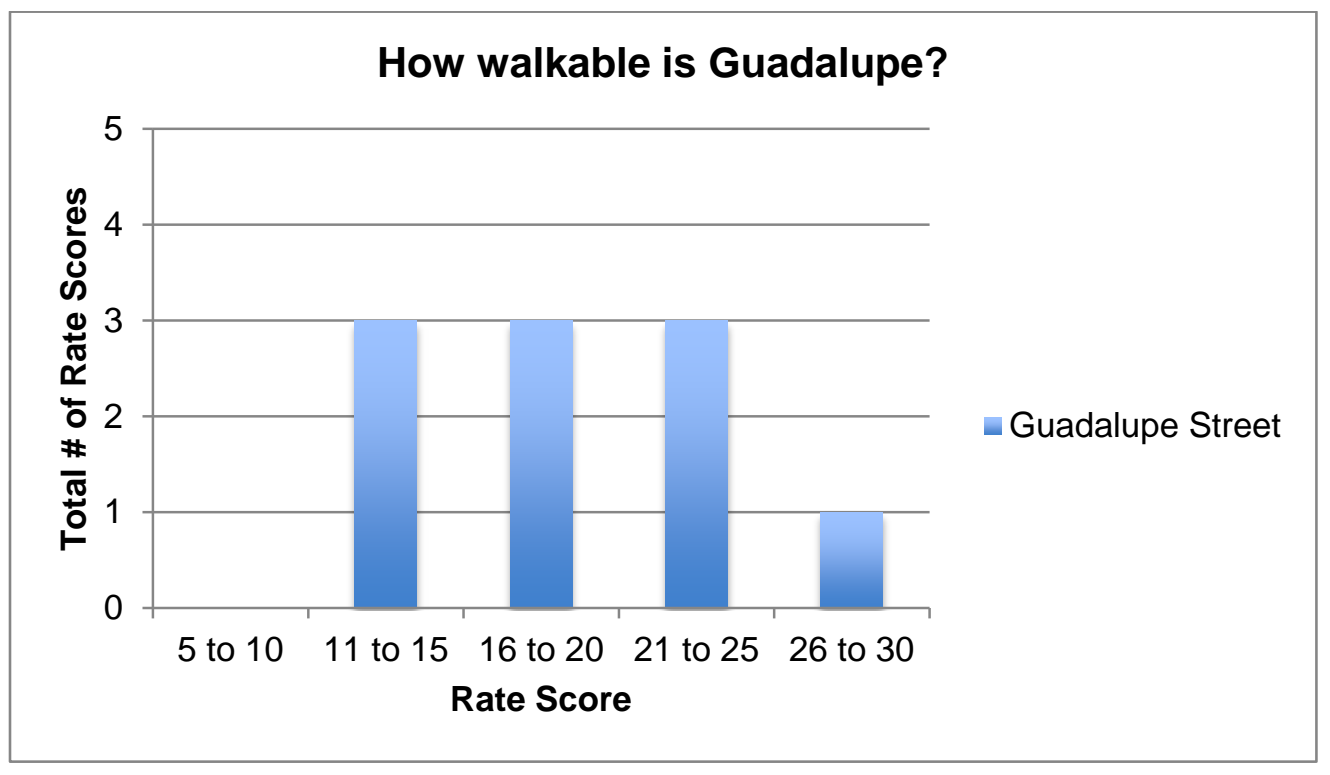

Figure 14. Rating Score: How Walkable is Jack O' Connell Park

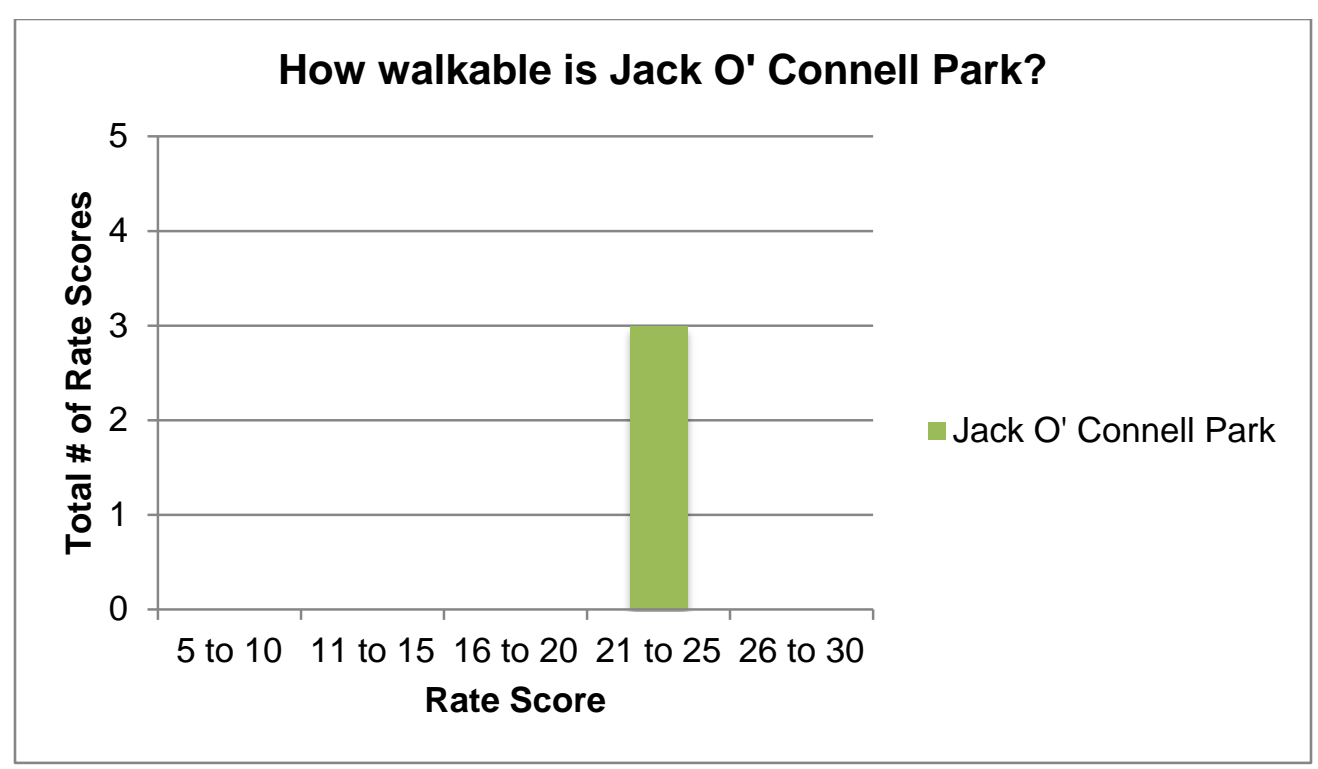


Table 8. Walkability Survey Rating Results

\begin{tabular}{|l|c|c|}
\hline & Guadalupe Street (10) & Jack O' Connell Park (4) \\
\hline Did you have room to walk? & 4.6 & 4.5 \\
\hline Was it easy to cross the streets? & 2.7 & 4 \\
\hline Did drivers behave well? & 3.7 & 4.25 \\
\hline Was it easy to follow safety rules? & 3.5 & 4.5 \\
\hline Was your walk pleasant? & 3.8 & 4.25 \\
\hline OVERALL RATING & 3.66 & 4.3 \\
\hline
\end{tabular}

Table 7 shows the results of the walkability surveys carried out by 14 university students. There were 10 surveys collected for Guadalupe Street and 4 surveys collected for Jack O' Connell Park. Each rating score is an average of the respective assessments. An overall rating was accumulated for the entire walkability survey for each area. Guadalupe Street scored an average of 3.66 and Jack O'Connell Park scored an average of 4.3. Overall, these two areas are good for walking.

There were a total of five questions on the walkability survey. In addition to providing a rating for each question, students were asked to address some problems for each question throughout their walk. Presented later in this chapter are charts and tables of findings of the problems addressed from the survey.

The most problems students encountered when walking around Guadalupe Street were incomplete sidewalks and paths and the lack of sidewalks, paths, or shoulders. These things can cause there to be little room to walk, make it difficult to cross streets, difficult to follow safety rules and decrease the feeling of pedestrian safety. Students noted that drivers on Guadalupe Street, the main road in Guadalupe, frequently drove too fast and did not yield to people crossing the streets. The traffic was loud and street was also very 
windy. As Guadalupe Street is the main road in Guadalupe and is also Highway 1, there is always traffic. There is a stripped crosswalk with lights to cross on Guadalupe Street. While the overall walkability rating of Guadalupe Street is walkable, some improvements could be done to help make the walks more walkable and crossable. The lack of more crosswalks and crosswalks with lights made the walk feel less pleasant. There have been reported past accidents of child pedestrians being hit by ongoing traffic on this street. Although most students agreed that it was easy to cross at crosswalks or were able to be seen by drivers on Guadalupe Street, it was noted that there were not enough crosswalks on the long stretch of the road. There was also an indication of the presence of cars, trees, or plants obstructing views of traffic on Guadalupe Street.

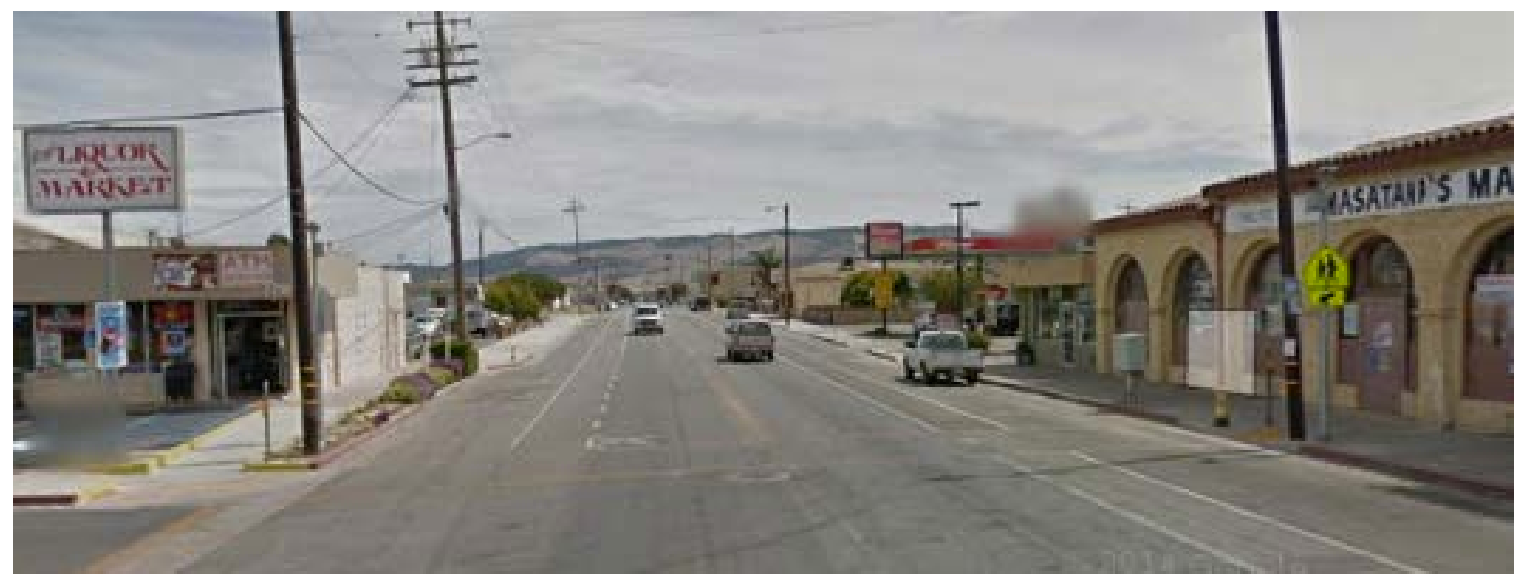

Figure 15. Cross walk with flashing lights on Guadalupe Street

The area around Jack O' Connell Park is walkable and includes wide sidewalks and crossable crosswalks, making it a pleasant environment to walk. Students noted that drivers around Jack O' Connell Park behaved well and there were no indicated problems. However, it was indicated that that roads at Jack O' Connell Park were too wide to cross. While the students had a good experience walking around on the shoulders and sidewalks of Jack O' Connell Park, they indicated that more grass, flowers, or trees were needed, in addition to a need for more lighting structures. Jack O' 
Connell Park has a large field of open space with grass, but does not have enough trees or shrubbery in it. A lack of lighting structures, give children less opportunities to play in the park after the sun goes down and could be unsafe at night with less light.

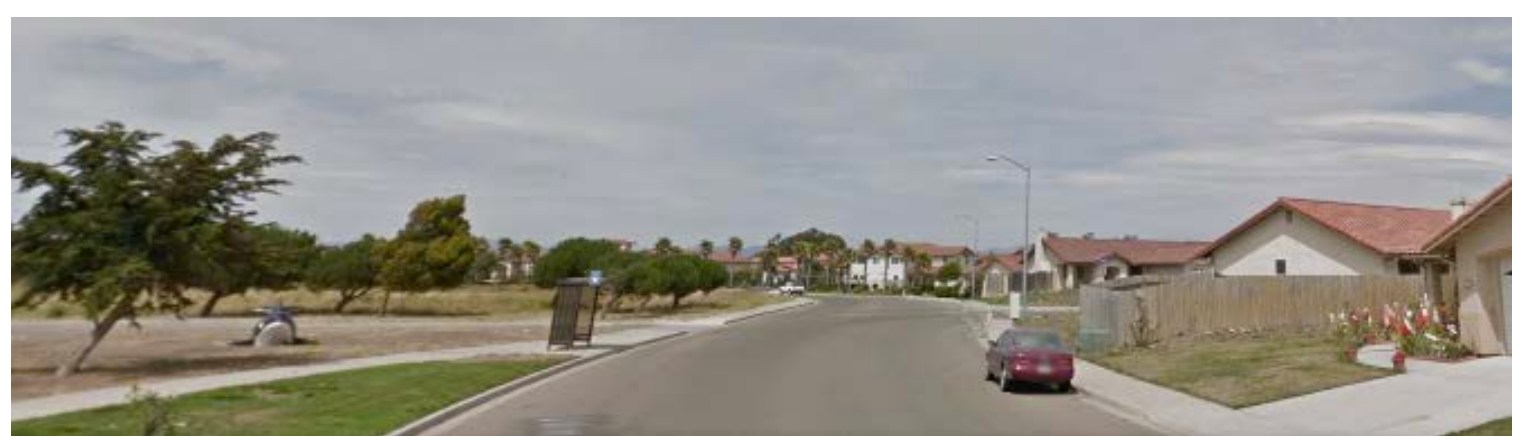

Figure 16. Wide roads around Jack O' Connell Park

Table 9. Question 1: Did You Have Room to Walk?

Some Problems
\begin{tabular}{|l|l|}
\hline A & Sidewalks or paths started and stopped \\
\hline B & Sidewalks were broken or cracked \\
\hline C & Sidewalks were blocked with poles, signs, shrubbery, dumpsters, etc. \\
\hline D & No sidewalks, paths, or shoulders \\
\hline E & Too much traffic \\
\hline F & Something else \\
\hline
\end{tabular}


Figure 17. Types of Problems Walking Around Guadalupe Street

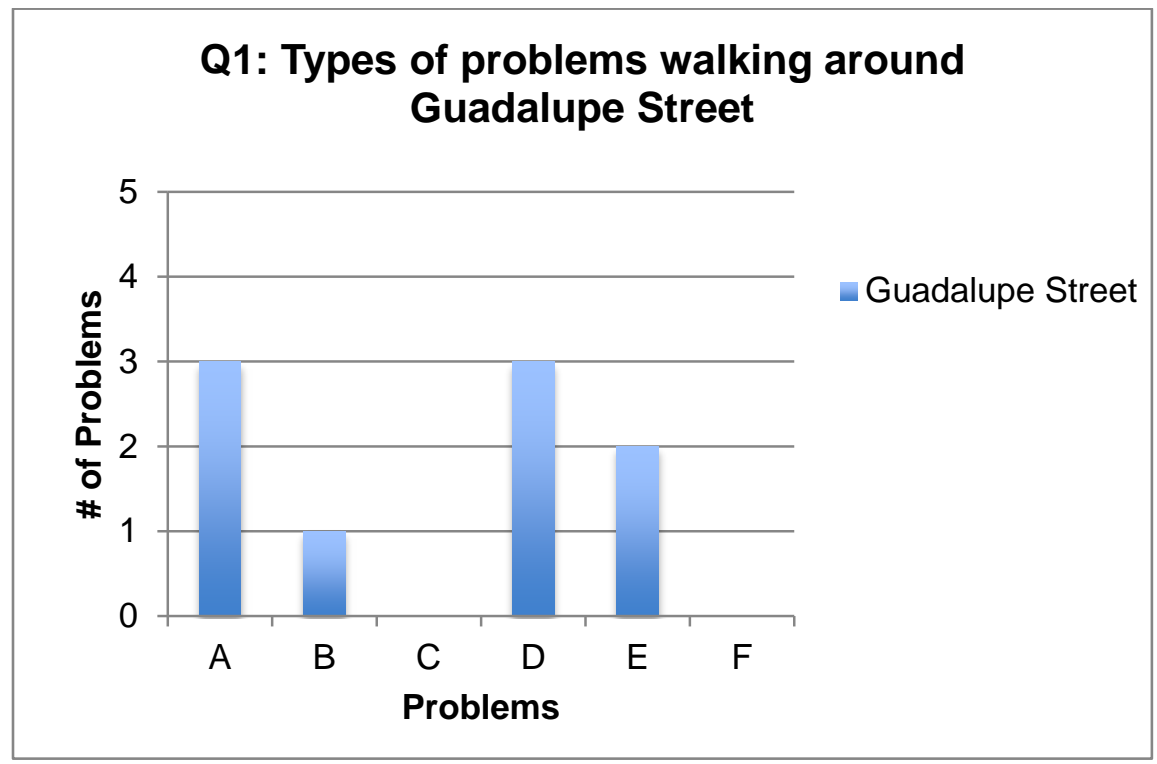

Table 10. Question 2: Was it Easy to Cross Streets?

Some Problems
\begin{tabular}{|c|l|}
\hline A & Road was too wide \\
\hline B & Traffic signals made us wait too long or did not give us enough time to cross \\
\hline C & Needed striped crosswalks or traffic signals \\
\hline D & Parked cars blocked our view of traffic \\
\hline E & Trees or plants blocked our view of traffic \\
\hline F & Needed curb ramps or ramps needed repair \\
\hline G & Something else \\
\hline
\end{tabular}


Figure 18. What are Some Problems Crossing Guadalupe Street?

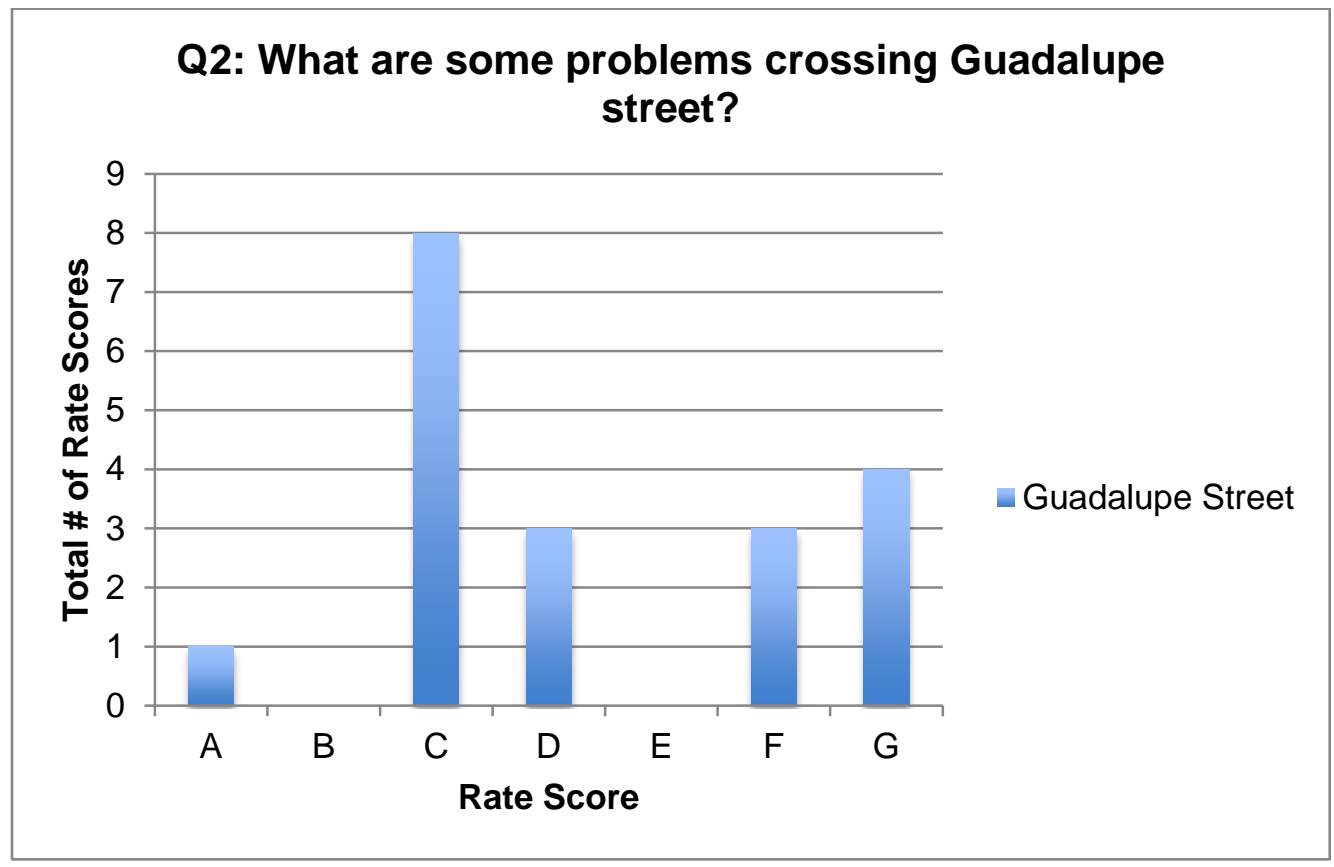

Figure 19. What are Some Problems Crossing Jack O' Connell Park?

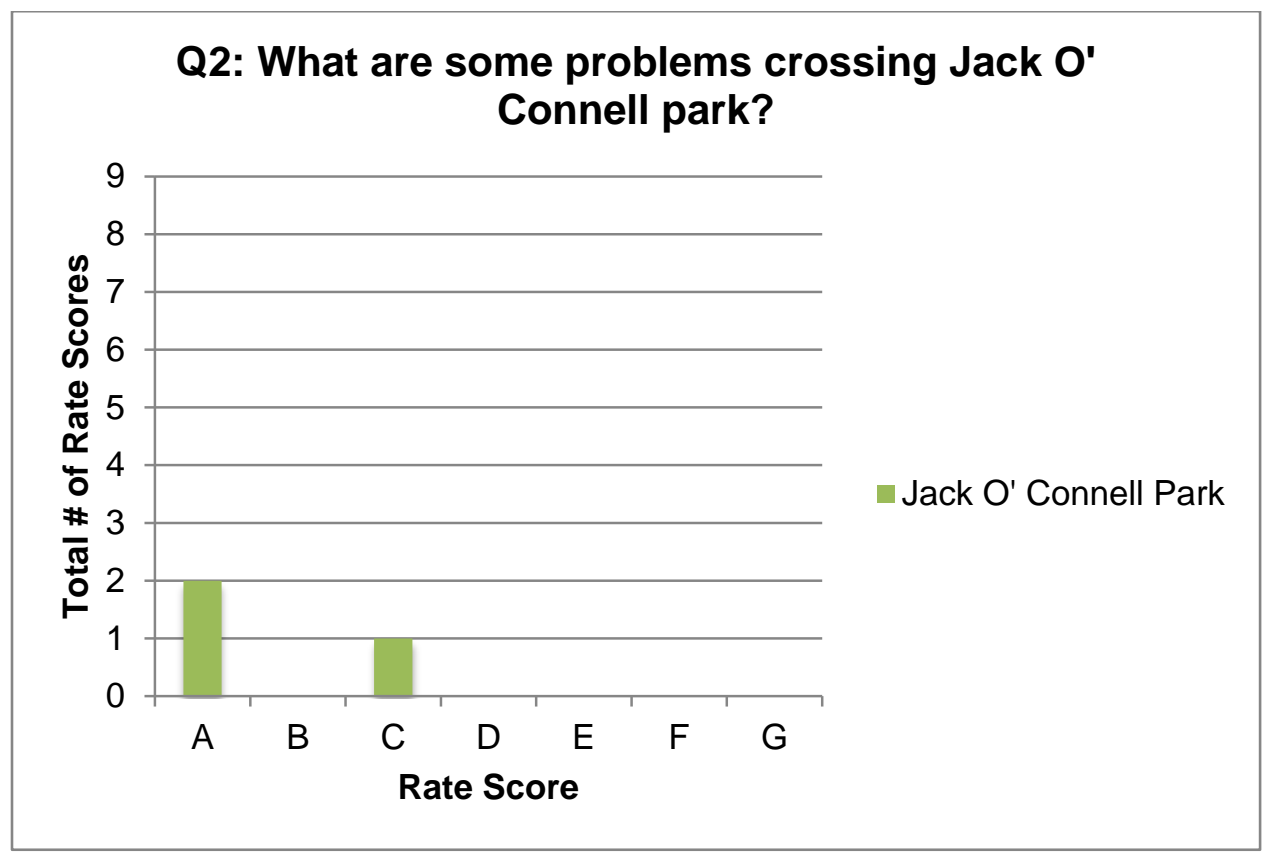


Table 11. Question 3: Did Drivers Behave Well?

\section{Some Problems}

\begin{tabular}{|c|l|}
\hline A & Backed out of driveways without looking \\
\hline B & Did not yield to people crossing the street \\
\hline C & Turned into people crossing the street \\
\hline D & Drove too fast \\
\hline E & Sped up to make it through traffic lights or drove through traffic lights \\
\hline F & Something else \\
\hline
\end{tabular}

Figure 20. What are Some Problems Noticed About the Drivers on Guadalupe Street?

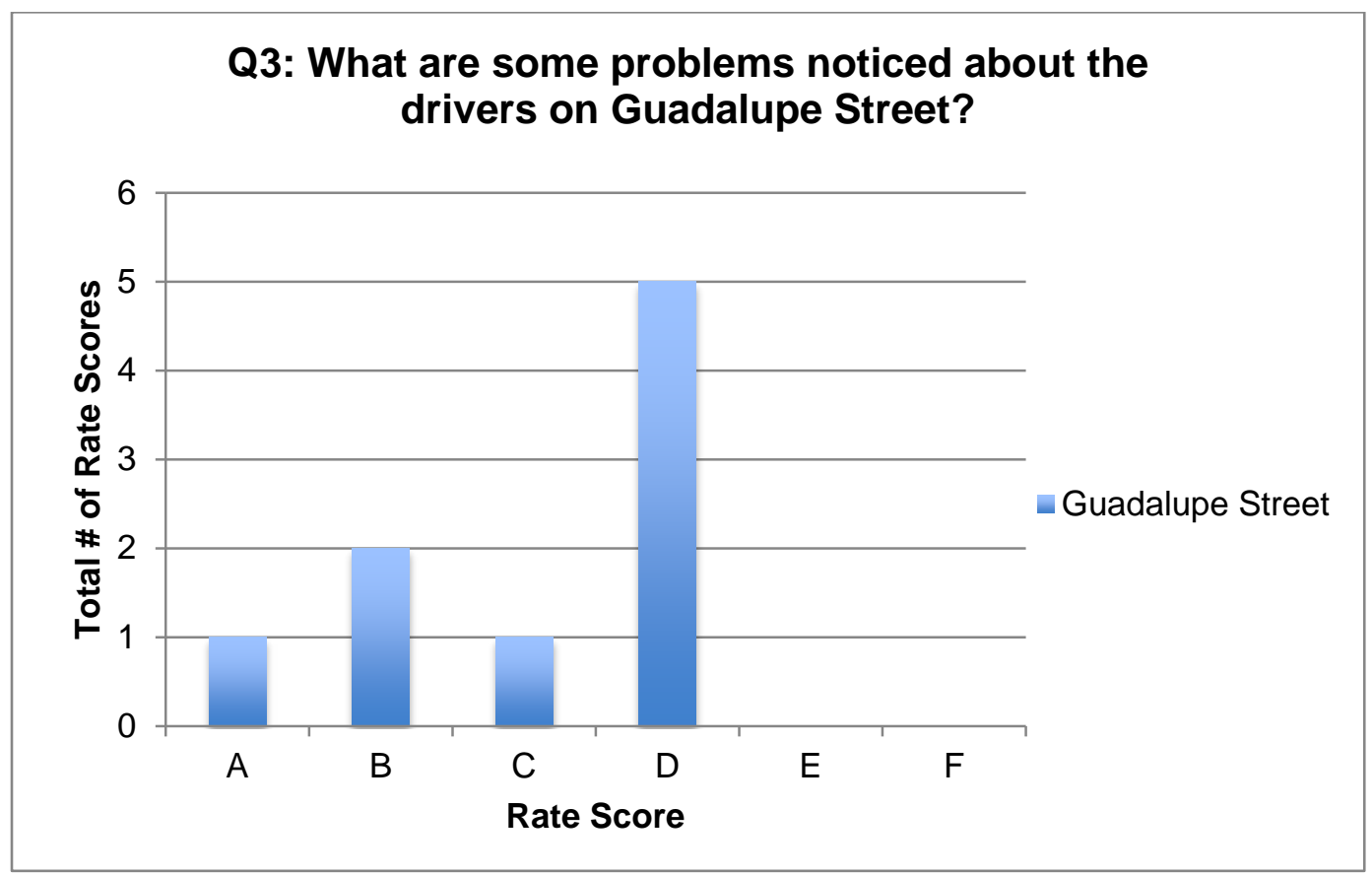

Table 12. Was it Easy to Follow Safety Rules? Could you and your Child...

\section{Could you and your child...}

A $\quad$ Cross at crosswalks or where you could see and be seen by drivers?

B Stop and look left, right, and then left again before crossing streets?

C Walk on sidewalks or shoulders facing traffic where there were no sidewalks?

D Cross with the light? 
Figure 21. Was it Easy to Follow Safety Rules? Could you and our Child on Guadalupe Street?

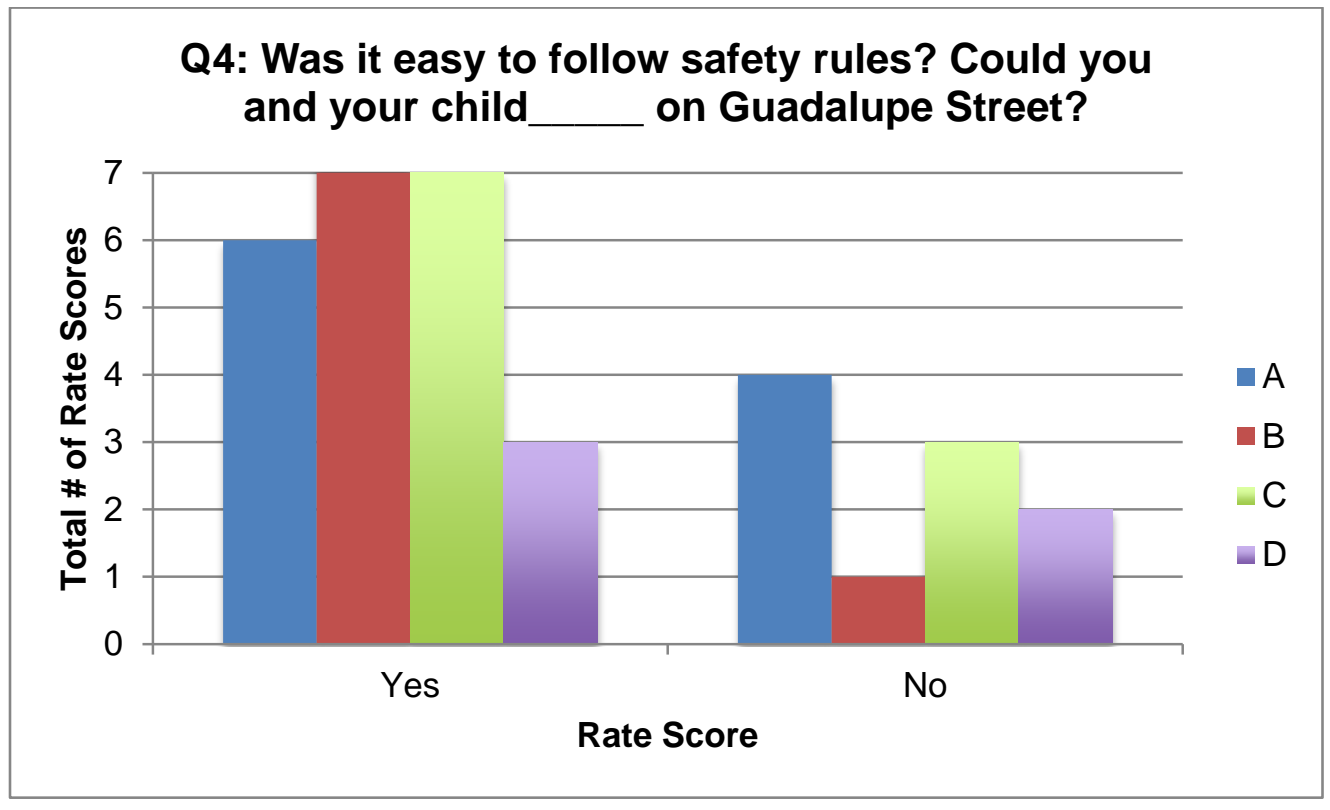

Figure 22. Was it Easy to Follow Safety Rules? Could you and Your Child at Jack O' Connell Park?

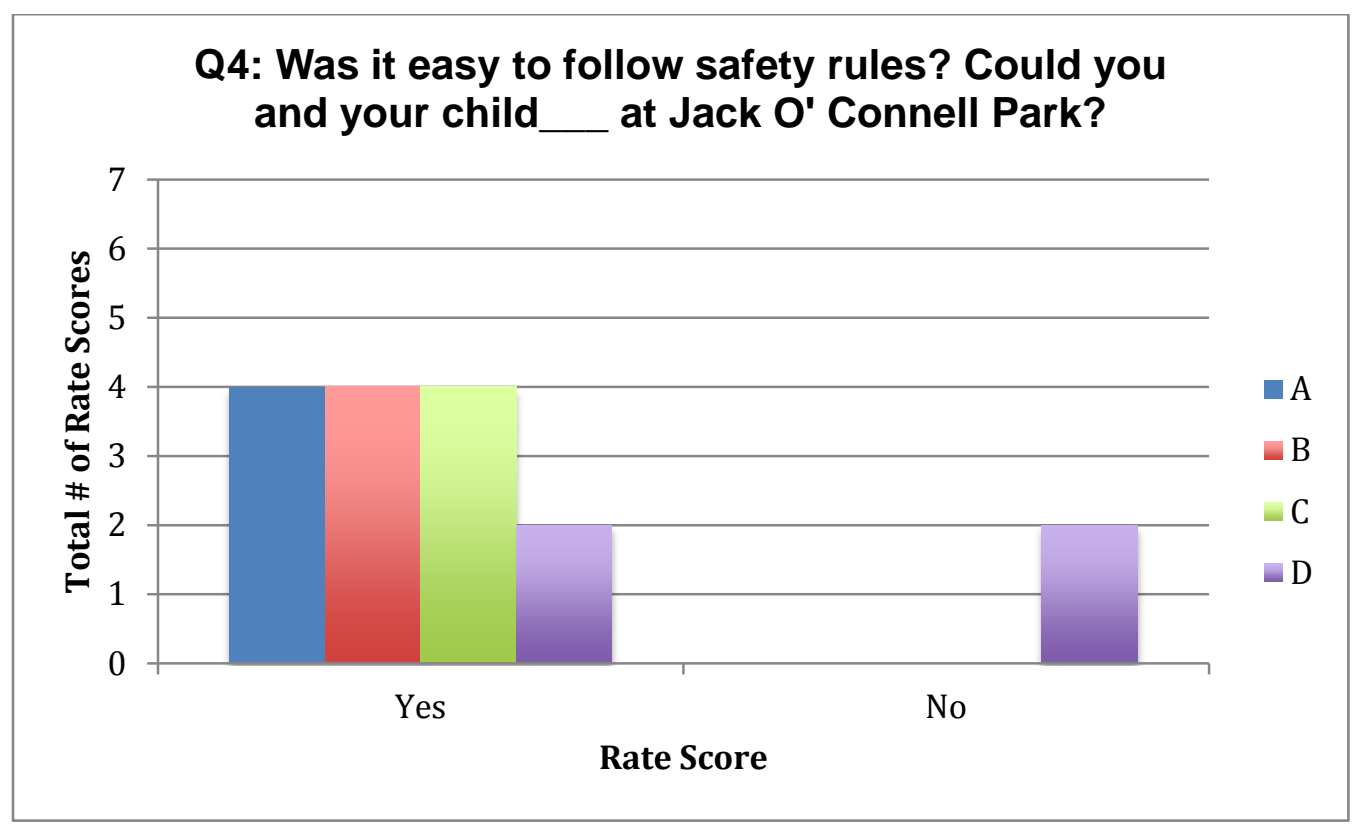


Table 13. Question 5: Was your Walk Pleasant?

\section{Some problems}

\begin{tabular}{|l|l|}
\hline A & Needed more grass, flowers, or trees \\
\hline B & Scary dogs \\
\hline C & Scary People \\
\hline D & Not well lighted \\
\hline E & Dirty, lots of litter or trash \\
\hline F & Dirty air due to automobile exhaust \\
\hline G & Something else \\
\hline
\end{tabular}

Figure 23. Problems that Made Walking on Guadalupe Street Unpleasant

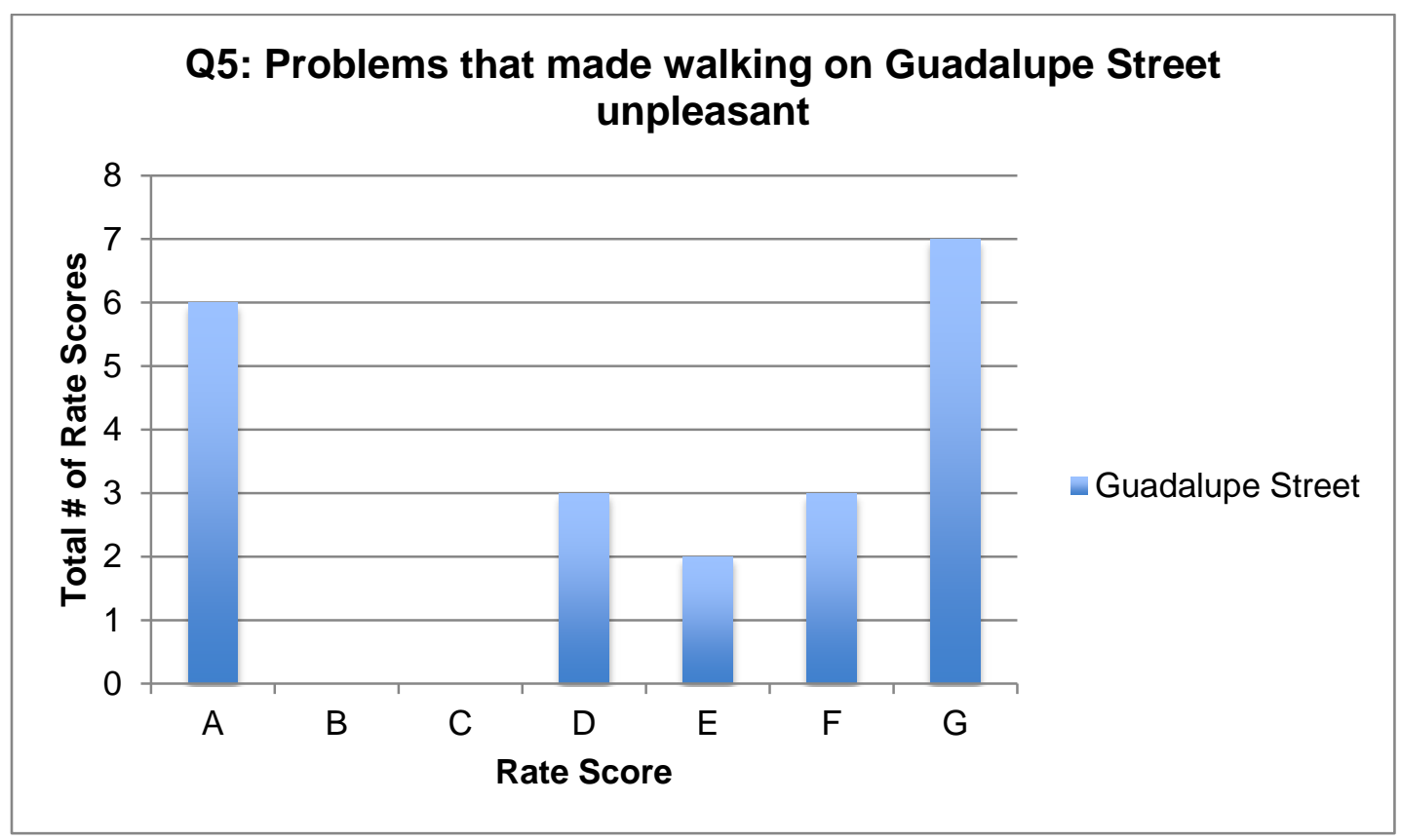


Figure 24. Problems that made walking at Jack O' Connell Park Unpleasant

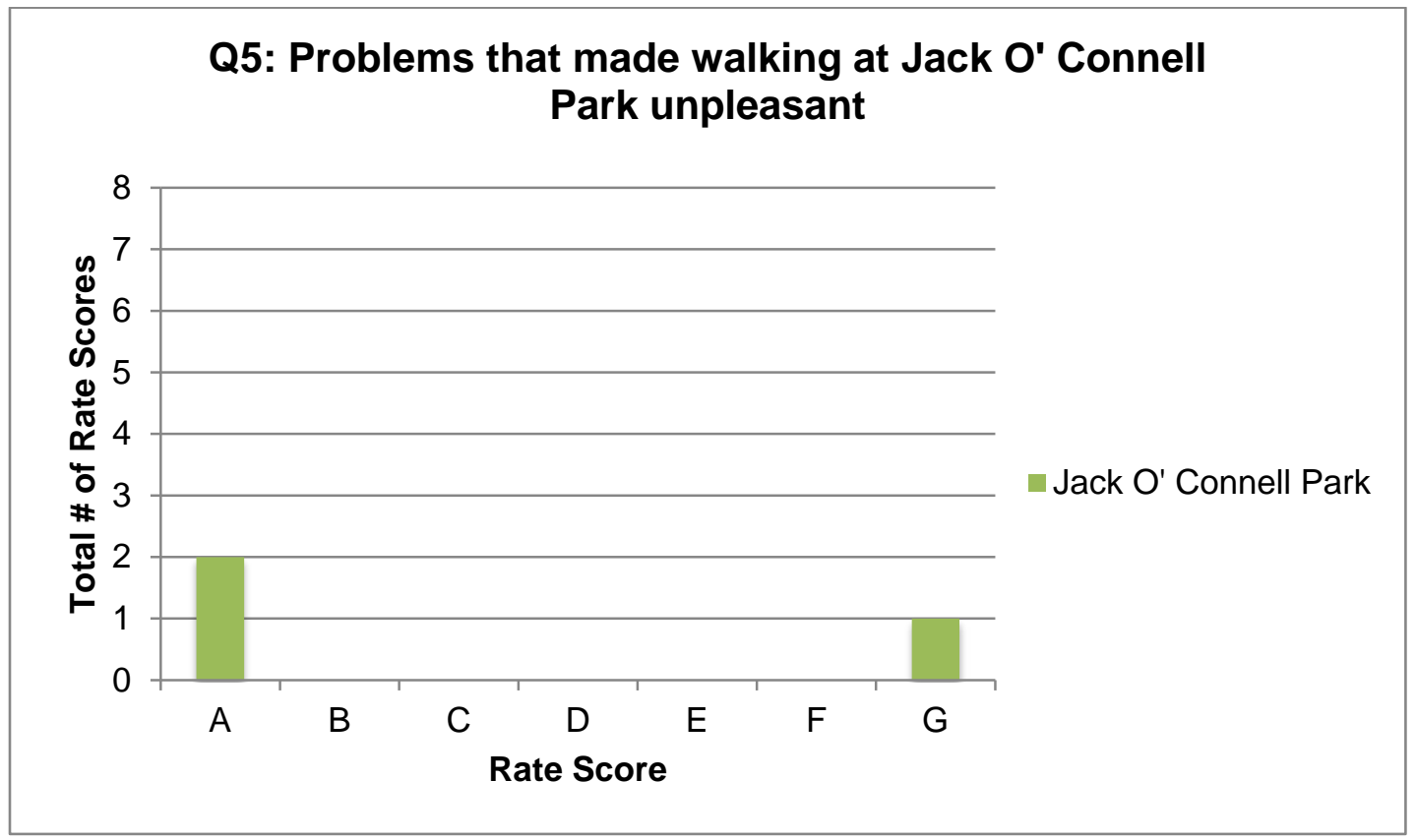

Based on the walkability and pedestrian safety findings and recommendations from current professional and academic literature on childhood obesity and the built environments, Guadalupe has an opportunity to improve its community by encouraging a Safe Routes to Schools (SRTS) program. SRTS programs seek to improve children's safety with safety, health, community and choice. SRTS resources and activities can help communities to build sidewalks, bicycle paths, pedestrian friendly infrastructure, reduce speeds in school zones and neighborhoods, address distracted drivers of all ages, and educate generations on pedestrian and bicycle safety. These goals would help to address the concerns of car speeds on Guadalupe Street and to encourage more complete streets for pedestrians. Having more pedestrian friendly infrastructure can encourage more active trips by foot and get children more involved. SRTS programs are very community oriented and pride in bringing families, neighbors, school officials and community leaders together, which could help Guadalupe build an even better sense of community and to encourage more parental involvement at the schools and beyond. 


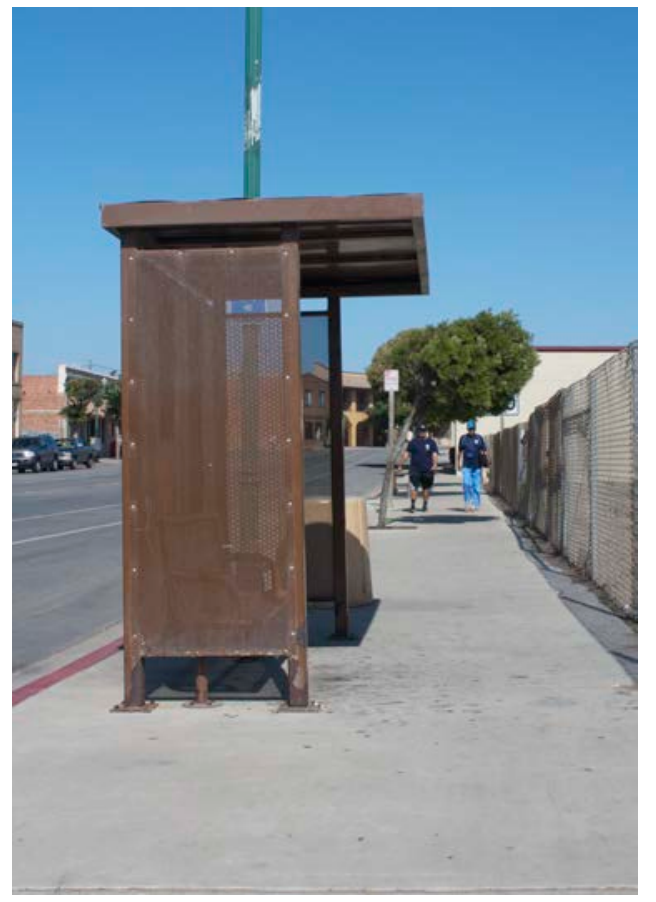

Figure 25. One bus stop on Guadalupe Street
Results indicated that several of the destinations are within easy walking distance, such as the food establishments. However, many streets lack benches, bus shelters, trees, and landscaping that are important to making a neighborhood walkable. While this project used a walkability survey to rate the walkability of Guadalupe Street and Jack O' Connell Park, it would be relevant to use other walkability tools, such as the

\section{Pedestrian Environmental Quality Index}

(PEQI) to better understand the connections between street design and physical activity on walkability. This tool has been used by public health departments, transportation departments, and community groups to raise recognition about pedestrian environmental quality. PEQI can help to encourage community engagement in land use planning processes in Guadalupe and gather more involvement from the community by raising awareness of the importance of building healthier and safer streets for the community.

Another opportunity to further utilize the walkability assessment that was used for this project is to involve school children in taking these surveys. The survey that was used for this project can be found in the Appendix of this report. The wording and scoring of this survey can be easily understood and can serve as an enlightening experience for the school children. This activity can raise awareness of their surroundings and comments that can help future policymakers. It would be interesting to see these essays in conjunction with a Photovoice project. 
To address the lack of street furniture and landscaping in Guadalupe, which is important to making a neighborhood more walkable, the Green Gym Program could be an appropriate solution. The Green Gym Program emphasizes the health benefits of working outdoors. It aims to provide people with a way to enhance their fitness and healthy while helping the outdoor environment around them. This could help Guadalupe bring its community closer together through community engagement in helping to rebuild and improve outdoor features such as planting trees, landscaping, There are numerous environmental benefits, many which can be enjoyed by the entire community.

\section{FOOD AVAILABILITY \& MARKETING}

The Food Availability and Marketing survey was designed for data collection at neighborhood food stores. These food stores include convenience stores, small markets, large grocery stores, and supermarket chains. Three small markets and one convenience store were assessed with this survey. These specific stores were surveyed because they are within a half-mile from a school and are locations frequented by students. Indicators examined included affordability, quality of fresh fruits and vegetables, quality and variety of fresh fruits and vegetables, and the extent to which the food store

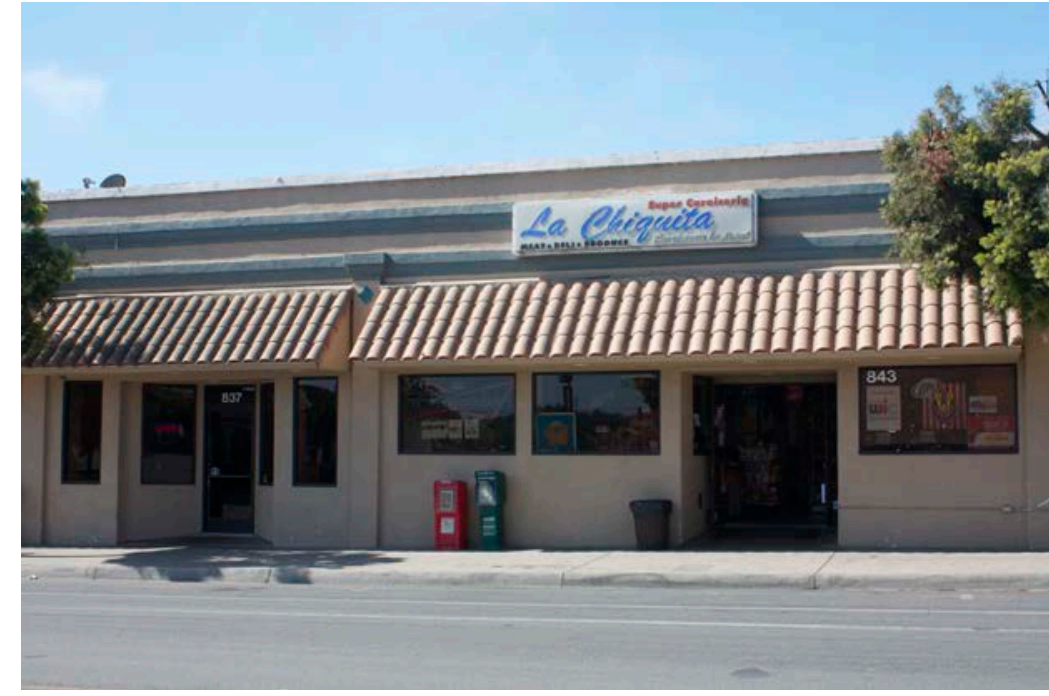

Figure 26. One market located on Guadalupe Street promoted healthy messages. 
Of the four food stores

surveyed, all three small

markets accepted WIC

coupons. While these food

stores did display unhealthy

ads promoting products such

as alcohol, there were healthy

ads displayed on the

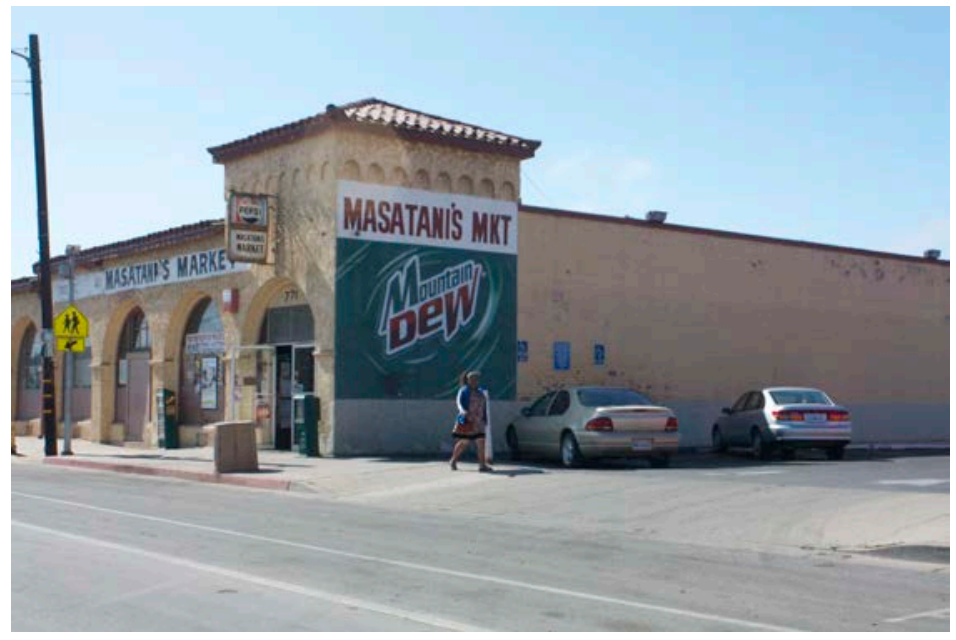

Figure 27. Another market site on Guadalupe Street

storefront. As the same with

healthy and unhealthy products located near the checkout counter, both were available.

La Chiquita Market had a fairly even amount of fresh fruits to vegetables that had little bruising. Romo's market had the least amount of fresh produce available, seven of which were unavailable at the time. One interesting find was YK market had a water filtration system.

Jack O' Connell Park was surveyed for marketing advertisements. The outdoor marketing environment survey evaluates the amount of advertising within 1000 feet of schools and parks. This survey was used to collect data on the prevalence, if any, of advertisements for food, beverages, and physical activity around schools and parks and the extent to which healthy items are promoted in these ads because children are often times influenced by these ads surrounding their environments. Visible at Jack O' Connell Park was one medium sized ad advertising a local business: Rabobank. Based on the low incidence of outdoor marketing, Jack O' Connell Park is an area of excellence. 
Table 14. Results of Food Availability and Marketing Survey

\begin{tabular}{|c|c|}
\hline & GUADALUPE \\
\hline STORE TYPES & $\begin{array}{l}3 \text { Small Markets } \\
1 \text { Convenience }\end{array}$ \\
\hline $1 / 2$ mile of school & Yes \\
\hline WIC & Yes \\
\hline Food Stamps & Yes \\
\hline Healthy ads on storefront & $1-2$ \\
\hline Unhealthy ads on storefront & $1-2$ \\
\hline More than $1 / 3$ of ads for alcohol & No \\
\hline Ads below check out level & Yes \\
\hline Unhealthy products located near checkout counter & Yes \\
\hline Healthy products located near checkout counter & Yes \\
\hline Is produce sold & Yes \\
\hline Variety of Fruit & 7 or more types \\
\hline Quality of fruit & Good Overall \\
\hline Ave price per pound* (apples, bananas, oranges) & $\$ 0.59$ \\
\hline Variety of Vegetables & 7 or more types \\
\hline Quality of Vegetables & Good Overall \\
\hline $\begin{array}{l}\text { Average price per pound* (carrots, tomatoes, broccoli, } \\
\text { cabbage) }\end{array}$ & $\$ 0.80$ \\
\hline Healthy foods available & Yes \\
\hline Healthy foods not available & Yes \\
\hline
\end{tabular}

Table 15. Outdoor Marketing Environment Survey Results

\begin{tabular}{|l|c|}
\hline \multicolumn{2}{|c|}{ Guadalupe } \\
\hline Location Type & Park \\
\hline Type and Size & Medium billboard, Other outdoor signage \\
\hline Product Ad & Local businesses \\
\hline Total Ads & 1 \\
\hline
\end{tabular}

Results from the various data collection methods used to reach a better understanding of the built environment and its affect on childhood obesity in Guadalupe provide evidence that childhood obesity is linked to the built environment in Guadalupe.

Reduced access to nutrition and physical activity has a direct impact on increased childhood obesity. Based on the survey responses and findings and recommendations from current professional and academic literature on childhood obesity and the food 
environment, communicating with store owners to improve on healthy foods and produce selections available would could be a first step for the community to become a community of excellency. Working closely with store owners to find better ways to represent the healthy items in the survey, such as including a wider variety of fruits, vegetables, and lean means could be initial steps that can be taken. To further educate school children about nutrition and healthy eating habits, community gardens are a great way to bring a community together to grow their own organic fruits and vegetables.

At Mary Buren Elementary School, there is currently a community garden where all students take part in spending time outdoors with the Master Gardener and their teacher, learning about agriculture and a mix of other subjects. It would be advantageous to see students cook and make dishes with the foods they have grown in the garden and showcase it to their parents. The STRIDE team at Cal Poly San Luis Obispo is an interdisciplinary team of students, faculty, and community partners that strive to create solutions through research in diet and exercise to advance knowledge and practice in obesity prevention by conducting cutting edge, interdisciplinary research, fostering collaborative partnerships among faculty, students and community and providing real-life learning experiences to develop the next generation of leaders. One of their projects include a Pink and Dude Chefs program that provides nutrition education and hands-on culinary skills to middle-school students. This program brings Cal Poly students to teach participants healthy and safe cooking skills in a fun environment. Taking on a Pink and Dude Chefs program at the schools in Guadalupe could help to engage school children to learn the basics of kitchen safety and to prepare nutritious meals. This could be an opportunity to utilize the organic foods grown at the community garden to teach the school children. 
While Jack O' Connell Park scored quite well with the little number of advertisements promoting unhealthy food products, the markets in Guadalupe could use more healthy advertisements. This could be done by encouraging storeowners to decrease the number of alcohol ads and replace them with healthy advertisements on the storefronts.

\section{THE GUADALUPE PHOTOVOICE PROJECT}

Students in Mr. Jeff Foote's

sixth, seventh, and eighth grade

class were provided a point and

shoot camera they shared in

groups of three to four students.

The students answered

questions that gave them a

chance to show their views of

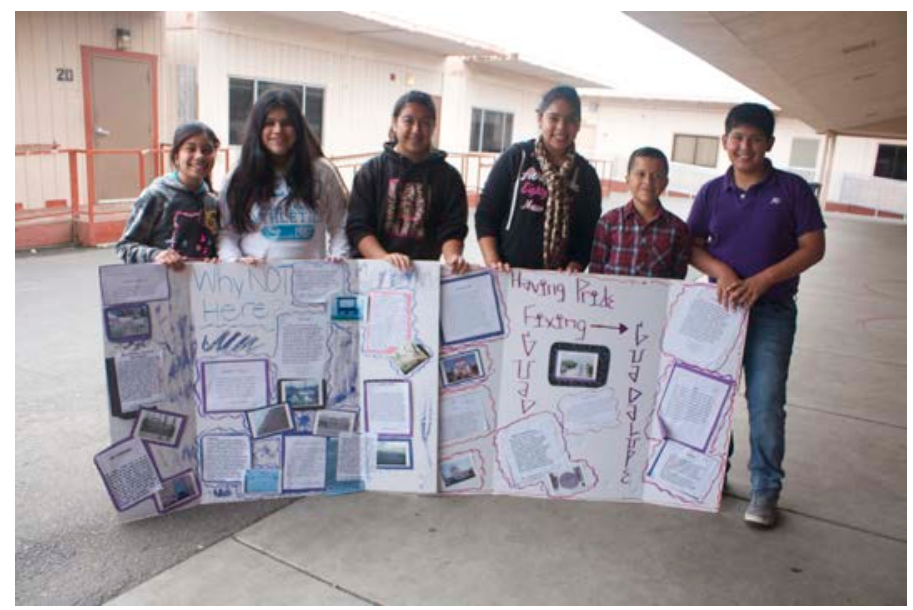

Figure 28. Students with their Photovoice board

Guadalupe by taking

photographs and writing narratives about their snapshots. They were started off with these following questions:

I. What do you like/dislike about Guadalupe?

II. Where do you like to hangout in Guadalupe?

III. What does healthy look like/mean to you in Guadalupe?

IV. What would you like to change about Guadalupe?

These questions helped the students stimulate deeper thoughts about how their built environment affects them. With the help from their teacher, the students formed themes from the pictures and narratives they composed. The three themes they came up with were: 
I. Having Pride

II. Why Not Here?

III. Where to Play?

These themes are all inclusive of the four questions that they were started with. From the themes drawn, some of the most significant finds include insight on the appearance of the physical layout, suggestions to improve Guadalupe, and the amount of trash found in empty lots. Some people mentioned the parks in Guadalupe to be lonely or only used by certain groups of people.

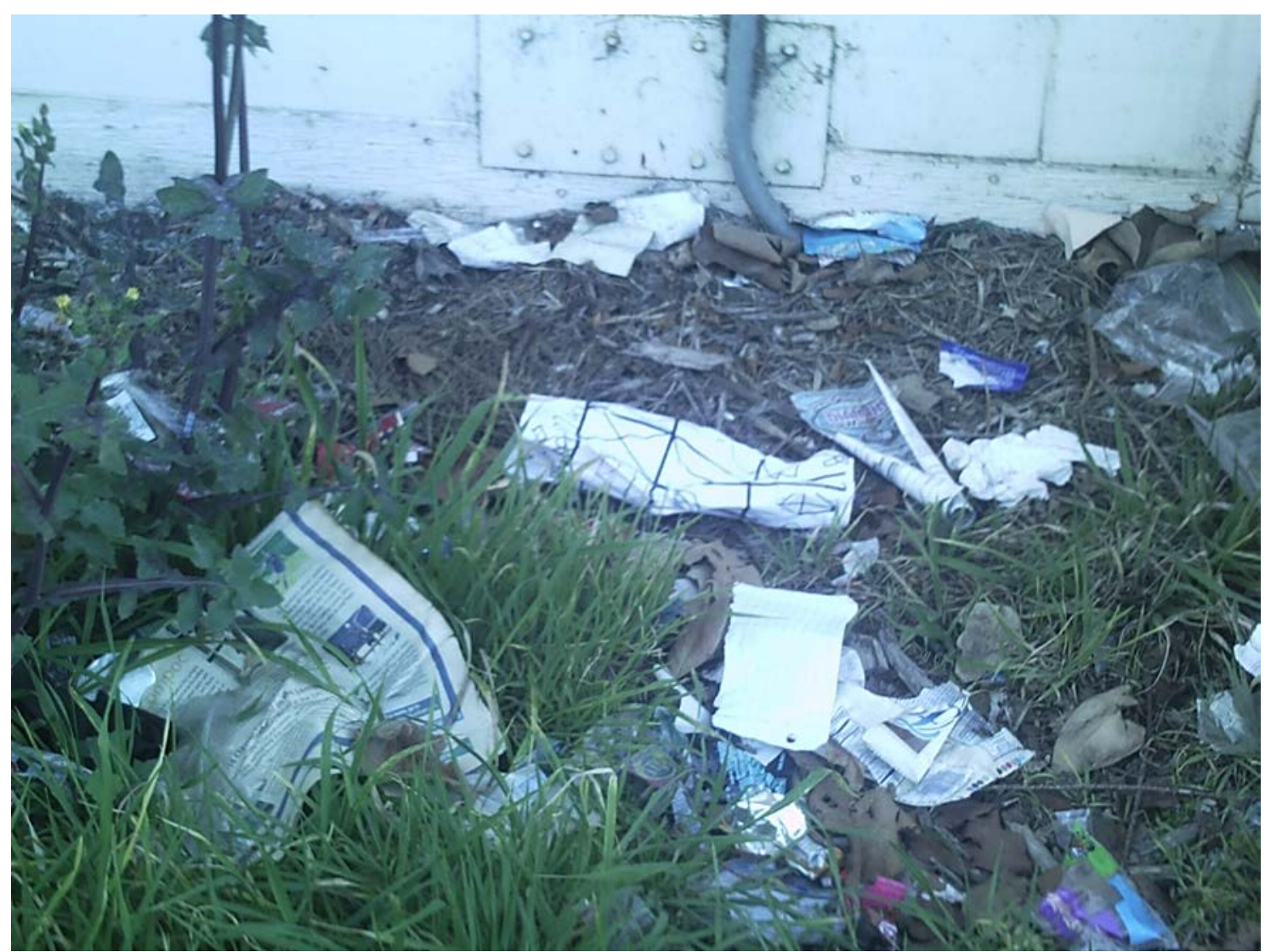

Figure 29. Picture of a "dirty pile" in Guadalupe that could be cleaned up

"Because when you enter Guadalupe there's a big space open with trash. It is filthy, and makes our town looks like we have no money to clean it. When we have tourists come 
they take pictures of good places are in Guadalupe, but it would be nice if they could take pictures all over Guadalupe."

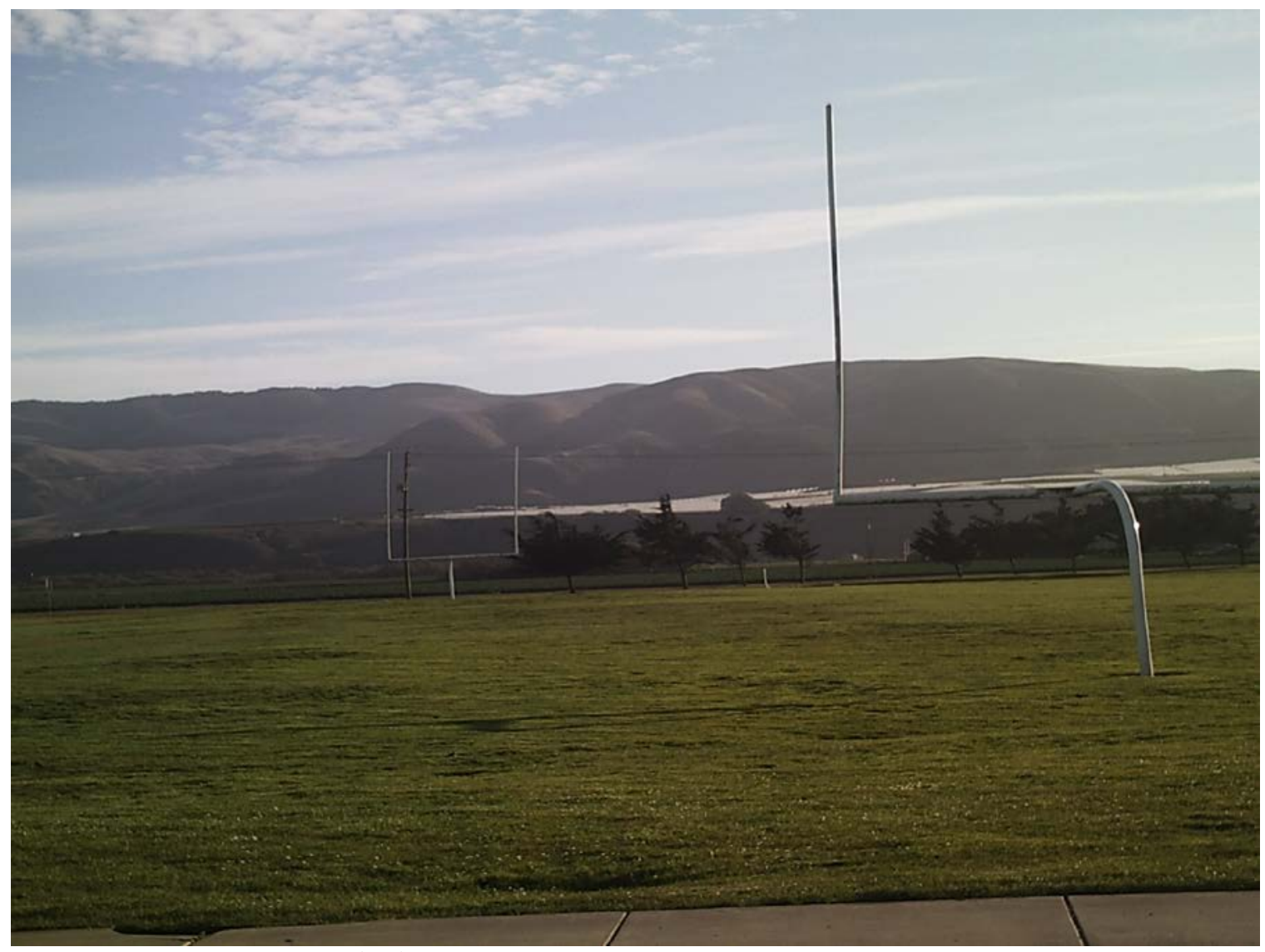

Figure 30. Field at Jack O' Connell Park

"This is a perfectly good field but nobody plays there. But mostly the only people that use the Jack O' Connell field are the football players and the people that walk the dogs but occasionally people play soccer at the Jack O' Connell field but the good thing about the park is that it does not have as many gopher holes." Perhaps, this reflects an opportunity for Parks and Recreation to encourage more recreational activities for children in Guadalupe. 
There are vacant lots in Guadalupe that have been mentioned a few times in the children's narratives. One student came up with a creative idea to turn empty lots into dog parks. This is a good indication that children have innovative ideas that could be valuable for future planning.

"All that can be removed within a few weeks and anything that Guadalupe needs can be used in the empty lot. They can put a dog park for both big and small dogs, but have to drive all the to Santa Maria to let their dogs run free. But if we put park for dogs in this empty lot, some people can easily walk there. It will be easier if they build a dog park because they wont have to waste gas just to go there. Or also, in this empty lot we can suggest that it would be cool to build a gym and pool for the people in Guadalupe"

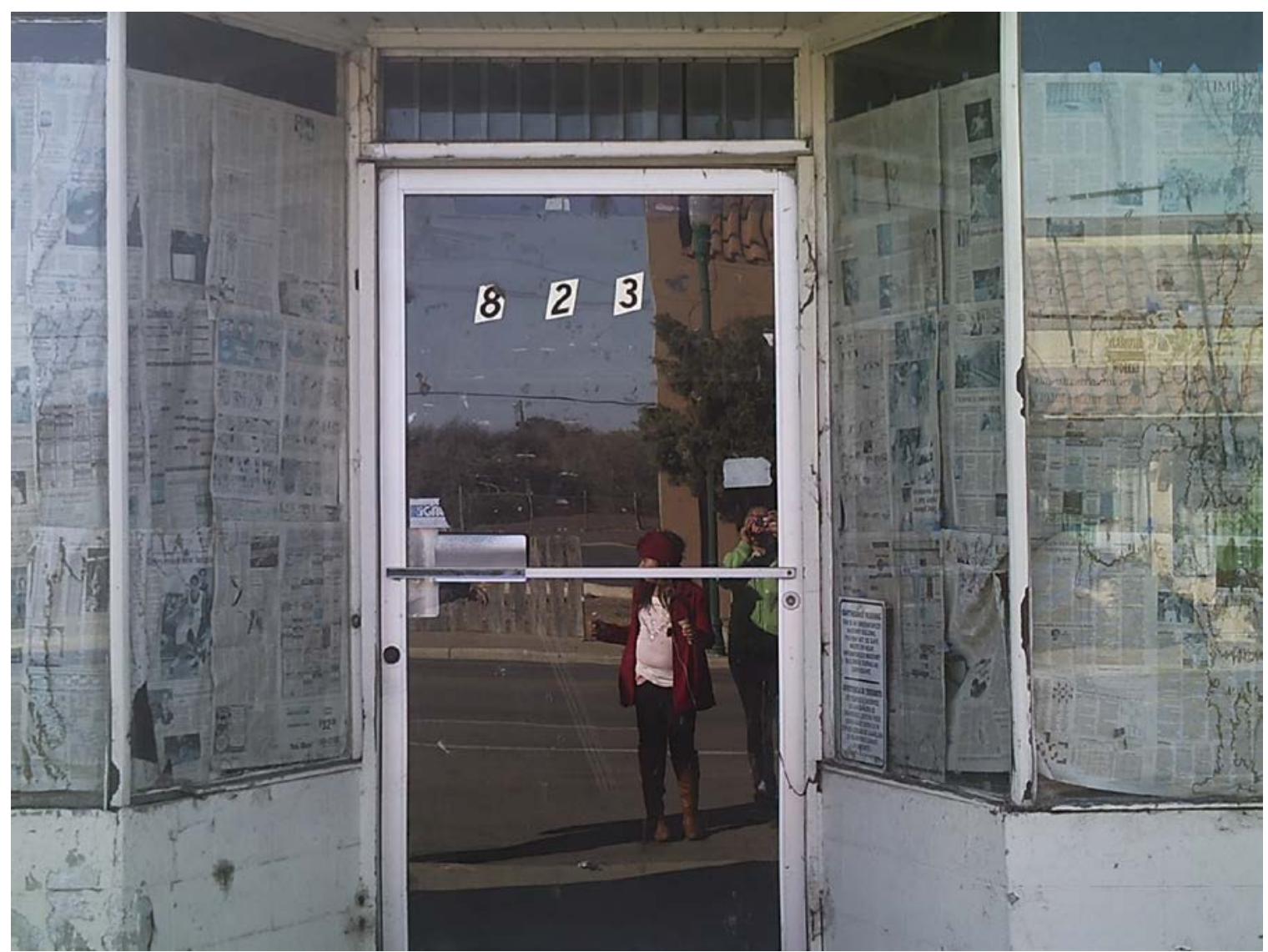

Figure 31. Vacant shop in Downtown Guadalupe 
There was mention of a lack of shops in Guadalupe. Children noted that their families would have to drive to Santa Maria, the next city over, to do their shopping. "If we make these changes we can make this town much better. Then, we can have grocery shops and we don't' have to go all the way to Santa Maria and to get gas all the way over there to. Later, we can reopen the movie theater to and also pick up all the trash around the town. Finally, they can also make this town bigger and we can have a better place and that's why I thank we can make this town better."

In one of the student's pictures, a picture of a food establishment was taken right across the street from Kermit McKenzie Junior High. This donut and deli shop was not surveyed using the $\mathrm{CX}^{3}$ field surveys, but was observed and noted by the student researcher. It would be interesting to take further observations of this food establishment for future endeavors to see what attracts students to this place the most. 


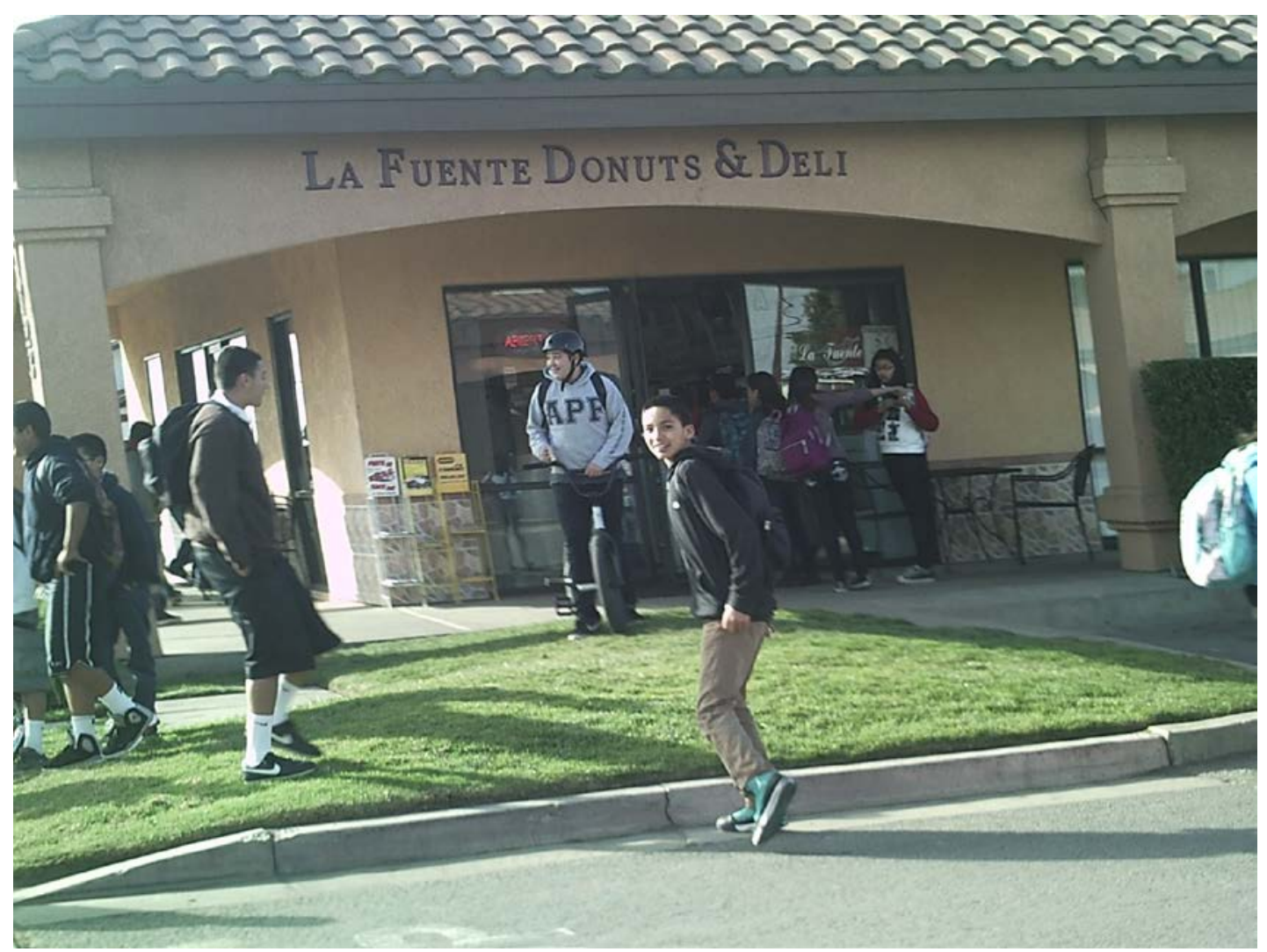

Figure 32. Donut and Deli shop across the street from Kermit McKenzie Junior High

Based on the children's narratives and pictures taken of their viewpoints of Guadalupe, there are many identified locations children feel proud of in their community. They see potential for abandoned and vacant lots that can be turned into areas of enjoyment that for the community. The children pointed out various pictures of empty lots with weeds and trash. One student suggested forming a clean up group to help clean up areas of trash in Guadalupe. Also, many students rated Jack O' Connell Park as a perfectly good park, but is very lonely. Perhaps, this is an opportunity to encourage more playground features, community group activities and lighting structures to take advantage of the park more often. 


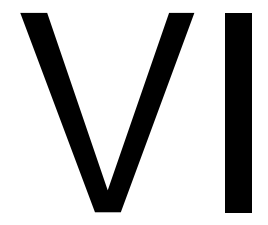

BIBLIOGRAPHY 


\section{BIBLIOGRAPHY}

American Public Health Association (2014). APHA: New Food System Principles Emphasize Health Benefits. [online] Available at:

http://www.apha.org/about/news/pressreleases/2010/food+safety+system+coaliti on+release.htm [Accessed 5 Jun. 2014].

Babey, S.H., Wolstein, J., Diamant, A.L, Bloom, A., Goldstein, H. (2011). A Patchwork of Progress Changes in Overweight and Obesity Among California Among California $5^{\text {th }}, 7^{\text {th }}, 9^{\text {th }}$ Graders, 2005-2010. UCLA Center for Health Policy Research and California Center for Public Health Advocacy.

Bauman AE, Bull FC. Environmental Correlates of Physical Activity and Walking in Adults and Children: A Review of Reviews. London: National Institute of Health and Clinical Excellence; 2007. Available at http://www.nice.org.uk/guidance/index.jsp?action=download\&o=34740 accessed July 15, 2008.

Breakfastintheclassroom.org (2014). Breakfast in the Classroom. [online] Available at: http://www.breakfastintheclassroom.org/ [Accessed 6 Jun. 2014].

Cal Poly CRP 554 Graduate Studio, (2014). Cal Poly Background Report. San Luis Obsipo: Cal Poly San Luis Obispo.

California Department of Public Health (2000). Communities of Excellence in Nutrition, Physical Activity and Obesity Prevention: Neighborhood Nutrition in Focus. [report] USDA's Food Stamp Program.

Carmona, Richard H. (2003). The Obesity Crisis in America. Retrieved June 5, 2014, from United States Department of Health and Services. Website: htttp://www.surgeongeneral.gov/news/testimony/obesity07162003.htm.

Centers for Disease Control and Prevention (2014). CDC - Obesity - Facts - Adolescent and School Health. [online] Available at: http://www.cdc.gov/healthyyouth/obesity/facts.htm [Accessed 5 Jun. 2014].

City of Guadalupe (2011). 2011 Revised Draft 2009 Housing Element Update. Guadalupe: Rincon Consultants.

Dannenberg, A., Frumkin, H. and Jackson, R. (2011). Making healthy places. 1st ed. Washington, D.C.: Island Press.

First 5 Santa Barbara County (2014). First 5 Santa Barbara - Funded Partners, Funding Opportunities, Volunteers, Partnerships. [online] Available at: http://www.first5santabarbaracounty.org/guadalupecollaborative.aspx [Accessed 6 Jun. 2014]. 
Guadalupe Cultural Arts and Education Center, (2014). Guadalupe Cultural Arts and Education Center. [online] Available at: http://www.guadalupeculturalcenter.com/ [Accessed 6 Jun. 2014].

Health Linkages Program, Santa Barbara County Education Office, 2011

Kipke, M., Iverson, E., Moore, D., Booker, C., Ruelas, V., Peters, A. and Kaufman, F. (2007). Food and Park Environments: Neighborhood-level Risks for Childhood Obesity in East Los Angeles. Journal of Adolescent Health, 40 (4), pp. 325-333. doi:10.1016/j.jadohealth.2006.10.021.

Larson, N., Story, M. and Nelson, M. (2009). Neighborhood environments: disparities in access to healthy foods in the US. American Journal of Preventive Medicine, 36 (1), pp. 74-81.

Leadership for Healthy Communities (2010). Overweight and Obesity Among Latino Youths. [report] May 2010: Leadership for Healthy Communities of the Robert Wood Johnson Foundation.

Lee, H. (2012). The Role of Local Food Availability in Explaining Obesity Risk Among Young School-Aged Children. Social Science \& Medicine, 74 (8), pp. 1193-1203.

Mair, J., Pierce, M. and Teret, S. (2005). The Use of Zoning to Restrict Fast Food Outlets: A Potential Strategy to Combat Obesity. [report] The Center for Law and the Public Health's at John's Hopkins \& Georgetown Universities.

People's Self-Help Housing, (2014). [online] Available at: http://www.pshhc.org/programs/youth_education_enhancement.html [Accessed 6 Jun. 2014].

Pool, Robert. (2001). Fat: Fighting the Obesity Epidemic. New York: Oxford University Press.

Rivera, A. (2013). Health First. Planning, Iss. 79(8) pp. 14-19.

Saferoutesinfo.org, (2014). National Center for Safe Routes to School. [online] Available at: http://www.saferoutesinfo.org/ [Accessed 6 Jun. 2014].

Santa Barbara County Public Health Department (2012). Fitness Promotion \& Obesity Prevention Plan. [report] Santa Barbara: Santa Barbara County Public Health Department.

Stride.calpoly.edu, (2014). About - STRIDE - Cal Poly, San Luis Obispo. [online] Available at: http://stride.calpoly.edu/content/about [Accessed 12 Jun. 2014].

Stride.calpoly.edu, (2014). Pink and Dude Chefs - STRIDE - Cal Poly, San Luis Obispo. [online] Available at: http://stride.calpoly.edu/content/programs/pink-and-dude-chefs [Accessed 12 Jun. 2014]. 
The Childhood Obesity Prevention Task Force (2008). Environment and Obesity in San Luis Obispo County: Measuring the Effect of Food Availability, Outdoor Marketing and Walkability on Childhood Obesity in San Miguel and Oceano, California. [report] San Luis Obispo: San Luis Obispo County Public Health Department, AmeriCorps.

THRIVE Guadalupe, (2013). Thriving Children Report: THRIVE Guadalupe, Draft. Gevirtz Graduate School of Education University of California, Santa Barbara County.

U.S. Census. (2010a). QT-P1. Age Group and Sex: 2010. Retrieved from http://factfinder2.census.gov/faces/tableservices/jsf/pages/productview.xhtml?pid =DEC_10_SF1_QTP1\&prodType=table

U.S. Census. (2010b). Profile of General Population and Housing Characteristics: 2010. Retrieved from

http://factfinder2.census.gov/faces/tableservices/jsf/pages/productview.xhtml?pid =DEC_10_SF1_SF1DP1\&prodType=table

The US Department of Health and Human Resources, (2008). 2008 Physical Activity Guidelines for Americans. Washington D.C.

Wakefield, J. 2004. Fighting obesity through the built environment. Environmental health perspectives, 112 (11), p. 616 


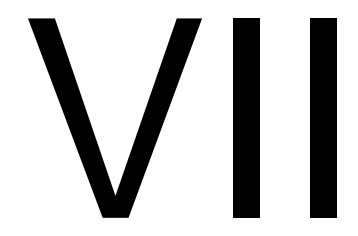

APPENDICIES 


\section{$\mathrm{CX}^{3}$ Food Availability \& Marketing Survey}

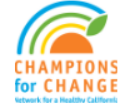

\section{CX $^{3}$ Tier 2 - NF 2-5 Food Availability \& Marketing Survey}

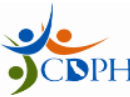

\section{A. STORE INFORMATION}

1) Store ID

$$
\text { County - Neighborhood - Store Code }
$$

2) Census Tract

3) Name/Address of Store:

\begin{tabular}{lll}
\hline (Street Address) & (Ciny)
\end{tabular}

4) Coder Narne/ID

5) Store Type: Obtain from GIS store lists (circle one)

At store visit if store type is different, mark through circled number and circle correct store type.

1. Supermarket chain (e.g., Safeway, Ralph's)

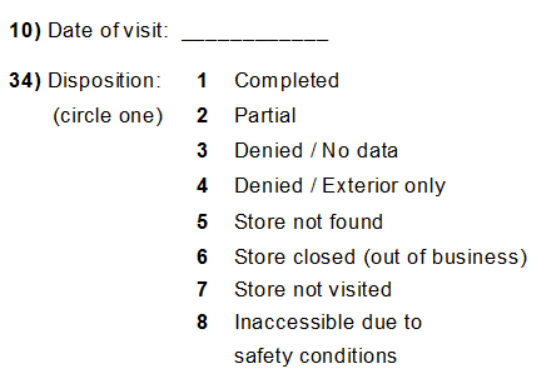

2. Large grocery store $>20$ employees or $\geq 4$ registers, but not large chain)

3. Small Market $<4$ registers, but not corvenience)

4. Convenience (sells food items and snacks, no fresh meat, may sell gas)

5. Other (NO liquor stores) (specify)

6) Is store with in $1 / 2$ mile of a school? 1 -Yes 0 - No $>$ if Yes, Name of school:

7) mc Vendor? 1 -Yes 0 -No (Obtain from GIS, Verify by phone or at store)

8) CalF resh, Food stamp or SNAP vendor? 1 -Yes 0 - No (Obtain from GIS, Verify by phone or at store)
9) Paiticipate as a Network for a Healthy Califomia retal store? 1 -Yes 0 - No

\section{B. STORE EXTERIOR}

11) Is a school visble from the store (circle one)? 1 - Yes 0 - No

12) Record information about healthy and unhealthy advertising and products on all doors and windows of the storefromt. Do not indude ads on the sides of the building or on other parts of the property such as the roof, fences or parking lot

For the following table, only include professionally-produced advertising that depicts brands, logos or products. See definitions to leam what types of iterns to count

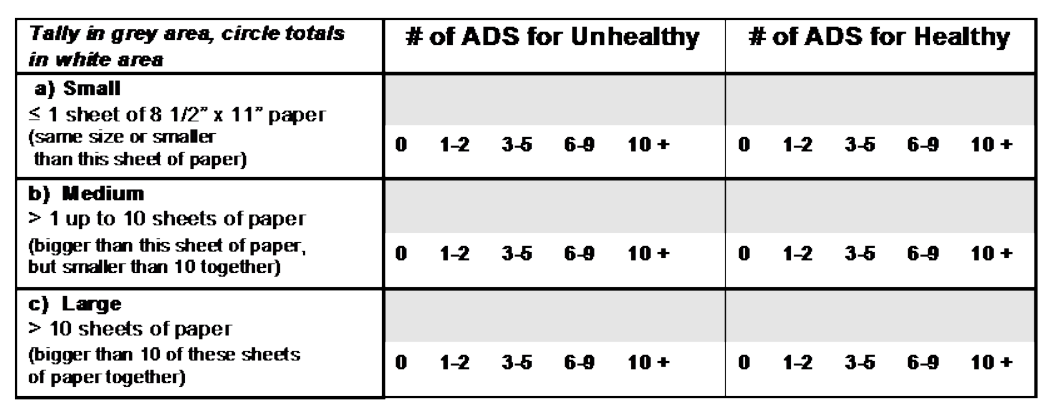

Unhealthy foods are high calorie Unhealthy foods are high calorie that includ that include alcoholic beverages, soft drinks and other sweetened beverages including diet drinks, sweet desserts and highly sugared cereals, chips and other salty snacks, most solid fats, frie foods, and other foods with high amounts of sugar, fat and/or sodium.

Healthy foods are fruits and vegetables, whole grains, beans, nuts and seeds, non-fat and low fat milk products, and lean meat, poultry, and fish. Healthy foods include minimal or no added fat, sugars, or sweeteners Unsweetened black coffee is included.

Do not consider: Cigarettes or tobacco products 


\begin{tabular}{|c|c|c|}
\hline Store Exterior Conditions & \multicolumn{2}{|c|}{ Circle One } \\
\hline 13) Are there any produce bins on the sidewalk in front of the store? & 1 -Yes & $\mathbf{0}$ - No \\
\hline \multirow{2}{*}{$\begin{array}{l}\text { 14) Are other products displayed on the sidewalk in front of the store or inside the } \\
\text { store next to the window so they are clearly vis ble from the outside? } \\
\text { Please check all that apply: } \\
\text { soda _ water_other. (specify) }\end{array}$} & \multicolumn{2}{|c|}{1 -Yes $\quad 0$ - No } \\
\hline & \multicolumn{2}{|c|}{$\mathscr{K}$ If Yes } \\
\hline \multirow{2}{*}{$\begin{array}{l}\text { 15) Are there vending machines on the sidewalk in front of the store? } \\
\text { Please check all that apply: } \\
\text { soda__water_other. (specify) }\end{array}$} & 1 -Yes & $\mathbf{0}$ - No \\
\hline & \multicolumn{2}{|c|}{$x<$ If Yes } \\
\hline \multirow{2}{*}{$\begin{array}{l}\text { 16) Is there adverting (banners, posters, temporary signs, etc.) on the roof, wals } \\
\text { or elsewhere on the property such as on fences, garbage cans or in the parking lot? } \\
\text { Please check all that apply: } \\
\text { healthy }\end{array}$} & \multicolumn{2}{|c|}{1 -Yes $\quad 0$ - No } \\
\hline & \multicolumn{2}{|c|}{$x<$ If Yes } \\
\hline $\begin{array}{l}\text { 17) Are there any inages of healthy food (e.g-tornato, apple) and/or } \\
\text { beverages (e.g. mik), painted on doors or windows of the storefront? }\end{array}$ & \multicolumn{2}{|c|}{1 -Yes $\quad 0$ - No } \\
\hline $\begin{array}{l}\text { 18) Are there any inages of un-healthy food (e.g. hamburger, hot dog) and/or } \\
\text { beverages (e.g., soda, shake) painted on doors or windows of the storefront? }\end{array}$ & \multicolumn{2}{|c|}{1 -Yes $\quad 0$ - No } \\
\hline $\begin{array}{l}\text { 19) Are there any painted murals of healthy food and/or beverages anywhere on } \\
\text { the buikding walls? }\end{array}$ & \multicolumn{2}{|c|}{1 -Yes $\quad 0$ - No } \\
\hline $\begin{array}{l}\text { 20) Are there permanent bars/chains on the windows or doors? (do not include } \\
\text { sliding or rolling chains or bars) }\end{array}$ & \multicolumn{2}{|c|}{1 - Yes $\quad 0$ - No } \\
\hline $\begin{array}{l}\text { 21) If the store sels alcohol, is more than } 1 / 3 \text { of the total window area covered by } \\
\text { any type of advertising? }\end{array}$ & \multicolumn{2}{|c|}{1 - Yes $\quad$ O - No $\begin{array}{r}\text { 9-N/A } \\
\text { (Sthredoes not } \\
\text { setl alocohol) }\end{array}$} \\
\hline 22) Is "We Accept WK" signage displayed? & \multicolumn{2}{|c|}{1 -Yes $\quad 0$ - No } \\
\hline 23) Is "We Accept CalF resh, Food Stamps/ EBT" signage or ads displayed? & \multicolumn{2}{|c|}{1 -Yes $\mathbf{0}$ - No } \\
\hline 23a) Are there any ads promoting EBT with food or beverage products Please & \multirow{2}{*}{\multicolumn{2}{|c|}{$\begin{array}{l}1-\text { Yes } 0-\text { No } \\
x<\text { If Yes }\end{array}$}} \\
\hline $\begin{array}{l}\text { Please check all that apply: } \\
\text { healthy unhealthy }\end{array}$ & & \\
\hline
\end{tabular}

\section{STORE INTERIOR}

24) Number of cash registers throughout store (staffed and unstaffed, for grocery items only)

25) Marketing of foods and beverages next to the main check-out area

Circle " 1 " for yes if the item or ad is present or " 0 " for no if the item or ad is not present.

\begin{tabular}{|c|c|c|}
\hline Presence of ads or promotions (fill in BOTH columns): & UNHEALTHY & HEALTHY \\
\hline Next to check-out (attached or directly next to) & 1 -Yes 0 - No & 1 -Yes $\mathbf{0}$-No \\
\hline Below check-out level & 1 -Yes 0 -No & 1 -Yes $\mathbf{0}$-No \\
\hline $\begin{array}{l}\text { On floor (if standing in checkout isk or next to counter) } \\
\text { Hanging from ceiling (directly over register) }\end{array}$ & $\begin{array}{l}1 \text { - Yes } 0 \text { - No } \\
1 \text {-Yes } 0 \text { - No }\end{array}$ & $\begin{array}{ll}1 \text { - Yes } & 0-\text { No } \\
1 \text {-Yes } & 0-\text { No }\end{array}$ \\
\hline \multicolumn{3}{|l|}{ Presence of UNHEALTHY products next to or below a check-out counter: } \\
\hline Gumbal or candy machine (next to counter or exit doorway) & 1 -Yes 0 -No & \\
\hline Candy (next to or below counter/check-out) & 1 -Yes $\mathbf{O}$-No & \\
\hline Soda (next to or below counter/check-out) & 1 -Yes 0 -No & \\
\hline Chips (next to or below counter/check-out) & 1 - Yes 0 - No & \\
\hline Other:specify (such as conkies, ice crean, beef jerky, ensgy dritks, etc.) & 1 -Yes 0 -No & \\
\hline \multicolumn{3}{|l|}{ Presence of HEALTHY products next to or below a check-out counter: } \\
\hline $\begin{array}{l}\text { Granola bars (whole grain, } \geq 2 \mathrm{~g} \text { fiber, } \leq 1 \mathrm{~g} \text { saturated fat, } \leq 14 \mathrm{~g} \text { sugar per serving) } \\
\text { Bagged Nuts'seeds (do not inchude honey roasted or w/ added sugar) (next to or below countercheck-out) }\end{array}$ & & $\begin{array}{l}1 \text { - Yes } 0 \text {-No } \\
1 \text {-Yes } 0 \text {-No }\end{array}$ \\
\hline Fresh fruit (next to or below counter/check-out) & & 1 - Yes $\mathbf{O}$-No \\
\hline Bottled water (next to or below counter/check-out) & & 1 - Yes $\mathbf{0}$-No \\
\hline Other:specify (such as died thut, trat mix, $100 \%$ juce, etc.) & & 1 - Yes $\mathbf{O}$-No \\
\hline
\end{tabular}

Unhealthy products are high calorie, low nutrient foods and beverages that include alcoholic beverages, soft drinks and other sweetened beverages including diet drinks, sweet desserts and highly sugared cereals, chips and other salty snacks, most solid fats, fried foods, and other foods with high amounts of sugar, fat and/or sodium

Healthy products include minimal or no added fat, sugars, or sweeteners. Examples include fresh or dried fruits and vegetables, whole grain snacks 


\section{PRODUCE SECTION}

26) Is produce sold? (Circle one) 1 -Yes 0 -No If yes, continue. If no $t$-Go to Question 33

27) Are there any health promotion items around the frit and vegetable display?

1 -Yes 0 - No If noג-Go to Question 28 .

28) If there are health promotion items around the fruit and vegetable display, circle a number next to the types of health promotion items that are present (more than one can be circled).

1 - 5 A Day signs (not an packaging)

2 - Nutrition information

3 - Fruit and Veggies: More matters

4- Network for a Healthy Calfornia: Champions for Change

5 - Other (specify)

28a) Are there any items promoting kocally grown produce? (Circle one) 1 -Yes 0 -No

29) Circle the number that best describes overall availability of fruits and vegetables inside and outside the store.

\begin{tabular}{|l|c|c|c|c}
\hline & None & $\begin{array}{c}\text { Limited } \\
\text { (1-3 types) }\end{array}$ & $\begin{array}{c}\text { Moderate variety } \\
\text { (4-6 types) }\end{array}$ & $\begin{array}{c}\text { Wide variety } \\
\text { (7 or more types) }\end{array}$ \\
\hline Fresh fruit & $\mathbf{1}$ & $\mathbf{2}$ & $\mathbf{3}$ & $\mathbf{4}$ \\
\hline Fresh vegetables & $\mathbf{1}$ & $\mathbf{2}$ & $\mathbf{3}$ & $\mathbf{4}$ \\
\hline
\end{tabular}

30) Circle the number that best describes the overall quality of the fresh fruit.

\begin{tabular}{|c|l|l|l|l|}
\hline $\mathbf{0}$ & \multicolumn{1}{|c|}{$\mathbf{1}$} & $\mathbf{2}$ & \multicolumn{1}{c|}{$\mathbf{3}$} & \multicolumn{1}{c|}{$\mathbf{4}$} \\
\hline None sold & $\begin{array}{l}\text { All or most of fruit is of } \\
\text { poor quality (brown, } \\
\text { bruised, ovemipe, witted) }\end{array}$ & $\begin{array}{l}\text { Mixed quality; } \\
\text { more poor } \\
\text { than good }\end{array}$ & $\begin{array}{l}\text { Mixed quality; } \\
\text { more good } \\
\text { than poor }\end{array}$ & $\begin{array}{l}\text { All or most of fruit is of good } \\
\text { quafty (very fresh, no soft } \\
\text { spots, excellent color) }\end{array}$ \\
\hline
\end{tabular}

31) Circle the number that best describes the overall quality of the fresh vegetables.

\begin{tabular}{|c|l|l|l|l|}
\hline $\mathbf{0}$ & \multicolumn{1}{|c|}{$\mathbf{1}$} & \multicolumn{1}{c|}{$\mathbf{2}$} & \multicolumn{1}{c|}{$\mathbf{4}$} \\
\hline None sold & $\begin{array}{l}\text { All or most of vegetable is } \\
\text { of poor quality (brown, } \\
\text { bruised, overnipe, witted) }\end{array}$ & $\begin{array}{l}\text { Mixed quality; } \\
\text { more poor } \\
\text { than good }\end{array}$ & $\begin{array}{l}\text { Mixed quality; } \\
\text { more good } \\
\text { than poor }\end{array}$ & $\begin{array}{l}\text { All or most of vegetable is } \\
\text { of good quality (very fresh, } \\
\text { no soft spots, excellent } \\
\text { color) }\end{array}$ \\
\hline
\end{tabular}

32) Record if the fresh fruit or vegetable is avalable and the price if possible. If more than one variety of a fruit (e.g. gala or red delicious apples) or vegetable is avalable, please record the lowest price option. Record the pricing if avalable (per pound is preferred). If the fuit or vegetable is avalable by the bag or bunch, record the price only if you can record a weight for the bag (marked on the bottom) or bunch. If a weight is not on the bag or bunch, weigh the item if a scale is present.

\begin{tabular}{|c|c|c|c|c|c|c|}
\hline & \multirow{2}{*}{$\begin{array}{l}\text { Available? } \\
\text { (circle one) }\end{array}$} & \multirow{2}{*}{$\begin{array}{l}\text { Price posted? } \\
\text { (circle one) }\end{array}$} & \multicolumn{3}{|c|}{ Price per } & \multirow{2}{*}{$\begin{array}{l}\text { If packagefounch, } \\
\text { record weight } \\
\text { in pounds and/or } \\
\text { ounces }\end{array}$} \\
\hline & & & $\begin{array}{c}\text { Pound } \\
\text { (preferred if } \\
\text { available) }\end{array}$ & Piece & $\begin{array}{l}\text { Package/Bunch } \\
\text { (only record if weight is } \\
\text { avaikable or can weigh) }\end{array}$ & \\
\hline \multicolumn{7}{|l|}{ Fruits } \\
\hline Apples & 1 -Yes 0 -No & 1 -Yes 0 - No & & & $\rho$ & \\
\hline Bananas & 1 -Yes 0 - No & 1 - Yes 0 - No & & & $/$ & \\
\hline Oranges & 1 -Yes 0 -No & 1 - Yes 0 - No & & & 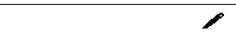 & \\
\hline \multicolumn{7}{|c|}{ Vegetables } \\
\hline $\begin{array}{l}\text { Canots } \\
\text { Tomatoes }\end{array}$ & $\begin{array}{ll}\text {-Yes } & 0-\text { No } \\
1-\text {-Yes } & 0-\text { No }\end{array}$ & $\begin{array}{l}1 \text {-Yes } 0 \text { - No } \\
1 \text {-Yes } 0 \text { - No }\end{array}$ & & & p & \\
\hline Broccoli & 1 -Yes 0 - No & 1 -Yes 0 - No & & & 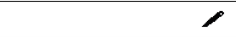 & \\
\hline Cabbage & 1 -Yes 0 - No & 1 -Yes 0 - No & & & $>$ & \\
\hline
\end{tabular}




\section{E. OTHER HEALTHY FOODS}

33) Record if the following items are available in the store.

\begin{tabular}{|c|c|}
\hline Food Item & Circle one \\
\hline Milk - skim, non fat, plain white (not lavored- chocolate, strawberry, vanila) & 1 -Yes 0 -No \\
\hline Milk - 1\%, low fat, plain white (not flavored- chocolate, strawbenry, vanila) & 1 -Yes 0 -No \\
\hline $\begin{array}{l}\text { Milk }-2 \% \text {, reduced fat, plain white (not lavored- chocolate, strawberry, } \\
\text { vanila) }\end{array}$ & 1 -Yes 0 -No \\
\hline Mozzarela cheese, part skim & 1 -Yes 0 -No \\
\hline $\begin{array}{l}\text { Ground beef or turkey, lean ( } 85 \% \text { or higher) } \\
\text { Whole chicken }\end{array}$ & $\begin{array}{l}1 \text {-Yes } 0 \text {-No } \\
1 \text {-Yes } 0 \text { - No }\end{array}$ \\
\hline $\begin{array}{l}\text { Whole wheat bread } \\
\text { Brown rice }\end{array}$ & $\begin{array}{l}1-\text { Yes } 0-\text { No } \\
\times \text { If Yes } \\
1 \text {-Yes } 0-\text { No }\end{array}$ \\
\hline $\begin{array}{l}\text { High fiber cereal ( } \geq 3 \text { grams fiber, } \leq 12 \text { grams sugar per serving) } \\
\text { Oatmeal (plain) } \\
\text { Tortillas, soft com or whole wheat (no lard) }\end{array}$ & $\begin{array}{l}1 \text { - Yes } 0 \text { - No } \\
1 \text { - Yes } 0 \text { - No } \\
1 \text {-Yes } 0 \text { - No }\end{array}$ \\
\hline
\end{tabular}

\begin{tabular}{|l|l|}
\hline Soy beverage, plain, with no added sugar or sweeteners & 1 -Yes 0 -No \\
\hline Soy beverage, flavored, vanila or chocolate & 1 -Yes 0 -No \\
\hline Tofu, plain & 1 -Yes 0 -No \\
\hline
\end{tabular}

\begin{tabular}{|l|l|}
\hline Beans, dried & 1 -Yes 0 -No \\
\hline Beans, canned with no added fats, sugar or sweetener & 1 -Yes 0 - No \\
\hline Tuna (Iight) canned in water & 1 -Yes 0 - No \\
\hline Salmon canned in water & 1 -Yes 0 - No \\
\hline Sardines canned in water, tomato, or mustard & 1 -Yes 0 - No \\
\hline
\end{tabular}

\begin{tabular}{|c|c|}
\hline Any canned fruit packed in $100 \%$ fruit juice & 1 -Yes $\mathbf{0}$ - No \\
\hline Any canned vegetable with no added fats, sugar, or sweetener & 1 -Yes 0 - No \\
\hline Any frozen fruit with no added fats, sugar, or sweetener & 1 -Yes 0 - No \\
\hline Any frozen vegetables with no added fats, sugar, or sweetener & 1 -Yes 0 - No \\
\hline Baby food, jarred, single fruit & 1 -Yes $\mathbf{0}-$ No \\
\hline Baby food, jarred, single vegetable & 1 -Yes $\mathbf{0}-\mathbf{N o}$ \\
\hline Baby food, jarred, single meat & 1 -Yes $\mathbf{0}-$ No \\
\hline
\end{tabular}

A dded sugars or sweeteners include: Sugar, raw sugar, invert sugar, brown sugar, sucrose, dextrose, fructose, glucose, maltose, high fructose corn syrup, corn sweetener, molasses, syrup, honey, malt syrup, fruit juice concentrates, evaporated cane juice, dehydrated cane juice, brown rice syrup, stevia, sorbitol, mannitol, maltitol, xylitol

34) Fill out the disposition on page 1

Things to remember:

Check for missing data! Be sure all questions are complete before leaving the store. 


\section{$\mathrm{CX}^{3}$ Outdoor Marketing Survey}
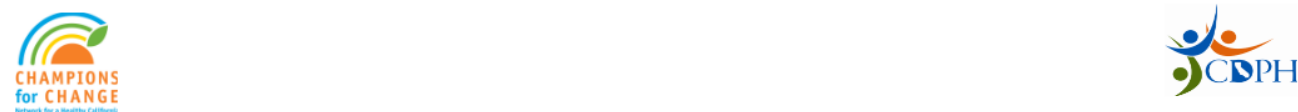

\section{CX ${ }^{3}$ Tier 2 - NF10 Food and Physical Activity Outdoor Marketing Survey}

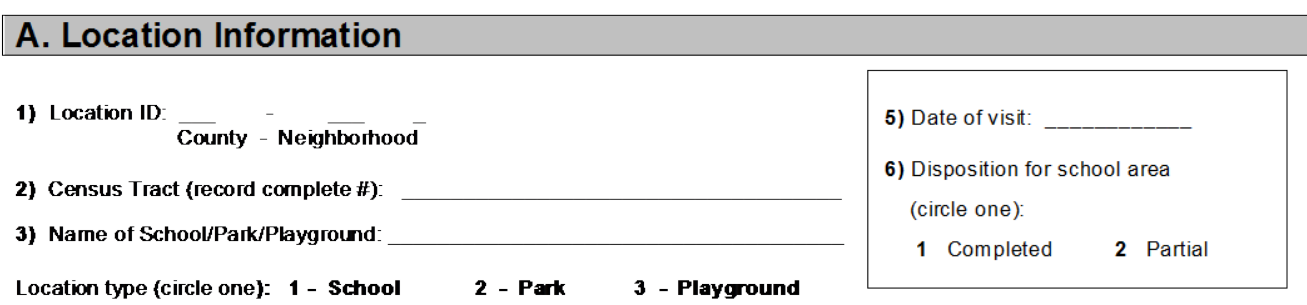

4) Coder Name/ID

\section{Messages and Products in Marketing - Category Descriptions}

\section{Fast Food Restaurants \\ Advertising for chain restaurants that sel burgers, fries, fied chicken, pizza, tacos or burritos but that do not display images of foods sold there. \\ 2 Other Restaurants \\ Advertising for restaurants that offer items other than those specified above or serve a broad range of items that may include some of those specified for fast food restaurants.}

\section{Healthy Foods and Messages Include}

- Low-fatinon-fat dairy products (not milk)

- Fruits and vegetables

- Low-fat meats (fish, seafood, skinless poultry)

- Soy products (including soy milk)

- Whole grain breads and cereals

- Energy bars, convenient health food (e.g., Power bar)

- Healthy prepared food

- PSAs (government, foundation sponsored, etc.) for healthy messages related to obesity prevention, healthy eating, activity

4 Unhealthy Foods Include

- Fast food (Burgers, fries, fried chicken, pizza, tacos and burritos)

- Low nutrient density snack food (chips, cookies, candy)

- High-fat meats (beef, pork, lamb, poultry with skin, fried poultry/fish/seafood)

- Refined grain breads and cereals

- Desserts (except fresh, frozen, or canned fruit in own juices)
5 Physical Activity/Sporting

Equipment/Facilities Include

- Basketball

- Baseball

- Tennis

- Golf

- Other (e.g., fitness centers/gyms)

6 Other (specify type in notes section)

Use this category for food related ads that do not fit into any of the above categories and provide a brief description of the products under notes/comments.

7 Unhealthy Beverages Include (specify beverage in notes section)

- Regular soda

- Diet soda/drinks (artificially sweetened beverages)

- Energy drinks (Red Bull, Rockstar, Go Girl)

- Sugary fruit drinks (Tampico, Sunny Delight)

- Vitamin Water

- Sports drinks (PowerAde, Gatorade)

- Specialty Coffee/Tea drinks (Frappuccino, Mocha, Sobe)

- Regular whole milk/flavored milks (chocolate, strawberry)

- Alcohol

8 Healthy Beverages and Messages (specify beverage in notes section)

- Water

- $100 \%$ Fruit juice

- Low-fat/non-fat milk

- Healthy beverages message 


\section{B. Types of Outdoor Advertising}

Record all the different types of outdoor advertising within 1,000 ' of the school or park. (One survey for each school/park)

Location type (circle one): 1 - School 2 - Park
\begin{tabular}{|ll|}
\hline Type/Size: \\
$\mathbf{1}$ & Large billboard $\left(14^{\prime} \times 48^{\prime \prime}\right)$ \\
$\mathbf{2}$ & Medium-sized billboard $\left(12^{\prime} \times 25^{\prime},{ }^{\prime} 30\right.$ sheets") \\
$\mathbf{3}$ & Small billboard $\left(6^{\prime} \times 12^{\prime},{ }^{\prime} 8\right.$ sheets") \\
$\mathbf{4}$ & Transit ad (bus bench/shelter/rail station) \\
$\mathbf{5}$ & Sandwich board ad \\
$\mathbf{6}$ & Electronic billboard \\
$\mathbf{7}$ & Mobile billboard \\
$\mathbf{8}$ & Other outdoor signage (please specify in \\
& notes/comments column)
\end{tabular}

3 - Playground

Product/Ad is for:

1 Fast food restaurant

2 Other restaurant

3 Healthy food item(s)/message

4 Unhealthy food item(s)

5 Physical activity (e.g., sports equipment, gyms)

6 Other Food/PA topic (please specify in notes/comments column)

7 Unhealthy Beverages (soda, energy drinks, other sugar sweetened beverages) (please specify in notes/comments column) notes/comments column

\begin{tabular}{|c|c|c|c|c|c|}
\hline \multirow[t]{2}{*}{ Location/Street } & $\begin{array}{l}\text { Photo } \\
\text { (mark } \\
\text { exposure \# if } \\
\text { photo taken) }\end{array}$ & $\begin{array}{l}\text { Schoolpark } \\
\text { visible from } \\
\text { ad? } \\
\text { (circle \#) }\end{array}$ & \multirow[t]{2}{*}{$\begin{array}{l}\text { Typersize } \\
\text { (enter } \\
\text { number) }\end{array}$} & \multirow[t]{2}{*}{$\begin{array}{l}\text { Product/Ad } \\
\text { is for: } \\
\text { (enter } \\
\text { number) }\end{array}$} & \multirow[t]{2}{*}{$\begin{array}{c}\text { Notes/Comments } \\
\text { (If Type/Size }=\text { “8-Other”) } \\
\text { (If Product/Ad }=\text { “6-Other") } \\
\text { (if Product/Ad = “Unhealthy Bev") }\end{array}$} \\
\hline & & 1 -Yes 0 - No & & & \\
\hline & & 1 -Yes 0 -No & & & \\
\hline & & 1 -Yes 0 -No & & & \\
\hline & & 1 -Yes 0 - No & & & \\
\hline & & 1 -Yes 0 -No & & & \\
\hline & & 1 -Yes 0 -No & & & \\
\hline & & 1 -Yes 0 -No & & & \\
\hline & & 1 -Yes 0 - No & & & \\
\hline & & 1 -Yes 0 - No & & & \\
\hline & & 1 -Yes 0 -No & & & \\
\hline & & 1 -Yes 0 -No & & & \\
\hline & & 1 -Yes 0 -No & & & \\
\hline & & 1 -Yes 0 - No & & & \\
\hline & & 1 -Yes 0 -No & & & \\
\hline & & 1 -Yes 0 - No & & & \\
\hline $\begin{array}{l}\text { 7. Total \# } \\
\text { ads } \\
\text { recorded }\end{array}$ & $\begin{array}{l}\text { 8. Total ads } \\
\text { visible from } \\
\text { school/park }\end{array}$ & & $\begin{array}{l}\text { Total ads } \\
\text { each } \\
\text { type/size }\end{array}$ & $\begin{array}{c}\text { 10. Total } \\
\text { ads } \\
\text { healthy }\end{array}$ & \\
\hline 9. Total \# ads for each $t$ & size: & 4 & & $\begin{array}{l}\text { 11. Total } \\
\text { ads }\end{array}$ & \\
\hline $\begin{array}{ll}1 & \text { Large billboard } \\
2 & \text { Medium billboard } \\
3 & \text { Small billboard } \\
4 & \text { Transit ad }\end{array}$ & $\begin{array}{ll}\mathbf{5} & \text { Sandwich bo } \\
\mathbf{6} & \text { Electronic bi } \\
7 & \text { Mobile billbo } \\
\mathbf{8} & \text { Other Outdo }\end{array}$ & $\begin{array}{l}\text { d ad } \\
\text { oard } \\
\text { d } \\
\text { signage }\end{array}$ & & $\begin{array}{l}\text { unhealthy } \\
\text { or FF } \\
\text { restaurant }\end{array}$ & \\
\hline
\end{tabular}

8 Healthy beverage(s)/message 


\section{Walkability Checklist}

Take a walk and use this checklist to rate your neighborhood's walkability.

\section{How walkable is your community?}

\section{Location of walk}

\section{Did you have room to walk?}

$\square$ Yes $\quad \square$ some problems:

$\square$ Sidewalks or paths started and stopped
$\square$ Sidewalks were broken or cracked
$\square$ Sidewalks were blocked with poles,
signs,shrubbery, dumpsters, etc.
$\square$ No sidewalks, paths, or shoulders
$\square$ Too much traffic
$\square$ Something else

Rating: (circle one)

$\begin{array}{llllll}1 & 2 & 3 & 4 & 5 & 6\end{array}$

Locations of problems:

\section{Was it easy to cross streets?}

$\square$ Yes $\square$ Some problems:

$\square$ Road was too wide

$\square$ Traffic signals made us wait too long or did not give us enough time to cross

$\square$ Needed striped crosswalks or traffic signals

$\square$ Parked cars blocked our view of traffic

$\square$ Trees or plants blocked our view of traffic

$\square$ Needed curb ramps or ramps needed repair Something else

Rating: (circle one)

Locations of problems:

$\begin{array}{llllll}1 & 2 & 3 & 4 & 5 & 6\end{array}$

\section{Did drivers behave well?}

$\square$ Yes $\quad \square$ Some problems: Drivers ...

$\square$ Backed out of driveways without looking

$\square$ Did not yield to people crossing the street

$\square$ Turned into people crossing the street

$\square$ Drove too fastp

$\square$ Sped up to make it through traffic lights or drove through traffic lights?

$\square$ Something else

Rating: (circle one)

Locations of problems:

$\begin{array}{llllll}1 & 2 & 3 & 4 & 5 & 6\end{array}$
Rating Scale:

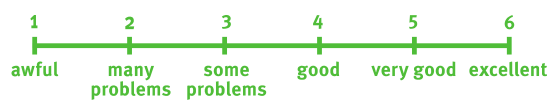

4. Was it easy to follow safety rules? Could you and your child... $\square$ Yes $\square$ No
$\square$ Yes $\square$ No
$\square$ Yes $\square$ No
$\square$ Yes $\square$ No

Rating: (circle one)

$\begin{array}{llllll}1 & 2 & 3 & 4 & 5 & 6\end{array}$
Cross at crosswalks or where you could see and be seen by drivers?

Stop and look left, right and then left again before crossing streets?

Walk on sidewalks or shoulders facing traffic where there were no sidewalks?

Cross with the light?

\section{Was your walk pleasant?}

$\square$ Yes $\square$ Some problems:

$\square$ Needed more grass, flowers, or trees

$\square$ Scary dogs

$\square$ Scary people

$\square$ Not well lighted

$\square$ Dirty, lots of litter or trash

$\square$ Dirty air due to automobile exhaust

$\square$ Something else

Rating: (circle one) Locations of problems:

$\begin{array}{llllll}1 & 2 & 3 & 4 & 5 & 6\end{array}$

How does your neighborhood stack up? Add up your ratings and decide.

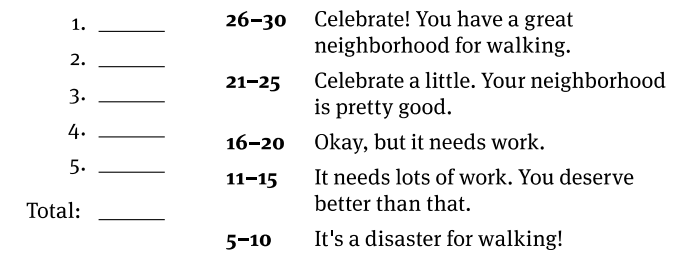

Now that you've identified the problems, go to the next page to find out how to fix them. 